\title{
Lipid lowering nutraceuticals in clinical practice: position paper from an International Lipid Expert Panel ${ }^{\#}$
}

Arrigo F.G. Cicero ${ }^{1 \star}$, Alessandro Colletti ${ }^{1}$, Gani Bajraktari ${ }^{2}$, Olivier Descamps ${ }^{3}$, Dragan M. Djuric ${ }^{4}$, Marat Ezhov ${ }^{5}$, Zlatko Fras ${ }^{6}$, Niki Katsiki', Michel Langlois ${ }^{8}$, Gustavs Latkovskis ${ }^{9}$, Demosthenes B. Panagiotakos ${ }^{10}$, Gyorgy Paragh ${ }^{11}$, Dimitri P. Mikhailidis ${ }^{12}$, Olena Mitchenko ${ }^{13}$, Bernhard Paulweber ${ }^{14}$, Daniel Pella ${ }^{15}$, Christos Pitsavos ${ }^{16}$, Željko Reiner ${ }^{17}$, Kausik K. Ray ${ }^{18}$, Manfredi Rizzo ${ }^{19}$, Amirhossein Sahebkar ${ }^{20}$, Maria-Corina Serban ${ }^{21}$, Laurence S. Sperling ${ }^{22}$, Peter P. Toth ${ }^{23}$, Dragos Vinereanu ${ }^{24}$, Michal Vrablík ${ }^{25}$, Nathan D. Wong ${ }^{26}$, Maciej Banach ${ }^{27 *}$ on behalf of the International Lipid Expert Panel (ILEP)

${ }^{1}$ Department of Medicine and Surgery Sciences, University of Bologna, Bologna, Italy; Italian Society of Nutraceuticals (SINut)

${ }^{2}$ Clinic of Cardiology, University Clinical Centre of Kosovo, Prishtina, Kosovo; Medical Faculty, University of Prishtina, Prishtina, Kosovo; Kosovo Society of Caridology ${ }^{3}$ Department of Internal Medicine, Centres Hospitaliers Jolimont, Haine Saint-Paul, Belgium; Belgian Atheroclerosis Society

${ }^{4}$ Institute of Medical Physiology "Richard Burian“, Faculty of Medicine, University of Belgrade, Belgrade, Serbia; Serbian Association for Arteriosclerosis, Thrombosis and Vascular Biology Research

${ }^{5}$ Russian Cardiology Research and Production Centre, Moscow, Russia; Russian National Atherosclerosis Society

${ }^{6}$ Preventive Cardiology Unit, Department of Vascular Medicine, Division of Internal Medicine, University Medical Centre Ljubljana, Slovenia; Chair for Internal Medicine, Faculty of Medicine, University of Ljubljana, Slovenia; Slovenian Society of Cardiology

${ }^{7}$ Second Department of Propaedeutic Internal Medicine, Medical School, Aristotle University of Thessaloniki, Hippocration Hospital, Thessaloniki, Greece ${ }^{8}$ Department of Laboratory Medicine, AZ Sint-Jan Hospital, Bruges, Belgium; Belgian Atheroclerosis Society

${ }^{9}$ Faculty of Medicine and Institute of Cardiology and Regenerative Medicine, University of Latvia, Riga, Latvia; Baltic Atherosclerosis Society

${ }^{10} \mathrm{School}$ of Health Science and Education, Department of Nutrition and Dietetics, Harokopio University of Athens, Athens, Greece

${ }^{11}$ Department of Internal Medicine, Faculty of Medicine, University of Debrecen, Debrecen, Hungary; Hungarian Atherosclerosis Society

${ }^{12}$ Department of Clinical Biochemistry, Royal Free Campus, Medical School, University College London (UCL), London, UK

${ }^{13}$ Dyslipidaemia Department, Institute of Cardiology AMS of Ukraine, Ukraine; Ukrainian Atherosclerosis Society

${ }^{14}$ First Department of Internal Medicine, Paracelsus Private Medical University, Salzburg, Austria; Austrian Atheroclerosis Society (AAS)

${ }^{15} 1^{\text {st }}$ Department of Internal Medicine, Faculty of Medicine, Pavol Jozef Safarik University, Košice, Slovakia; Slovak Association of Atherosclerosis

${ }^{16}$ Cardiology Clinic, School of Medicine, University of Athens, Greece; Hellenic Atherosclerosis Society

${ }^{17}$ University Hospital Centre Zagreb, School of Medicine University of Zagreb, Department of Internal Medicine, Zagreb, Croatia; Croatian Atherosclerosis Society ${ }^{18}$ Department of Primary Care and Public Health, Imperial College, London, UK ${ }^{19}$ Biomedical Department of Internal Medicine and Medical Specialties, University of Palermo, Palermo, Italy; Euro-Mediterranean Institute of Science and Technology, Palermo, Italy

${ }^{20}$ Biotechnology Research Center, Mashhad University of Medical Sciences, Mashhad, Iran

${ }^{21}$ Center for Interdisciplinary Research, University of Medicine and Pharmacy "Victor Babes", Timisoara, Romania; Department of Functional Sciences, University of Medicine and Pharmacy "Victor Babes", Timisoara, Romania

${ }^{22}$ Division of Cardiology, Emory University, Emory Clinical Cardiovascular Research Institute, Atlanta, Georgia, USA

\section{${ }^{*}$ Corresponding authors:}

Arrigo F.G. Cicero MD, PhD

Atherosclerosis

Research Center

Via Albertoni 15

40138 Bologna, Italy

Phone: ++39512142224

Fax ++39 516826125

E-mail: arrigo.cicero@unibo.it

Prof. Maciej Banach MD, PhD, FNLA, FAHA, FESC, FASA

Department of

Hypertension

WAM University

Hospital in Lodz

Medical University

of Lodz

113 Zeromskiego St

90-549 Lodz, Poland

Phone: +48 426393771

Fax: +48 426393771

E-mail: maciejbanach77@

gmail.com

\#Published in parallel in Archives of Medical Science and Nutrition Reviews. 
A.F.G. Cicero, A. Colletti, G. Bajraktari, O. Descamps, D.M. Djuric, M. Ezhov, Z. Fras, N. Katsiki, M. Langlois, G. Latkovskis, D.B. Panagiotakos, G. Paragh, D.P. Mikhailidis, O. Mitchenko, B. Paulweber, D. Pella, C. Pitsavos, Ž. Reiner, K.K. Ray, M. Rizzo, A. Sahebkar, M.C. Serban, L.S. Sperling, P.P. Toth, D. Vinereanu, M. Vrablík, N.D. Wong, M. Banach

${ }^{23}$ The Johns Hopkins Ciccarone Center for the Prevention of Heart Disease, Baltimore,

MD, USA; Preventive Cardiology, CGH Medical Center, Sterling, Illinois, USA

${ }^{24}$ University of Medicine and Pharmacy "Carol Davila”, Bucharest, Romania;

Department of Cardiology, University and Emergency Hospital, Bucharest, Romania;

Romanian Society of Cardiology

${ }^{25}$ Third Department of Internal Medicine, First Medical Faculty, Charles University,

Prague, Czech Republic; Czech Atherosclerosis Society

${ }^{26}$ Heart Disease Prevention Program, Division of Cardiology, University of California, Irvine, USA

${ }^{27}$ Department of Hypertension, Chair of Nephrology and Hypertension, Medical

University of Lodz, Poland; Polish Mother's Memorial Hospital Research Institute (PMMHRI), Lodz, Poland; Cardiovascular Research Centre, University of Zielona Gora, Zielona Gora, Poland; Lipid and Blood Pressure Meta-Analysis Collaboration (LBPMC) Group; Polish Lipid Association (PoLA)

With the official endorsement of:

Austrian Atheroclerosis Society (AAS)

Baltic Atherosclerosis Society

Belgian Atheroclerosis Society

Croatian Atherosclerosis Society

Czech Atherosclerosis Society

Hellenic Atherosclerosis Society

Hungarian Atherosclerosis Society

Italian Society of Nutraceuticals (SINut)

Kosovo Society of Caridology

Lipid and Blood Pressure Meta-Analysis Collaboration (LBPMC) Group

Polish Lipid Association (PoLA)

Romanian Society of Cardiology

Russian National Atherosclerosis Society

Serbian Association for Arteriosclerosis, Thrombosis and Vascular Biology Research

Slovak Association of Atherosclerosis

Slovenian Society of Cardiology

Ukrainian Atherosclerosis Society

Submitted: 25 July 2017

Accepted: 28 July 2017

Arch Med Sci 2017; 13, 5: 965-1005

DOI: https://doi.org/10.5114/aoms.2017.69326

Copyright (c) 2017 The article has been co-published with permission in Archives of Medical Science and Nutrition Reviews. All rights reserved in respect of Nutrition Reviews, ( ) The Authors 2017, and in respect of Archives of Medical Science, (C) The Authors 2017. This is an Open Access article distributed under the terms of the Creative Commons Attribution-NonCommercial-ShareAlike 4.0 International License (https://creativecommons.org/licenses/by-nc-sa/4.0/). The articles are identical except for minor stylistic and spelling differences in keeping with each journal's style. Either citation can be used when citing this article. 


\section{Contents}

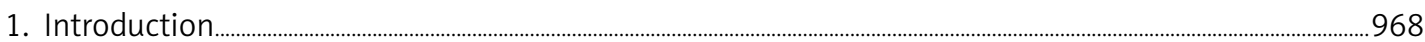

1.1. Cardiovascular disease and dyslipidemia: prevalence and global economic impact......................968

1.2. The importance of treating dyslipidemia to reduce cardiovascular risk ....................................................968

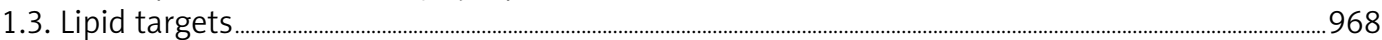

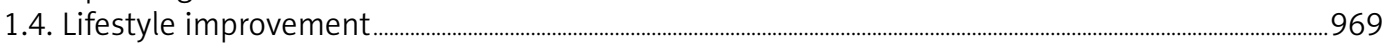

1.5. Indication of lipid-lowering nutraceuticals in clinical practice .........................................................................969

1.6. Clinical evidence on individual lipid-lowering nutraceuticals .............................................................................970

2. Inhibitors of intestinal cholesterol absorption ............................................................................................................................9. 971

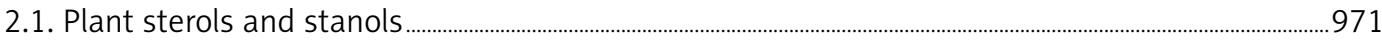

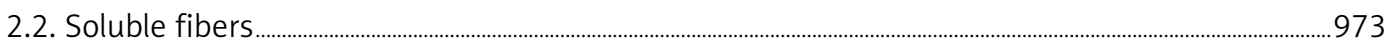

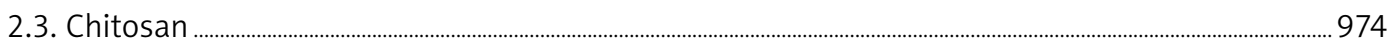

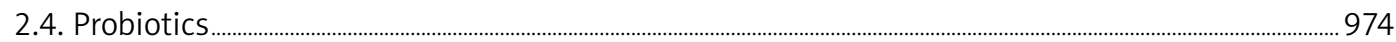

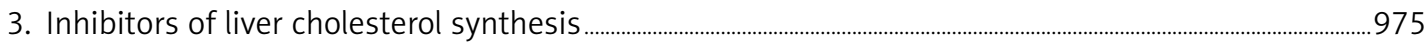

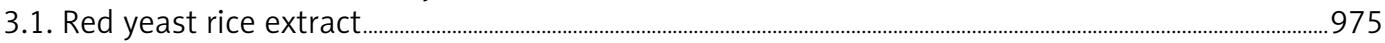

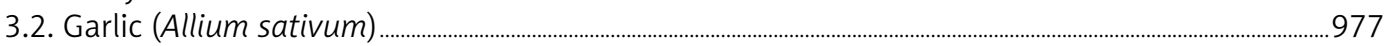

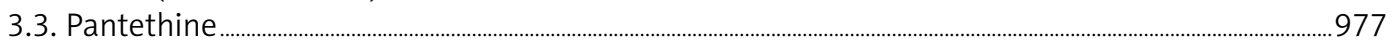

3.3. Bergamot (Citrus bergamia) ....................................................................................................................................................978

3.4. Policosanols ..............................................................................................................................................................................................9 979

4. Inducer of LDL-cholesterol excretion .........................................................................................................................................979

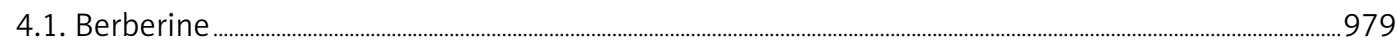

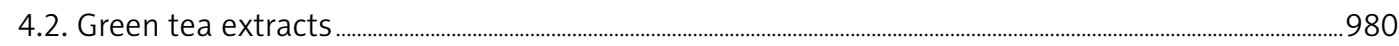

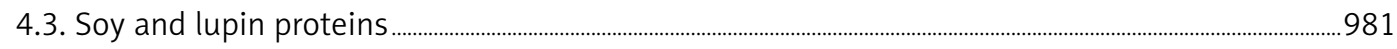

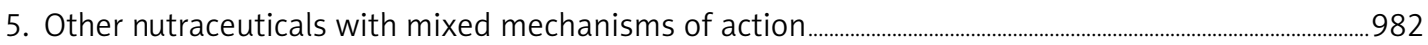

5.1. Polyunsaturated $\omega-3$ fatty acids .................................................................................................................................................... 982

5.2. $\gamma$-oryzanol .

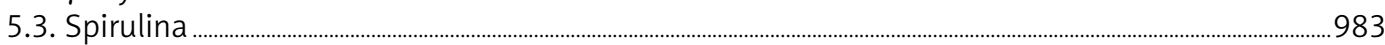

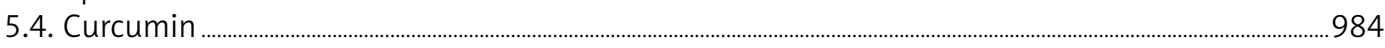

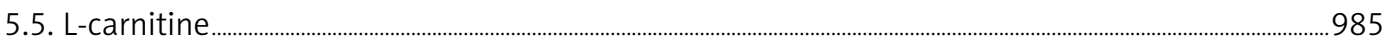

5.6. Artichoke (Cynara scolymus, Cynara cardunculus) ........................................................................................ 985

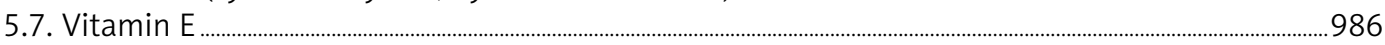

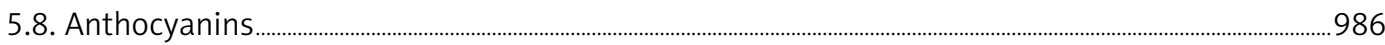

5.9. Silymarin (Silybum marianum) .................................................................................................................................................98

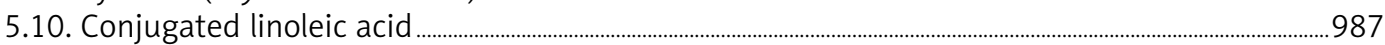

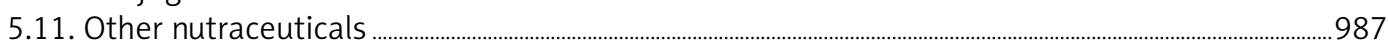

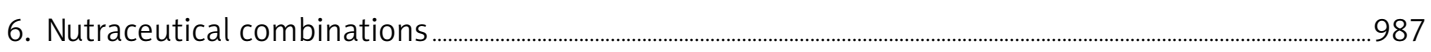

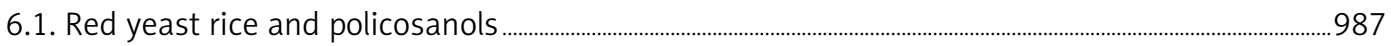

6.2. Red yeast rice, policosanols and berberine ...........................................................................................................................98

6.3. Red yeast rice and plant sterols .......................................................................................................................................98 98

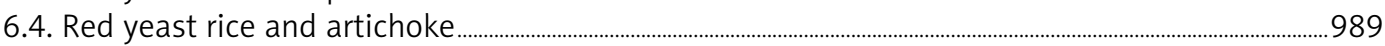

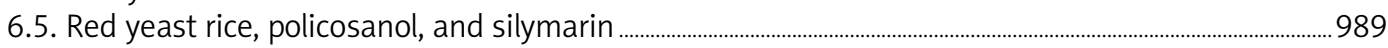

6.6. Red yeast rice and antioxidants .......................................................................................................................................99

6.7. Berberine combined with bioactive lipid-lowering agents other than red yeast rice......................990

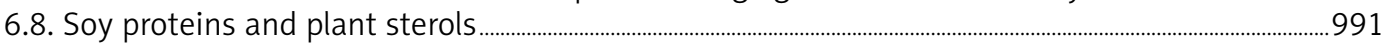

6.9. Different nutraceutical combinations supported by single RCTs .............................................................991

7. Nutraceuticals combined with pharmacological therapy......................................................................................99 992

7.1. Statins and polyunsaturated fatty acids........................................................................................................................993

7.2. Statins and soluble fibers................................................................................................................................................ 993

7.3. Ezetimibe, red yeast rice, policosanol and berberine .............................................................................................993

7.4. Ezetimibe or statins and berberine with silymarin ................................................................................9. 993

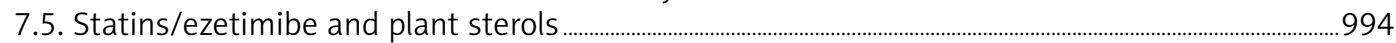

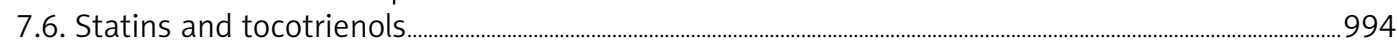

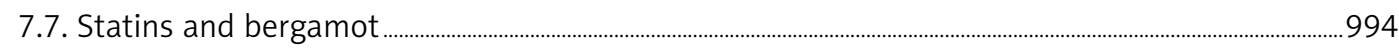

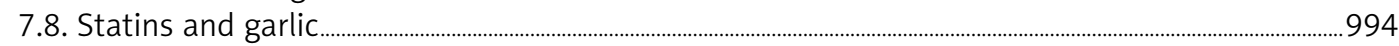

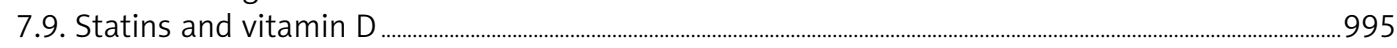

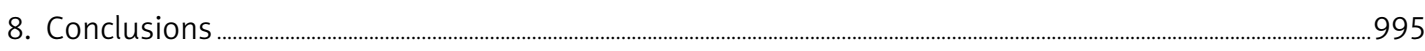

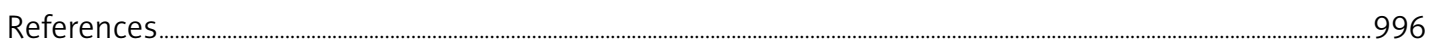


A.F.G. Cicero, A. Colletti, G. Bajraktari, O. Descamps, D.M. Djuric, M. Ezhov, Z. Fras, N. Katsiki, M. Langlois, G. Latkovskis, D.B. Panagiotakos, G. Paragh, D.P. Mikhailidis, O. Mitchenko, B. Paulweber, D. Pella, C. Pitsavos, Ž. Reiner, K.K. Ray, M. Rizzo, A. Sahebkar, M.C. Serban, L.S. Sperling, P.P. Toth, D. Vinereanu, M. Vrablík, N.D. Wong, M. Banach

\section{Introduction}

\subsection{Cardiovascular disease and dyslipidemia: prevalence and global economic impact}

Cardiovascular diseases (CVDs) are the leading cause of mortality worldwide, reaching 31\% of deaths in 2012 [1]. In particular, atherosclerosis and ischemic heart disease (IHD) are the main causes of premature death in Europe and are responsible for $42 \%$ of deaths in women and $38 \%$ in men under 75 years old [2]. The global economic impact of CVD is estimated to have been US $\$ 906$ billion in 2015 and is expected to rise by $22 \%$ by 2030 [3]. Cardiovascular diseases also represent the major cause of disability in developed countries. It has been estimated that their growing burden could lead to a global increase in loss of disability-adjusted life years (DALYs), from a loss of 85 million DALYs in 1990 to a loss of $\sim 150$ million DALYs in 2020 , becoming a major non-psychological cause of lost productivity [4].

Several risk factors contribute to the etiology and development of CVD; they are divided into those modifiable through lifestyle changes or by taking a pharmacologic treatment (e.g. for hypertension, smoking, diabetes mellitus, hypercholesterolemia) and those that are not modifiable (age, male gender, and family history) [5]. Elevated total cholesterol (TC) and low-density lipoprotein cholesterol (LDL-C) blood concentrations are the major modifiable risk factors for coronary heart disease (CHD), whereas high concentrations of plasma high-density lipoprotein cholesterol (HDL-C) in certain conditions are considered protective [6]. Moreover, LDL-C remains a fundamental CV risk factor (and a main target of therapy) even when statins are largely used in the general population [7].

An examination of the data of 18053 participants aged $\geq 20$ years who participated in the $\mathrm{Na}$ tional Health and Nutrition Examination Surveys (NHANES) from 1999 to 2006 showed that the unadjusted prevalence of hypercholesterolemia ranged from $53.2 \%$ to $56.1 \%$ in United States adults [8]. Differences related to gender and race or ethnicity were observed; in particular, a lower rate of control was found among women than men and lower rates of having a cholesterol check and being told about hypercholesterolemia were reported by African Americans and Mexican Americans than whites [8].

A recent report from the American Heart Association confirmed that in the US only $75.7 \%$ of children and $46.6 \%$ of adults present targeted TC levels (TC < $170 \mathrm{mg} / \mathrm{dl}$ for children and $<200 \mathrm{mg} /$ dl for adults, in untreated individuals) [9]. The pattern is similar in other Western countries $[10,11]$.

\subsection{The importance of treating dyslipidemia to reduce cardiovascular risk}

Many available clinical trials and meta-analyses have shown a relationship between a decrease in the levels of LDL-C and a reduction in relative risk of CVD [12]. In particular, a meta-analysis of the Cholesterol Treatment Trialists' (CTT) Collaboration, based on data from 14 randomized controlled trials (RCTs), which involved 90056 individuals, demonstrated a greater reduction in coronary and vascular events, which was related to a greater decrease in absolute levels of LDL-C [10]. Furthermore, in a report from the CTT Collaboration on more than 170000 subjects, it was stated that with the cholesterol-lowering drug therapy, each further reduction of LDL-C by $1 \mathrm{mmol} / \mathrm{l}(\sim 40 \mathrm{mg} / \mathrm{dl})$ decreased by about one-fifth the risk of revascularization, coronary artery disease and ischemic stroke, highlighting that a reduction of LDL-C of $3.2 \mathrm{mmol} / \mathrm{l}(125 \mathrm{mg} / \mathrm{dl})$ could lead to a decrease in risk of about $40-50 \%$, in the absence of an increased risk of cancer or non-CV-related death [13]. One $\mathrm{mmol} / \mathrm{l}$ is a reduction that is achievable through lifestyle improvements associated with lipid-lowering nutraceuticals. Moreover, it has been estimated that every $1 \%$ reduction in LDL-C level corresponds to a reduction of the relative risk for CV events greater than about 1\% [14, 15].

\subsection{Lipid targets}

In all adults a fasting or non-fasting lipoprotein profile should be obtained at least every 5 years [16]. Levels of LDL-C $<100 \mathrm{mg} / \mathrm{dl}(\sim 2.5 \mathrm{mmol} / \mathrm{l})$ are associated with a low risk for CHD and are considered optimal in the absence of CVD or other risk factors [17]. Consequently, current guidelines recommend achieving of LDL-C levels of $<115 \mathrm{mg} / \mathrm{dl}(\sim 3.0 \mathrm{mmol} / \mathrm{l})$ in patients at low and moderate risk for CHD. The LDL-C treatment target is $<100 \mathrm{mg} / \mathrm{dl}(\sim 2.6 \mathrm{mmol} / \mathrm{l})$ for patients at high risk and $<70 \mathrm{mg} / \mathrm{dl}(\sim 1.8 \mathrm{mmol} / \mathrm{l})$ for patients at very high risk [18].

High-risk subjects include those patients with prior atherosclerotic cardiovascular disease (ASCVD) events, including prior coronary events, transient ischemic attack, ischemic stroke, atherosclerotic peripheral artery disease (PAD) (e.g. ankle/brachial index < 0.90) and other atherosclerotic diseases (e.g. renal atherosclerosis, atherosclerotic aortic aneurysm and carotid plaque $\geq 50 \%$ stenosed). Other patient populations considered at high risk include patients with diabetes mellitus (DM), chronic kidney disease (CKD; stage $\geq 3 \mathrm{~B}$ ), and those with very high levels of individual risk factors, such as familial hypercholesterolemia (FH) [16]. 
Elevated triglycerides (TGs) are also an independent risk factor for CVD, and their levels should be optimized in order to reduce residual CVD risk [19].

\subsection{Lifestyle improvement}

Currently, according to the severity of dyslipidemia and the level of CV risk, treatment is based on lifestyle changes that include dietary habits and physical activity, or pharmacological therapy [20]. In fact, it is important to emphasize that non-pharmacological management should always accompany the lipid-lowering therapy [21]. Lifestyle treatment for hypercholesterolemia includes a diet low in saturated fat ( $<7 \%$ of total energy), moderate or higher intensity physical activity $(\geq$ $150 \mathrm{~min} /$ week) and weight loss (5-10\% of body weight) for those who are overweight or obese. Exposure to active or passive tobacco smoking must be avoided as well [22, 23].

The American Heart Association (AHA) recommends a diet with a high content of fruits, vegetables, whole grains, low-fat dairy products, poultry, fish and nuts [24]. It also recommends limiting consumption of red meat and sugary foods and beverages. Many diets fit that pattern, including the "Dietary Approaches to Stop Hypertension" (DASH) and the "Mediterranean Diet" [25]. LDL-C (and non$\mathrm{HDL}-\mathrm{C}$ ) reductions with lifestyle improvements are most often in the range of $5 \%$ to $15 \%$, an amount that, if maintained over a long period, may result in meaningful CVD risk reduction $[5,26,27]$.

For patients with hypertriglyceridemia, lifestyle interventions are key to reducing TGs; including weight a loss if overweight or obese (initially targeting loss of $5-10 \%$ of body weight), physical activity ( $\geq 150 \mathrm{~min} /$ week of moderate or higher intensity activity), and restriction of alcohol, simple sugars, and refined carbohydrate intake [28].

If sufficient progress is not made towards achieving atherogenic cholesterol goals, consideration may be given to the use of lipid-lowering nutraceuticals, alone or in combination with pharmacological therapy, which is indicated for patients with borderline lipid values (out-of-target) or intolerant to drugs [29]. It is however important to strongly emphasize that nutraceuticals cannot replace indicated lipid-lowering therapy in patients at CVD risk.

\subsection{Indication of lipid-lowering nutraceuticals in clinical practice}

In recent years, nutraceuticals and functional foods have shown their role as possible supporting therapies for lowering plasma TC, LDL-C and TG, especially for hypercholesterolemic subjects, whose blood cholesterol level is moderately elevated (for instance, TC $=200-240 \mathrm{mg} / \mathrm{dl}$ or $5.2-6.2 \mathrm{mmol} / \mathrm{l}$, LDL-C $=130-160 \mathrm{mg} / \mathrm{dl}$ or $3.4-4.1 \mathrm{mmol} / \mathrm{l}$, $\mathrm{TG}=150-200 \mathrm{mg} / \mathrm{dl}$ or $1.7-2.3 \mathrm{mmol} / \mathrm{l}$ in subjects in primary prevention for CVD) but not high enough to require pharmacological treatment [30, 31]. Based on current knowledge, nutraceuticals could exert significant lipid-lowering activity, and their intake has many advantages. First of all, the lipid-lowering effect of most nutraceuticals occurs through multiple mechanisms: the possibility of acting simultaneously on multiple stages of lipid-induced vascular damage makes them potential candidates for improving the lipid-lowering effects when used in combination with diet, drugs or other nutraceuticals [32]. Moreover, they can have a large number of positive pleiotropic effects, including improvement of endothelial dysfunction and arterial stiffness, as well as anti-inflammatory and anti-oxidative properties [33]. Furthermore, a relatively large amount of epidemiological and clinical data supports the tolerability and safety of many nutraceuticals with demonstrated lipid-lowering action, including in patients intolerant to statins [34]. According to the European Atherosclerosis Society (EAS) consensus document, in the last 10 years a number of observational studies have reported unfavorable side effects related to statins, in particular musculoskeletal disorders (statin-associated muscle symptoms (SAMS)), gastrointestinal disorders and fatigue [35]. This is particularly relevant since it is estimated that the range of people intolerant to conventional statin treatment is between 45000 and 290000 individuals/year [36] (complete statin intolerance is estimated at less than 5\%) and that statin intolerance represents one of the main reasons for statin discontinuation and non-adherence and consequently failure of lipid-lowering treatment [37-39].

Another group of patients who might benefit from such nutraceuticals consists of very old patients (especially those aged over 75) or patients with sarcopenia [40]. A further category of patients who could benefit from nutraceuticals refers to those already treated with statins and/or ezetimibe, and who have not reached the targeted LDL-C level although not being too far from it. The development of new powerful (and very expensive) lipid-lowering drugs will be able to fill the gap (and in consequence reduce the residual CV risk), but their use seems to be cost-effective only for a limited number of patients [41]. Therefore, nutraceuticals might cost-effectively fill these gaps. The recent 2016 European guidelines for dyslipidemia management consider the possibility to use some lipid-lowering nutraceuticals, not considering fully a number of prospective and observational studies as well as a positive meta-analysis of randomized clinical trials (RCTs) supporting the 
A.F.G. Cicero, A. Colletti, G. Bajraktari, O. Descamps, D.M. Djuric, M. Ezhov, Z. Fras, N. Katsiki, M. Langlois, G. Latkovskis, D.B. Panagiotakos, G. Paragh, D.P. Mikhailidis, O. Mitchenko, B. Paulweber, D. Pella, C. Pitsavos, Ž. Reiner, K.K. Ray, M. Rizzo, A. Sahebkar, M.C. Serban, L.S. Sperling, P.P. Toth, D. Vinereanu, M. Vrablík, N.D. Wong, M. Banach

possible use of a relatively large number of natural compounds [18]. Therefore the present position paper provides an up-to-date summary of the findings on the lipid-lowering effects of the most important nutraceuticals and functional foods.

\subsection{Clinical evidence on individual lipid-lowering nutraceuticals}

Nutraceuticals with lipid-lowering effects can be divided into 3 categories according to their mechanisms of action: natural inhibitors of intestinal cholesterol absorption, inhibitors of hepatic cholesterol synthesis, and enhancers of the excretion of LDL-C (Figures 1-3). Nevertheless, there are many functional food/nutritional supplements with multiple or unclear mechanisms of action. Nutraceuticals described in the literature are numerous and show different levels of effectiveness and evidence of their lipid-lowering effect: the objective of this consensus is to clarify which are the major nutraceuticals with the greatest evidence and clinical efficacy. For each nutraceutical, we will briefly describe the main mechanism of action, active principles, effective dosages, clinical evidence of effects on lipid profile, extra-lipid-lowering properties (e.g. endothelial function and arterial stiffness), and safety profile (if such data are available).
The level of evidence and the strength of recommendation of particular lipid-lowering treatment options have been weighed and graded according to predefined scales, as outlined in Tables I and II. The experts of the writing and reviewing panels completed Declaration of interest forms where real or potential sources of conflicts of interest might be perceived (at the end of the paper).

Following the final approval of the contents of the position paper, the final version of the document is scheduled for parallel publication in $A r-$ chives of Medical Science (full-scope journal), and Nutrition Reviews (specialized journal) in order to maximally increase the number of readers of these important recommendations. Physicians and medical professionals of other specialties treating patients with lipid disorders are encouraged to consider the position paper in the process of evaluating the clinical status of their patients, and determining and implementing medical strategies for the prevention, diagnosis and treatment of dyslipidemias. However, the position paper does not override in any way the individual responsibility of physicians to make appropriate and accurate decisions taking into account the condition of a given patient, in consultation with that patient, and, where necessary, with the patient's guardian or carer. It is also the responsibility of health professionals to verify the rules and regu-

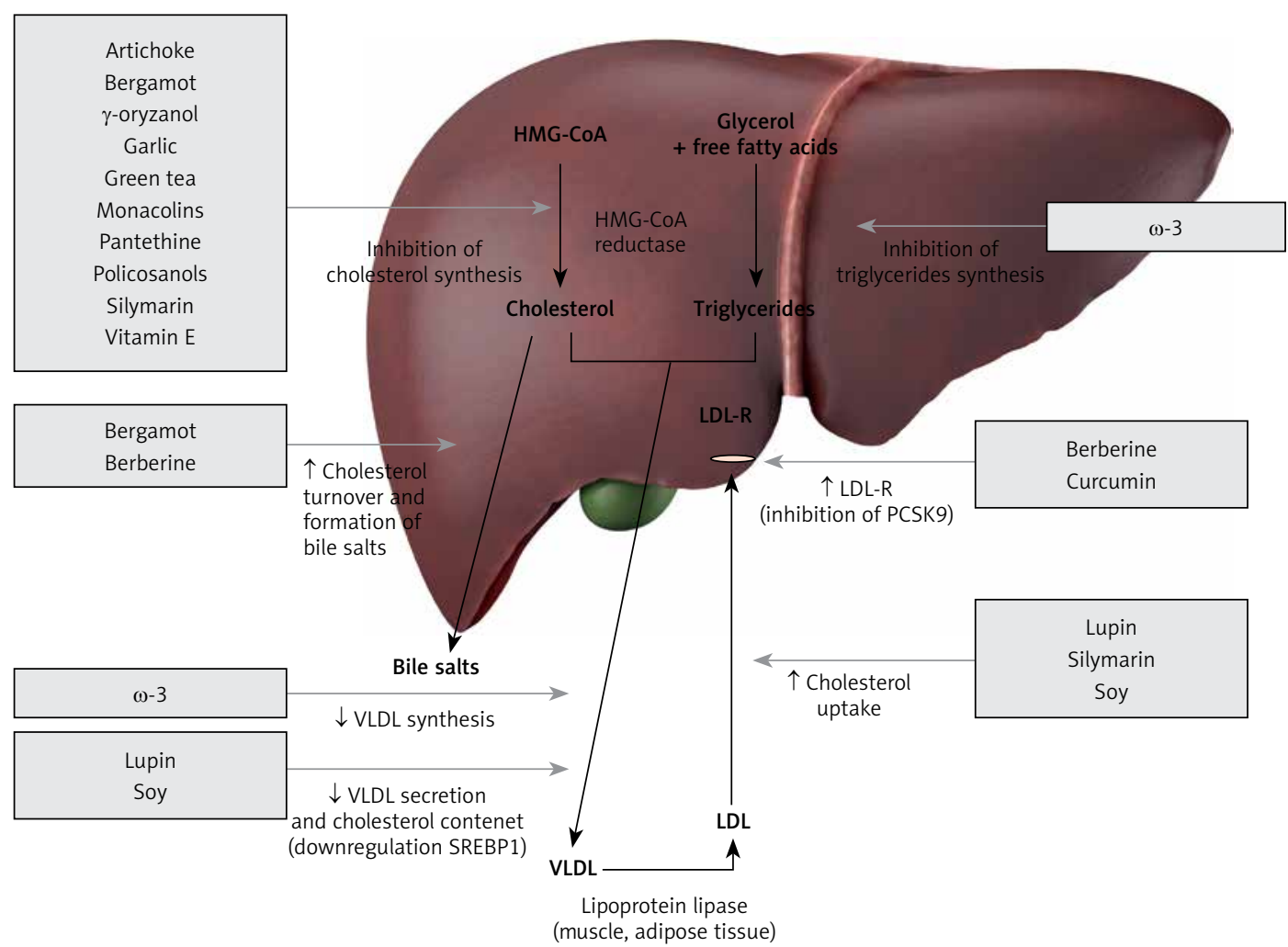

Figure 1. Nutraceuticals acting as inhibitors of liver cholesterol synthesis

HMG-COA - 3-hydroxy-3-methylglutaryl-coenzyme A, LDL-R - low-density lipoprotein receptor, PCSK9-proprotein convertase subtilisin/kexin type 9, SREBP1 - sterol regulatory element-binding protein 1, VLDL - very-low-density lipoprotein. 


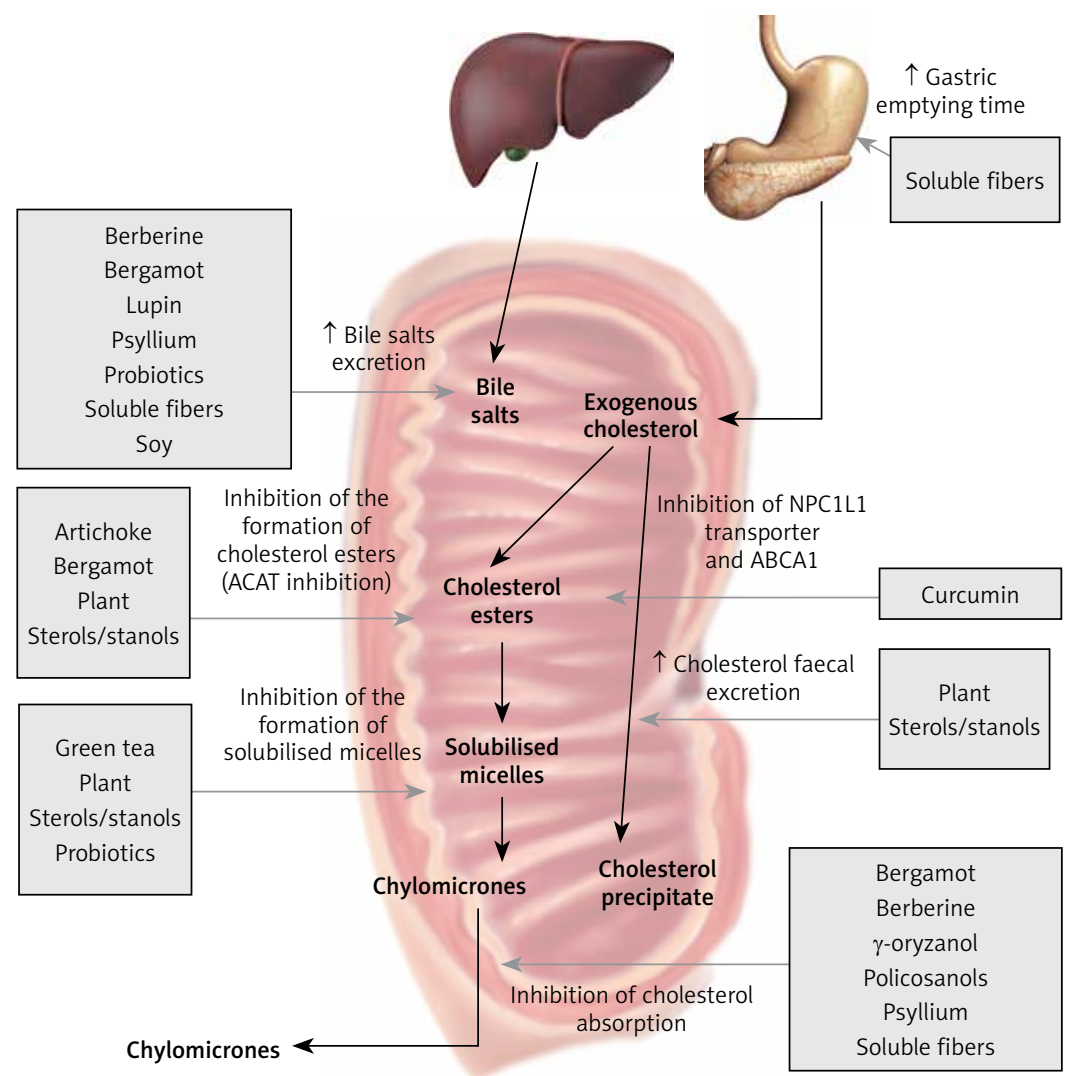

Figure 2. Nutraceuticals acting as inhibitors of intestinal cholesterol absorption and enhancers of cholesterol excretion

ABCA1 - ATP-binding cassette transporter, NPC1L1 - Niemann-Pick C1-Like 1.
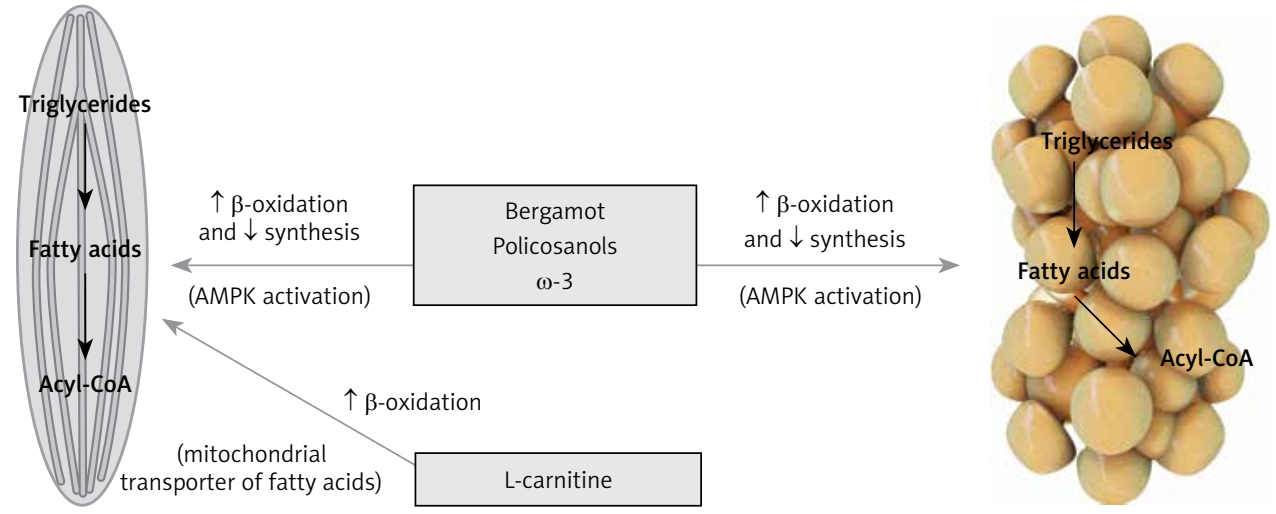

Figure 3. Nutraceuticals acting on fatty acids

AMPK - AMP-activated protein kinase.

lations applicable to drugs and devices at the time of their prescription/use.

\section{Inhibitors of intestinal cholesterol absorption}

\subsection{Plant sterols and stanols}

Mechanism of action: Plant sterols, present in almost all plant sources (in particular in vegetable oils, nuts, seeds, legumes and fat spreads), are structurally similar to cholesterol, differing in the side chain at C24 that presents a methyl or ethyl group (campesterol and B-sitosterol, respectively) or an extra double bond in C22 (stigmasterol) [42]. Plant sources also contain plant stanols, such as $\beta$-sitostanol, campestanol and stigmastanol, that are saturated derivatives of sterols [43]. Plant sterols + stanols (PS) average daily intake in the common diet is low: between 150 and $450 \mathrm{mg} /$ day; however, some populations, such 
A.F.G. Cicero, A. Colletti, G. Bajraktari, O. Descamps, D.M. Djuric, M. Ezhov, Z. Fras, N. Katsiki, M. Langlois, G. Latkovskis, D.B. Panagiotakos, G. Paragh, D.P. Mikhailidis, O. Mitchenko, B. Paulweber, D. Pella, C. Pitsavos, Ž. Reiner, K.K. Ray, M. Rizzo, A. Sahebkar, M.C. Serban, L.S. Sperling, P.P. Toth, D. Vinereanu, M. Vrablík, N.D. Wong, M. Banach

Table I. Classes of recommendation

\begin{tabular}{|c|c|c|}
\hline Class of recommendation & Definition & Suggested wording \\
\hline Class I & $\begin{array}{c}\text { Evidence and/or general agreement that a given } \\
\text { treatment or procedure is beneficial, useful, } \\
\text { effective }\end{array}$ & Is recommended/Is indicated \\
\hline Class II & $\begin{array}{l}\text { Conflicting evidence and/or a divergence } \\
\text { of opinion about the usefulness/ } \\
\text { efficacy of the given treatment or procedure }\end{array}$ & \\
\hline Class IIa & $\begin{array}{c}\text { Weight of evidence/ opinion is in favor } \\
\text { of usefulness/efficacy }\end{array}$ & Should be considered \\
\hline Class IIb & $\begin{array}{c}\text { Usefulness/efficacy is less well established } \\
\text { by evidence/opinion }\end{array}$ & May be considered \\
\hline Class III & $\begin{array}{l}\text { Evidence or general agreement that the given } \\
\text { treatment or procedure is not useful/effective and } \\
\text { in some cases may be harmful }\end{array}$ & $\begin{array}{l}\text { Is not recommended (no } \\
\text { efficacy on lipid profile) }\end{array}$ \\
\hline
\end{tabular}

Table II. Level of evidence

\begin{tabular}{|lc|}
\hline Level of evidence & $\begin{array}{c}\text { Definition } \\
\text { Level A }\end{array}$ \\
\hline Level B & $\begin{array}{c}\text { Data derived from multiple } \\
\text { randomized clinical trials or their } \\
\text { meta-analysis }\end{array}$ \\
\hline Level C & $\begin{array}{c}\text { Data derived from single } \\
\text { randomized clinical trial or large } \\
\text { non-randomized studies }\end{array}$ \\
\hline $\begin{array}{c}\text { Consensus or opinion of } \\
\text { experts and/or small studies, } \\
\text { retrospectives studies, registries }\end{array}$ \\
\hline
\end{tabular}

as the Japanese or vegetarians, consume at least twice as much [43].

Efficacy: PS reduce LDL-C by decreasing intestinal absorption of exogenous cholesterol, competing with it in the formation of solubilized micelles $[44,45]$. The micelles interact with the brush border membrane and are substrate of Niemann-Pick C1-Like 1 (NPC1L1) transporter that facilitates the transport of sterols from the intestinal lumen. However, the ATP-binding cassette protein family (ABCG5 and ABCG8) shuttles and blows out again unesterified cholesterol and the majority of sterols and stanols in the intestinal lumen [44, 45]. As a result, PS have extremely low bioavailability $(0.5-2 \%$ rapidly excreted by the liver vs. $55-60 \%$ of exogenous cholesterol); in general, plant sterols have higher bioavailability than stanols, probably due to a different arrangement in the intestinal micelles [44, 45]. This determines an increase in the intestinal lumen of the precipitate and excreted cholesterol via feces. PS also intensify the expression of ABCA1 transporter and inhibit the acyl-CoA:cholesterol O-acyltransferase (ACAT) enzyme, reducing the amount of cholesterol absorbed from $30 \%$ to $50 \%$. It is important to emphasize that for better therapeutic efficacy, an excellent vehicle for the PS are spreadable fats that improve their solubil- ity, promoting dispersion and incorporation into micelles [44, 45].

The lipid-lowering effects of PS have been highlighted in several meta-analyses of RCTs. The meta-analysis of Ras et al. included 41 clinical trials with 2084 individuals [44]. The mean dose of phytosterols provided was $1.6 \mathrm{~g} /$ day $(0.3$ to $3.2 \mathrm{~g} /$ day) administered through different sources (yoghurt, milk, dressing, mayonnaise, and bread), and the median duration of studies was 28 days (21-315 days). The meta-analysis showed not only the significant reduction of LDL-C of $0.33 \mathrm{mmol} / \mathrm{l}$ $(12.8 \mathrm{mg} / \mathrm{dl})(-8.5 \%)$, but also an average increase in levels of sitosterol $2.24 \mu \mathrm{mol} / \mathrm{l}(+31 \%)$ and campesterol $5.00 \mu \mathrm{mol} / \mathrm{l}$ (+37\%) compared to controls [44]. The increase of plasma levels of sitosterol and campesterol showed a dose-dependent trend: in fact, in the subgroup analysis a "high dose" of PS (2.0 to $3.2 \mathrm{~g} /$ day) showed the highest levels of sitosterol and campesterol (on average 3.56 and $7.64 \mu \mathrm{mol} / \mathrm{l}$, respectively). However, total PS level remained below $1 \%$ of total sterols and stanols circulating in the blood [44]. PS could also have some impact on TG but only in patients with high TG levels at baseline [46]. Moreover, PS supplementation has a mild but significant improving effect on high-sensitivity C-reactive protein (hs-CRP) [47].

The lipid-lowering effect of PS is dose dependent and proportional up to the attainment of a plateau (reached at approximately $3 \mathrm{~g} /$ day of PS achieving an average effect on LDL-C of $-12 \%$ ) due to saturation of the uptake of cholesterol and transport process. At doses up to $3 \mathrm{~g} /$ day there were no differences in efficacy on cholesterolemia, between stanols and sterols [48]. Another metaanalysis of RCTs showed that two of the best fat carriers for PS are rapeseed or canola because of their high content of monounsaturated fatty acids and $\omega-3$ that enhances the functionality of PS [45]. The effect of PS on endothelial function has 
been recently investigated in two large RCTs that furnished conflicting results $[49,50]$.

Safety: In conclusion, PS produce a mean reduction of LDL-C by $8-12 \%$ in subjects with hypercholesterolemia. PS have also shown a high safety profile in the middle-term; however, data for treatment longer than 2 years are still not available [44, 50].

\begin{tabular}{|c|c|c|c|c|c|}
\hline Class & Level & $\begin{array}{c}\text { Active } \\
\text { daily } \\
\text { doses }\end{array}$ & $\begin{array}{c}\text { Expected } \\
\text { effects } \\
\text { on LDL-C }\end{array}$ & $\begin{array}{c}\text { Effects } \\
\text { on other } \\
\text { CV risk } \\
\text { biomark- } \\
\text { ers }\end{array}$ & $\begin{array}{c}\text { Direct } \\
\text { vascular } \\
\text { effects }\end{array}$ \\
\hline Ila & A & $\begin{array}{c}400- \\
3000 \mathrm{mg}\end{array}$ & $\begin{array}{c}-8 \% \text { to } \\
-12 \%\end{array}$ & $\begin{array}{l}\downarrow \text { hs-CRP } \\
\text { Not } \\
\text { demon- } \\
\text { strated }\end{array}$ \\
\hline
\end{tabular}

\subsection{Soluble fibers}

Dietary fibers is a term commonly used for a variety of substances of vegetable origin resistant to enzymatic digestion in the gastrointestinal tract. Generally, they are divided according to their solubility into soluble and insoluble fibers [51]. For the last several years, some studies have focused on the lipid-lowering properties of soluble fibers, including pectin, guar gum, mucilage, oats and psyllium, showing a reduction in TC and LDL-C $[51,52]$. The lipid-lowering mechanisms of action of soluble fibers are different, including prolonged gastric emptying time, an increase of satiety, the inhibition of hepatic cholesterol synthesis and an increase of fecal excretion of cholesterol and bile salts [52]. The reduction of cholesterol obtained by soluble fibers described in the literature is variable and dependent on the type of fiber, doses, subjects treated, study size and different diets: the effective range of the reduction of TC varies from 0 to $18 \%$ for oat-based fibers, 3-17\% for psyllium, $5-16 \%$ for pectin, and $4-17 \%$ for guar gum [51].

\subsection{1. $\beta$-glucan}

Mechanism of action: $\beta$-glucan is a soluble fiber derived from the walls of different plant cells, bacterial, algae, fungi and yeasts. $\beta$-glucan has high viscosity, which confers lipid-lowering action [32].

Efficacy: A meta-analysis of 17 RCTs with 916 patients showed that $\beta$-glucan consumption in a hypercholesterolemic population significantly reduced LDL-C $(-0.21 \mathrm{mmol} / \mathrm{l}(8.1 \mathrm{mg} / \mathrm{dl})(95 \% \mathrm{Cl}$ : 0.27 ; -0.14$) p<0.00001)$. However, there were no significant differences in HDL-C and TG. No adverse effects were reported among the eligible trials [53]. In 2010 the European Food Safety Authority (EFSA) confirmed that oat $\beta$-glucan is able to reduce plasmatic cholesterol levels; however, at least $3 \mathrm{~g} /$ day of $\beta$-glucan is necessary [54]. According to the American and European guidelines for the management of dyslipidemia, the consumption of 5-15 g/day (European guidelines) or 10-25 g/day (US guidelines) of soluble fibers derived from oat rich in $\beta$-glucan can essentially reduce the levels of cholesterol in the blood [55, 56]. Finally, the study of Tabesh et al. showed that the consumption of $\beta$-glucan for 4 weeks in 60 patients with hypercholesterolemia increases the serum levels of nitric oxide (NO) $(p=0.017)$ but has no effect on flow-mediated dilatation (FMD) [57].

Safety: Due to the lack of enough data it seems to be important to evaluate the efficacy and safety of administration of $\beta$-glucan in the long-term follow-up as well as to clarify whether there is a dose-response relationship and whether it can decrease the $\mathrm{CV}$ risk.

\subsubsection{Psyllium}

Mechanism of action: Psyllium is a natural source of concentrated fibers derived from the husks of blonde psyllium seed. The mechanisms of action of psyllium are similar to those of other fibers discussed, including increased excretion of bile acids (stimulating $7 \alpha$-hydroxylase), reduced absorption of intestinal cholesterol and a reduction of hepatic cholesterol synthesis (via the short-chain fatty acid byproducts of fiber fermentation) [58].

Efficacy: A meta-analysis of 21 studies, which enrolled a total of 1030 and 687 subjects receiving psyllium or placebo, respectively, concluded that compared with placebo, consumption of psyllium lowered serum LDL-C by $0.278 \mathrm{mmol} / \mathrm{l}$ $(10.8 \mathrm{mg} / \mathrm{dl})(95 \% \mathrm{Cl}: 0.213 ; 0.312 \mathrm{mmol} / \mathrm{l})$. With random-effect meta-regression, a significant dose-response relationship was found between doses (3-20.4 g/day) and total cholesterol or LDL-C changes. Following an average intake of psyllium of $10 \mathrm{~g} /$ day, an average reduction of LDL-C of $7 \%$ was observed [59]. Moreover, psyllium showed good efficacy also in children and adolescents, with the percentage of $\mathrm{LDL}-\mathrm{C}$ reduction similar to the one in adults [60]. The reduction of cholesterol was more pronounced in American subjects with hypercholesterolemia, who consumed a high-fat diet (LDL-C -8/20\%) [61]. Psyllium supplementation might also have a positive effect on glucose metabolism related parameters [62]. However, psyllium has shown no significant effects on vascular function [63].

Safety: All available clinical trials and meta-analyses confirm the good safety profile of psyllium (at doses up to $20 \mathrm{~g} /$ day) that is documented by the Food and Drug Administration (FDA), the Select Committee on Generally Recognized Safe Substances and the Expert Panel from the Life Sciences Research Office. However, in some cases minor gastrointestinal side effects were reported (especially with micronized fibers) that might slightly reduce the adherence to this nutraceutical [64]. 
A.F.G. Cicero, A. Colletti, G. Bajraktari, O. Descamps, D.M. Djuric, M. Ezhov, Z. Fras, N. Katsiki, M. Langlois, G. Latkovskis, D.B. Panagiotakos, G. Paragh, D.P. Mikhailidis, O. Mitchenko, B. Paulweber, D. Pella, C. Pitsavos, Ž. Reiner, K.K. Ray, M. Rizzo, A. Sahebkar, M.C. Serban, L.S. Sperling, P.P. Toth, D. Vinereanu, M. Vrablík, N.D. Wong, M. Banach

\subsubsection{Glucomannan}

Mechanism of action: Glucomannan is a particular soluble fiber, widely used in the Orient for over a thousand years, derived from Amorphophallus konjac, commonly referred as konjac root, available as a nutraceutical in different forms such as capsules, tablets and sachets. Structurally glucomannan is a polysaccharide constituted by glucose and mannose (ratio $1: 1.6)$ bound through $\beta$-1,4-glycosidic bonds [32]. Unlike other fibers, glucomannan does not act by binding bile acids, but it seems to reduce the absorption of cholesterol in the jejunum and the absorption of bile acids in the ileum, yielding improvements in apolipoprotein $B(A p o B)$ and plasma LDL-C levels. It also increases the activity of $7 \alpha$-hydroxylase, an enzyme that converts cholesterol into bile acids [65].

Efficacy: A recent meta-analysis including 14 RCTs with 531 patients concluded that the use of glucomannan (at doses ranging between 1.24 and $15.1 \mathrm{~g}$ /day) significantly reduces LDL-C and TG respectively by $-0.41 \mathrm{mmol} / \mathrm{l}(15.9 \mathrm{mg} / \mathrm{dl})$ and $-0.13 \mathrm{mmol} / \mathrm{l}(11.5 \mathrm{mg} / \mathrm{dl})$ ( $p<0.05$ for both) compared to placebo. The reduction of serum triglycerides is a peculiarity of glucomannan, probably due to its high viscosity and its ability to interact with the hepatic cholesterol and lipoprotein metabolism, but not of other soluble fibers, which have only a very modest action on triglyceride levels [66]. Data on weight reduction are controversial; in general it can be said that glucomannan is able to promote the maintenance of weight and in some cases (with at least 5.2 weeks of treatment) it can cause a small reduction of weight (according to some meta-analyses significant, according to others not), although only less than $1 \mathrm{~kg}$ [67]. Treatment with glucomannan has also given positive results in children with primary hyperlipidemia. Guardamagna et al. conducted a study with 36 dyslipidemic children (6-15 years old) treated with glucomannan twice daily for 8 weeks. The results showed a significant reduction in LDL-C $(-7.3 \%, p=0.008)$ and non-HDL-C $(-7.2 \%, p=0.002)$ compared to placebo. These effects had a more pronounced trend in females than in males [68]. The same correlation was also found in the study of Martino et al., where 40 children were treated with 2-3 g/day of glucomannan and benefited by a reduction of LDL-C of $30 \%$ in females and $9 \%$ in males $(p=0.046)$. This gender-dependent effect was also observed with other soluble fibers, and it would seem to be caused by the interaction between sex hormones and lipid metabolism; nevertheless, further corroboration is necessary [69]. The abovementioned results have been confirmed in a further study by the same authors on a larger sample of 120 hypercholesterolemic children [70].
Safety: The intake of glucomannan may interfere with the absorption of certain drugs, in particular lipophilic drugs/nutraceuticals: for example, glucomannan could reduce the absorption of vitamin $E$, calcium and other minerals, whereas it does not hinder the absorption of water-soluble vitamins. Therefore it is recommended to take the medication $1 \mathrm{~h}$ before or at least four hours after taking glucomannan [32]. In general, the consumption of glucomannan does not cause serious side effects; most of them concern gastrointestinal such as diarrhea, flatulence and abdominal discomfort.

\begin{tabular}{|c|c|c|c|c|c|}
\hline Class & Level & $\begin{array}{c}\text { Active } \\
\text { daily } \\
\text { doses }\end{array}$ & $\begin{array}{c}\text { Expected } \\
\text { effects } \\
\text { on LDL-C }\end{array}$ & $\begin{array}{c}\text { Effects } \\
\text { on other } \\
\text { CV risk } \\
\text { biomark- } \\
\text { ers }\end{array}$ & $\begin{array}{c}\text { Direct } \\
\text { vascular } \\
\text { effects }\end{array}$ \\
\hline IIa & A & $5-15 \mathrm{~g}$ & $\begin{array}{c}-5 \% \text { to } \\
-15 \%\end{array}$ & $\begin{array}{c}\downarrow \text { TG, } \\
\text { glyce- } \\
\text { mia, } \\
\text { HOMA } \\
\text { index, } \\
\text { body } \\
\text { weight }\end{array}$ & $\begin{array}{c}\downarrow \text { CVD } \\
\text { risk (ep- } \\
\text { idemio- } \\
\text { logical } \\
\text { data on } \\
\text { fiber-rich } \\
\text { foods) }\end{array}$ \\
\hline
\end{tabular}

\subsection{Chitosan}

Mechanism of action: Chitosan is a non-fiber lipid-lowering agent isolated from shellfish and sea crustaceans that inhibits cholesterol absorption in the bowel.

Efficacy: A meta-analysis of 6 RCTs including 416 patients with hypercholesterolemia concluded that it has a significant effect on TC $(-0.3 \mathrm{mmol} / \mathrm{l}(11.6 \mathrm{mg} /$ $\mathrm{dl}), p=0.002)$, but not on LDL-C, HDL-C or TG [71]. Since other trials have yielded conflicting results with a significant reduction of all lipid parameters [72], further studies are necessary to have clear data on efficacy both in the short and long term of consumption. However, chitosan supplementation is associated with mild weight loss [73] and an improvement in insulin-resistance related parameters [74].

Safety: Transient side effects such as abdominal pain, diarrhea, vomiting, and constipation occur in rare cases at doses ranging between 1 and $6 \mathrm{~g} /$ day (indicative daily doses) [75].

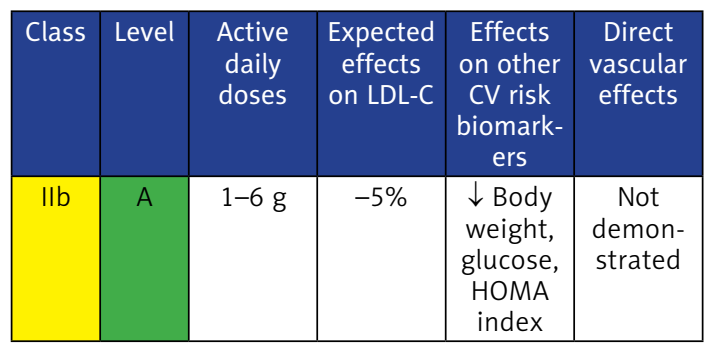

\subsection{Probiotics}

Mechanism of action: Probiotics are defined as vital microorganisms which confer health benefits 
to the host when taken in adequate amounts. The consumption of probiotics is considered safe and free of serious side effects [76]. In recent years, some clinical studies have supported the hypothesis of a possible clinical use of certain strains of microorganisms as cholesterol-lowering agents. Nevertheless, it is still very difficult to draw firm conclusions due to the great heterogeneity of the studies in duration, type of probiotic strains used, dosage, clinical characteristics of the participants and dosage form/vehicle.

The mechanisms of action whereby probiotics reduce cholesterolemia are still unclear. Among the proposed mechanisms, it is possible that probiotics interact with the intestinal cholesterol, binding or incorporating it into the cell membrane [77]. Lactobacillus acidophilus and $L$. bulgaricus contain some enzymes (cholesterol dehydrogenase/isomerase) able to catalyze the transformation of cholesterol into cholest-4-en-3-one, an intermediate cofactor in the conversion of cholesterol to coprosterol or coprostanol, which are directly excreted in the feces [78]. Other probiotics reduce the enterohepatic circulation of bile salts through activity of bile salt hydrolase (BSH) enzymes; there is a mechanism based on the ability of some lactobacilli and bifidobacteria to deconjugate bile acids enzymatically, increasing their excretion rates and attracting greater mobilization of systemic cholesterol to the liver for de novo synthesis of bile salts [79]. Finally, some probiotics may alter bowel $\mathrm{pH}$, the formation of micelles, the transport pathways of cholesterol and/ or lipoprotein (such as NPC1L1 gene expression) and cholesteryl esters [80]. These mechanisms are hypothetical, so further well-designed studies are required to elucidate which of these have a greater influence on cholesterol reduction.

Efficacy: A recent meta-analysis included 30 RCTs to investigate the effect of probiotics on TC, HDL-C and TG and 27 RCTs on LDL-C. The most studied probiotic strains were $L$. acidophilus, L. acidophilus + Bifidobacterium lactis and L. plantarum. The mean duration of the studies was 7 weeks involving normo- (TC $<200 \mathrm{mg} / \mathrm{dl}$ ) or hypercholesterolemic subjects. The pooled mean net change in LDL-C was $-0.19 \mathrm{mmol} / \mathrm{l}(7.35 \mathrm{mg} / \mathrm{dl})$ $(p<0.01)$ compared to controls. TG and HDL-C did not change significantly compared to the control groups. In a subgroup analysis, the maximum reduction in LDL-C was obtained in studies that included hypercholesterolemic subjects, with higher levels of cholesterol at baseline [81].

Based on available data it seems that the best results were obtained with Lactobacillus strains. One possible explanation might be the adaptation of Lactobacillus species (in particular L. acidophilus and L. plantarum) that can survive in acid and bile environment and easily colonize the gastro- intestinal tract [82]. A stronger cholesterol-lowering effect of Lactobacillus was confirmed in the meta-analysis of RCTs by Shimizu et al., where the most promising results were obtained after a treatment period of more than 4 weeks, but they could not prove any significant improvements in either HDL-C or TG [83]. More studies are needed to strictly define the types of subjects who would benefit most, the probiotic strains, the dosage forms or the administration vehicles of the strains (researching any interference or pleiotropic action due to the vehicle), the duration of the treatment, the dosages and the cholesterol-lowering mechanisms. To date, the clinical findings are still not sufficient to recommend probiotics as a nonpharmacologic alternative to improve the lipid profile.

Safety: Probiotics are considered to be generally very safe, and side effects are rare. The report released by the Agency for Healthcare Research and Quality (2011) concluded that, although the existing probiotic clinical trials reveal no evidence of increased risk, there are not enough data to answer questions on the safety of probiotics in intervention studies with confidence [84].

\begin{tabular}{|c|c|c|c|c|c|}
\hline Class & Level & $\begin{array}{c}\text { Active } \\
\text { daily } \\
\text { doses }\end{array}$ & $\begin{array}{c}\text { Expected } \\
\text { effects } \\
\text { on LDL-C }\end{array}$ & $\begin{array}{c}\text { Effects } \\
\text { on other } \\
\text { CV risk } \\
\text { biomark- } \\
\text { ers }\end{array}$ & $\begin{array}{c}\text { Direct } \\
\text { vascular } \\
\text { effects }\end{array}$ \\
\hline IIb & B & $\begin{array}{c}\text { Strain- } \\
\text { depen- } \\
\text { dent }\end{array}$ & $\begin{array}{c}-5 \% \\
\text { (strain- } \\
\text { depen- } \\
\text { dent) }\end{array}$ & $\begin{array}{c}\text { None } \\
\text { (at least } \\
\text { none } \\
\text { with } \\
\text { a lipid- } \\
\text { lowering } \\
\text { effect) }\end{array}$ & $\begin{array}{c}\text { Not } \\
\text { demon- } \\
\text { strated }\end{array}$ \\
\hline
\end{tabular}

\section{Inhibitors of liver cholesterol synthesis}

\subsection{Red yeast rice extract}

Mechanism of action: Red yeast rice (RYR) is a nutraceutical obtained by the fermentation of a particular yeast (in general Monascus purpureus, M. pilosus, M. floridanus or M. ruber) in rice (Oryza sativa) that gives the typical red coloration to the rice for the presence of pigments produced by the secondary fermentative metabolism. Red yeast rice contains sugars $(25-73 \%$, in particular starch), proteins (14-31\%), water (2-7\%), fatty acids (1-5\%), pigments (such as rubropunctamine, monascorubramine, rubropunctatin, monascorubrin, monascin, ankaflavin), sterols, isoflavones and polyketides [85]. The yeast during the fermentation process enriches the rice of a complex of substances with important lipid-lowering activities including polyketides such as monacolins. Usually the food supplements derived from red yeast rice contain a concentration of monacolins of up to $1.9 \%$ [86]. Based on the conditions 
A.F.G. Cicero, A. Colletti, G. Bajraktari, O. Descamps, D.M. Djuric, M. Ezhov, Z. Fras, N. Katsiki, M. Langlois, G. Latkovskis, D.B. Panagiotakos, G. Paragh, D.P. Mikhailidis, O. Mitchenko, B. Paulweber, D. Pella, C. Pitsavos, Ž. Reiner, K.K. Ray, M. Rizzo, A. Sahebkar, M.C. Serban, L.S. Sperling, P.P. Toth, D. Vinereanu, M. Vrablík, N.D. Wong, M. Banach

of fermentation and the yeast strain used, today several types of monacolins have been identified (compactin, monacolins $M, L, J, X$ ) including the subtype monacolin K (MonK), structurally identical to lovastatin. The main cholesterol-lowering putative mechanism of action of red yeast rice is due by a reversible inhibitory action on 3-hydroxy-3-methyl-glutaryl-CoA (HMG-CoA) reductase (the key enzyme in endogenous cholesterol synthesis).

Despite having the same structure, MonK and lovastatin pharmacokinetic profiles and bioavailability can be different: in fact, if on one hand lovastatin is administered in conventional pharmaceutical form as a single active ingredient (31\% of bioavailability in humans), MonK is only one of the components of the red yeast rice that can interact to change the typical pharmacokinetic profile of lovastatin. Another important aspect that emphasizes the possible pharmacokinetics and clinical efficacy differences regards the chemical structure of MonK: the ratio of lactone to acid strongly varies, the acid being the active one and much better absorbed. The acid form can range from $5 \%$ to $100 \%$ of the total MonK (difficult to estimate), greatly influencing the bioavailability of the molecule. The lactone ring opening can occur following metabolism in alkaline conditions or enzymatically by the small intestine and liver cytochrome P450 (CYP) 3A family [87, 88].

Efficacy: The lipid-lowering efficacy of RYR has been confirmed by some meta-analyses of RCTs; the most recent one included 20 trials evaluating the efficacy and safety profile of this nutraceutical. The results showed that (after 2-24 months) RYR reduced LDL-C on average by $1.02 \mathrm{mmol} / \mathrm{l}$ $(-1.20 ;-0.83)(39.4 \mathrm{mg} / \mathrm{dl})$ compared to placebo, which was not different from moderate-intensity statins (pravastatin $40 \mathrm{mg}$, simvastatin $10 \mathrm{mg}$, lovastatin $20 \mathrm{mg})(0.003 \mathrm{mmol} / \mathrm{l} ;-0.36 ; 0.41)$ $(0.12 \mathrm{mg} / \mathrm{dl})$. A small increase of HDL-C (0.007 $\mathrm{mmol} / \mathrm{l}$; 0.03 ; 0.11) $(0.3 \mathrm{mg} / \mathrm{dl})$ and decrease of TG $(-0.26 \mathrm{mmol} / \mathrm{l} ;-0.35 ;-0.17)(23 \mathrm{mg} / \mathrm{dl}) \mathrm{com}$ pared to placebo was observed. The doses of RYR used were different and varied from $1200 \mathrm{mg}$ to $4800 \mathrm{mg} /$ day containing from $4.8 \mathrm{mg}$ to $24 \mathrm{mg}$ of MonK. Concerning the safety profile, the incidence of cases of liver abnormalities and kidney injury was between 0 and $5 \%$ in both groups (RYR and control). In addition, the incidence of developing muscular symptoms was lower in RYR groups (0 to $23.8 \%$ ) compared to control groups (0-36\%). There were no cases of rhabdomyolysis or myopathy with CK levels increased more than 10 times the upper limit [89]. In fact it has been clearly shown that the safety profile of RYR is similar to that of low-dose statins [90]. These data consolidate the results obtained in a previous Chinese meta-analysis including 93 trials with a total of 9625 participants included [91].
The reason why the reduction of serum cholesterol is comparable between "RYR" and "statin" groups (at doses many times higher than the corresponding MonK) is still unclear. It is possible that "non-statin components" of RYR (such as polyunsaturated fatty acids) exert pleiotropic actions on reducing cholesterol, thus reaching the values as the groups treated with single-component statins [85]. Furthermore, the tolerance of RYR is usually greater than statin treatment. The reason is again not clear, but it could be explained by the fact that the daily dose of MonK in dietary supplements is usually much lower than that of statins.

RYR also improves endothelial function in humans. In a clinical trial involving 50 patients with CHD, treated with $1200 \mathrm{mg} /$ day of RYR or placebo for a period of 6 weeks and following a meal with high fat intake ( $50 \mathrm{~g}$ ), the levels of hs-CRP and FMD (at 0 and $4 \mathrm{~h}$ ) and the lipid parameters were monitored. The results showed that the group treated with RYR at the end of the 6-week follow-up obtained a reduction of hs-CRP and the area under the curve (AUC) of triglyceride (TG-AUC) $(p<0.001$ for each), in addition to an improvement of postprandial and pre-prandial FMD $(p<0.001)$. There were no significant changes in serum lipids and FMD in the placebo group [92].

RYR use is a rare example of a nutraceutical studied to evaluate its effects on CV outcomes. RYR supplementation has shown relevant efficacy in reducing CVD risk in adult and elderly patients in secondary prevention [92]. In a large trial involving 66 hospitals in China, 1445 patients (aged between 65 and 75 years) with a history of myocardial infarction (MI) were randomized to two groups (placebo vs. RYR) and followed for a mean of 4 years. RYR supplementation showed a reduction in the risk of CHD $(31.0 \%, p=0.04)$, allcause mortality $(31.9 \%, p=0.01)$, stroke $(44.1 \%$, $p=0.04$ ), the need for coronary artery bypass graft (CABG) or a percutaneous coronary intervention ( $\mathrm{PCI})(48.6 \%, p=0.07)$ and malignancies $(51.4 \%$, $p=0.03)$. It was also estimated that following RYR treatment for 4 years, the number needed to treat (NNT) to prevent one coronary event, one coronary death and one mortality due to all causes in elderly patients were respectively 18,33 and 23 . In adults, however, these numbers were 23,82 and 51 . Side effects were not significantly different between the groups [93].

Safety: Inhibitors or inducers of CYP450 may cause alterations of plasma concentrations of MonK. In fact, the concomitant use of some nutraceuticals (such as grapefruit juice) [94], food or drugs (cyclosporine, niacin, fibrates, coumarin, verapamil, antifungals, macrolides, nefazodone, HIV protease inhibitors [93]), which are CYP450 inhibitors may increase the risk of myotoxic side effects and in some rare cases cause rhabdomy- 
olysis [95]. While the chronic administration of monacolins could be responsible for mild to moderately severe side effects, it is usually well tolerated. However, serious attention must be paid to citrinin, a mycotoxin metabolite derived from the fermentation of Monascus [96]. The chronic ingestion of citrinin is nephrotoxic in various animal species, gradually leading to hyperplasia of the renal tubular epithelium, renal adenomas and in some cases to renal tumors (at a dose of $50 \mathrm{mg} / \mathrm{kg}$ body weight (b.w.) causing tumors in $100 \%$ of the animals tested). Moreover, citrinin induces reproductive toxicity, malformations and proven embryo toxicity in vitro and in vivo [97-99]. The EFSA has established as $0.2 \mu \mathrm{g} / \mathrm{kg}$ b.w. per day the highest quantity of citrinin which can be taken by humans with no nephrotoxic effects [100]. However, at these doses genotoxic and carcinogenic effects are not excluded. In the market RYR supplements were detected with levels of citrinin exceeding $114 \mu \mathrm{g} /$ capsule and for 4 capsules/day (recommended dosage) the mean was $456 \mu \mathrm{g} /$ day of citrinin, which is well above the level of $20 \mu \mathrm{g} / \mathrm{kg}$ b.w. per day suggested by the EFSA [86].

In summary, the administration of RYR can be recommended because of its effects on LDL-C in patients with moderately elevated cholesterol, especially in primary prevention. On the basis of the available evidence, the EFSA has expressed a scientific opinion on the substantiation of health claims about the relationship between administration of RYR and the maintenance of plasma LDL-C levels - the relationship is possible using a dose of RYR which contains $10 \mathrm{mg}$ of MonK (maximum daily dose in Europe as dietary supplement) [101]. However, some National Regulatory Agencies in Europe have recently suggested using lower dosages of MonK for safety purposes. Moreover, specific attention has to be given when full dosed RYR is administered in previously statin-intolerant subjects.

\begin{tabular}{|c|c|c|c|c|c|}
\hline Class & Level & $\begin{array}{c}\text { Active } \\
\text { daily } \\
\text { doses }\end{array}$ & $\begin{array}{c}\text { Expected } \\
\text { effects } \\
\text { on LDL-C }\end{array}$ & $\begin{array}{c}\text { Effects } \\
\text { on other } \\
\text { CV risk } \\
\text { biomark- } \\
\text { ers }\end{array}$ & $\begin{array}{c}\text { Direct } \\
\text { vascular } \\
\text { effects }\end{array}$ \\
\hline I & A & $\begin{array}{c}3-10 \mathrm{mg} \\
\text { (mona- } \\
\text { colin K) }\end{array}$ & $\begin{array}{c}-15 \% \text { to } \\
-25 \%\end{array}$ & $\begin{array}{c}\downarrow \text { ApoB, } \\
\text { hs-CRP, } \\
\text { MMP-2, } \\
\text { MMP-9 }\end{array}$ & $\begin{array}{c}\uparrow \text { FMD, } \\
\text { PWV } \\
\downarrow \text { CV } \\
\text { events } \\
\text { in sec- } \\
\text { ondary } \\
\text { preven- } \\
\text { tion }\end{array}$ \\
\hline
\end{tabular}

\subsection{Garlic (Allium sativum)}

Mechanism of action: Garlic (Allium sativum) is a nutraceutical known for its multiple health properties. One of the most important molecules present in garlic is allicin (diallyl thiosulfinate) produced from the non-proteinogenic amino acid alliin (S-allyl cysteine sulfoxide) in a reaction catalyzed by alliinase [102]. Allicin could be one of the chemical entities responsible for the garlic lipid-lowering mechanism of action. In fact, it seems to be an inhibitor of HMG-CoA reductase, squalene-monooxygenase and acetyl-CoA synthetase enzymes. Allicin contains a thiol group, so it is also possible that it reacts with non-acetylated-CoA directly, reducing acetyl-CoA available for endogenous synthesis of cholesterol [103]. Other suggested mechanisms of action of garlic are blocking the absorption of dietary cholesterol and fatty acids and increased excretion of bile acids. However, further studies are necessary to finally confirm these effects and the molecules responsible for these possible lipid-lowering activities [104].

Efficacy: In a meta-analysis of 39 RCTs enrolling 2298 mild-to-moderate hypercholesterolemic subjects the consumption of garlic extracts for at least 2 months showed a reduction of LDL-C (-0.23 $\mathrm{mmol} / \mathrm{l}(9 \mathrm{mg} / \mathrm{dl})$, more evident in individuals with $\mathrm{TC}<5.17 \mathrm{mmol} / \mathrm{l}(200 \mathrm{mg} / \mathrm{dl})$ at baseline) [103]. The same author highlighted the beneficial effect on blood pressure of garlic [105], while Jung et al. [106] underlined that it is able to reduce apoB and increase the LDL/Apo B ratio. According to a recent meta-analysis of RCTs, garlic seems not to have any effect on lipoprotein (a) (Lp(a)) level [107]. Finally, garlic might exert a significant antiplatelet activity in humans [108]. In conclusion, garlic at a dose of $6 \mathrm{~g} /$ day (depending on the percentage of allicin) could be useful in the management of mild cholesterolemia, probably more for the parallel anti-hypertensive and anti-platelet effect than for the lipid-lowering one. The high doses required and the common aftertaste could limit the longterm compliance with treatment.

Safety: Side effects are usually minimal (mostly gastrointestinal) and the extracts are well tolerated [104].

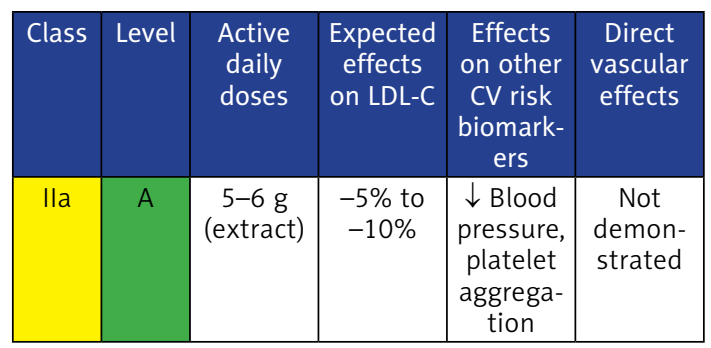

\subsection{Pantethine}

Mechanism of action: Pantethine, a dimeric form of pantetheine, produced from pantothenic acid (vitamin $B_{5}$ ) by the addition of cysteamine, has been widely tested for lipid-lowering activ- 
A.F.G. Cicero, A. Colletti, G. Bajraktari, O. Descamps, D.M. Djuric, M. Ezhov, Z. Fras, N. Katsiki, M. Langlois, G. Latkovskis, D.B. Panagiotakos, G. Paragh, D.P. Mikhailidis, O. Mitchenko, B. Paulweber, D. Pella, C. Pitsavos, Ž. Reiner, K.K. Ray, M. Rizzo, A. Sahebkar, M.C. Serban, L.S. Sperling, P.P. Toth, D. Vinereanu, M. Vrablík, N.D. Wong, M. Banach

ity. In vitro it inhibits fatty acid synthesis and HMG-CoA reductase $[109,110]$. Several human trials have confirmed these effects in humans $[111,112]$.

Efficacy: Recently a 16-week triple-blinded RCT carried out on 120 subjects with low to moderate CVD risk was published [113]. The authors showed that following an adequate diet in comparison with placebo, pantethine 600-900 mg/day demonstrated significant $(p<0.005)$ and sustained reductions (from baseline to week 16) in TC (3\% $0.16 \mathrm{mmol} / \mathrm{l}(6 \mathrm{mg} / \mathrm{dl})), \mathrm{LDL}-\mathrm{C}(4 \%-0.10 \mathrm{mmol} / \mathrm{l}$ $(4 \mathrm{mg} / \mathrm{dl}))$ and apoB $(5 \%-0.0001 \mathrm{mmol} / \mathrm{l}(4 \mathrm{mg} /$ $\mathrm{dl})$ ). The data suggest that pantethine supplementation for 16 weeks (600 mg/day for weeks 1-8 then $900 \mathrm{mg} /$ day for weeks 9-16) is safe and significantly lowers TC and LDL-C (although with relatively limited clinical relevance) over and above the effect of therapeutic lifestyle changes (TLC) or diet alone [114]. In a further 16-week triple-blinded RCT carried out on mildly hypercholesterolemic subjects pantethine 600-900 mg/day reduced LDL-C level by $11 \%$ [115].

Safety: The tolerability of pantethine is overall high, with acceptable safety confirmed also in children [114] and patients in hemodialysis [116].

\begin{tabular}{|c|c|c|c|c|c|}
\hline Class & Level & $\begin{array}{c}\text { Active } \\
\text { daily } \\
\text { doses }\end{array}$ & $\begin{array}{c}\text { Expected } \\
\text { effects } \\
\text { on LDL-C }\end{array}$ & $\begin{array}{c}\text { Effects } \\
\text { on other } \\
\text { CV risk } \\
\text { biomark- } \\
\text { ers }\end{array}$ & $\begin{array}{c}\text { Direct } \\
\text { vascular } \\
\text { effects }\end{array}$ \\
\hline Ila & A & $\begin{array}{c}600-900 \\
\text { mg }\end{array}$ & $\begin{array}{c}\text { Not ap- } \\
\text { plicable }\end{array}$ & $\begin{array}{c}\text { Not } \\
\text { demon- } \\
\text { strated }\end{array}$ & $\begin{array}{c}\text { Not } \\
\text { demon- } \\
\text { strated }\end{array}$ \\
\hline
\end{tabular}

\subsection{Bergamot (Citrus bergamia)}

Mechanism of action: Bergamot is the common name of the fruit Citrus bergamia Risso and differs from other Citrus fruits in its composition, particularly rich in flavonoids (as neoeriocitrin, neohesperidin, naringin, rutin, neodesmin, rhoifolin, poncirin) [117]. In particular, the 3-hydroxy-3-methyl-glutaryl flavanone enriched fraction (HMGF: brutieridin, melitidin and HMG-neoeriocitrin) has been extracted from the bergamot peel; they act as statins by inhibiting HMG-CoA reductase and ACAT, reducing the formation of cholesterol esters and limiting the transport of cholesterol in the blood. Bergamot also contains naringin: like neoeriocitrin, melitidin and rutin it inhibits the oxidation of LDL-C, initiates adenosine-monophosphate-kinase (AMPK) and has shown scavenging activity, suggesting a possible preventive antiatherosclerotic mechanism. It is also possible that bergamot increases the fecal excretion of cholesterol, reducing the intestinal absorption and increasing the turnover and excretion of bile acids [118, 119].

Efficacy: Clinical studies on the lipid-lowering properties of bergamot are still very few. The study by Gliozzi et al., a prospective, open-label, parallel group, placebo-controlled trial, involved 77 patients with mixed dyslipidemia divided into 5 groups: placebo $(n=15)$, rosuvastatin $10 \mathrm{mg}(n=16)$, rosuvastatin $20 \mathrm{mg}(n=16)$, bergamot $1000 \mathrm{mg}$ (bergamot derived polyphenolic fraction, BPF) $(n=15)$ and bergamot $1000 \mathrm{mg}+$ rosuvastatin $10 \mathrm{mg}(n=$ 15). After 4 weeks of treatment, LDL-C decreased from a baseline value of $4.94 \mathrm{mmol} / \mathrm{l}(191 \pm 3 \mathrm{mg} /$ dl) to a value of $2.97 \mathrm{mmol} / \mathrm{l}(115 \pm 4 \mathrm{mg} / \mathrm{dl})$ (level of reduction: $-1.96 \mathrm{mmol} / \mathrm{l} / 75.8 \mathrm{mg} / \mathrm{dl})$ after rosuvastatin $10 \mathrm{mg}$, to $2.26 \mathrm{mmol} / \mathrm{l}(87.3 \mathrm{mg} / \mathrm{dl})(-2.69$ $\mathrm{mmol} / \mathrm{l} / 104 \mathrm{mg} / \mathrm{dl})$ after rosuvastatin $20 \mathrm{mg}, 2.92$ $\mathrm{mmol} / \mathrm{l}(113 \pm 4 \mathrm{mg} / \mathrm{dl})(-2.02 \mathrm{mmol} / \mathrm{l} / 78.1 \mathrm{mg} / \mathrm{dl})$ after BPF $1000 \mathrm{mg}$, and $2.33 \mathrm{mmol} / \mathrm{l}(90 \pm 3 \mathrm{mg} /$ dl) $(-2.61 \mathrm{mmol} / \mathrm{l} / 100.9 \mathrm{mg} / \mathrm{dl})$ after rosuvastatin $10 \mathrm{mg}+$ BPF $1000 \mathrm{mg} /$ day. Moreover, the groups treated with BPF (either alone or in combination) experienced a reduction of some biomarkers of vascular oxidative damage including malonyldialdehyde (MDA; one of the major aldehydes formed during lipid peroxidation) and oxidized LDLs [120]. The same author evaluated the effects of bergamot $(1300 \mathrm{mg} /$ day) in 107 patients (divided into two groups) with metabolic syndrome (MetS) and non-alcoholic fatty liver disease (NAFLD) during 120 consecutive days. They found that the treated group experienced a marked reduction of small dense LDL (sdLDL) and TG, and increased HDL-C levels compared to placebo. Moreover, this was accompanied by a significant reduction of serum glucose, transaminases, $\gamma$-glutamyl-transferase, and inflammatory biomarkers such as hs-CRP and tumor necrosis factor- $\alpha$ (TNF- $\alpha)$ [121]. Moreover, the amount of atherogenic sdLDL significantly decreased $(-35 \%)$ while large buoyant LDLs increased $(+38 \%$; both $p<0.05)$ compared to baseline levels. These data are important, and emphasize the potential use of bergamot for reducing CVD risk, knowing that elevated levels of sdLDL-C associated with NAFLD are associated with an increased CV risk [122]. A further study involved 237 patients divided into four groups: A ( $n=104)$ - subjects with hypercholesterolemia (LDL-C > $3.36 \mathrm{mmol} / \mathrm{l}(130 \mathrm{mg} / \mathrm{dl})$ ) treated with bergamot $(500 \mathrm{mg} /$ day for 30 days); $\mathrm{B}(n=42)$ - patients with hyperlipidemia (hypercholesterolemia and hypertriglyceridemia) treated with bergamot (1000 mg/day for 30 days); C $(n=59)$ - patients with MetS treated with placebo; and D $(n=32)$ - hyperlipidemic patients who stopped treatment with simvastatin because of side effects (cramps and increased serum levels of creatine kinase (CK)), treated with bergamot $(1500 \mathrm{mg} /$ day for 30 days) after a 60 -day wash-out period. The results showed dose-dependent lipid-lowering action of bergamot (groups A and B respectively LDL-C: $-24.1 \%$ and $-30.6 \%$, TG: $-28.2 \%$ and $-37.9 \%$, HDL-C: $+22.3 \%$ and $+40.1 \%, p<0.001$ for all) compared to baseline. Group C (placebo) did not show significant reductions 
in serum cholesterol. Group D showed a reduction of LDL-C and TG $(-25.0 \%$ and $-27.6 \%$, respectively; $p<$ 0.001 for all), without any side effects [123]. In summary, the evidence indicates that bergamot has lipid-lowering effects, both quantitative and qualitative, especially by reducing the levels of SdLDL and TG and significantly increasing HDL-C levels. This suggests a potential use of bergamot in hypercholesterolemic and/or hypertriglyceridemic patients, intolerant to statins, with NAFLD and MetS. The main limitation of the evidence on bergamot efficacy is related to the fact that the greater part of the clinical literature has been provided by a single research unit and not confirmed elsewhere. Moreover, data on vascular parameters such as endothelial function and arterial stiffness are not available yet.

Safety: Clinical studies conducted to date with dosages between 500 and $1500 \mathrm{mg} /$ day showed a good safety profile, with no side effects detected.

\begin{tabular}{|c|c|c|c|c|c|}
\hline Class & Level & $\begin{array}{c}\text { Active } \\
\text { daily } \\
\text { doses }\end{array}$ & $\begin{array}{c}\text { Expected } \\
\text { effects } \\
\text { on LDL-C }\end{array}$ & $\begin{array}{c}\text { Effects } \\
\text { on other } \\
\text { CV risk } \\
\text { biomark- } \\
\text { ers }\end{array}$ & $\begin{array}{c}\text { Direct } \\
\text { vascular } \\
\text { effects }\end{array}$ \\
\hline Ila & B & $\begin{array}{c}500- \\
1000 \mathrm{mg} \\
\text { (BPF) }\end{array}$ & $\begin{array}{l}-15 \% \text { to } \\
-40 \%\end{array}$ & $\begin{array}{c}\downarrow \text { sdLDL, } \\
\text { hs-CRP, } \\
\text { TNF- } \alpha\end{array}$ & $\begin{array}{c}\text { Not } \\
\text { demon- } \\
\text { strated }\end{array}$ \\
\hline
\end{tabular}

\subsection{Policosanols}

Mechanism of action: Policosanols are aliphatic primary alcohols mainly extracted from sugarcane (Saccharum officinarum L) wax. The interest in policosanols has increased based on early Cuban studies, indicating the lipid-lowering and antiplatelet effects of this nutraceutical [124]. Policosanols have demonstrated inhibitory action on HMG-CoA reductase and on bile acid absorption, in addition to an activating effect on AMPK (increase of fatty acid $\beta$-oxidation) [125].

Efficacy: In recent years several clinical studies have suggested a reducing action of this nutraceutical on lipid profile, but the results are often non-significant. The study by Berthold et al. showed that the administration of policosanols in hypercholesterolemic patients does not statistically improve the levels of TC, TG, HDL-C and LDL-C. This trial included 143 subjects divided into five groups each treated with 10, 20, 40, $80 \mathrm{mg}$ of policosanols or placebo. Nobody in any group at the end of the study (12 weeks) showed a reduction of more than $10 \%$ in LDL-C [126]. These data were confirmed by the study of Backes et al., where policosanols did not significantly change the lipid profile of hypercholesterolemic subjects in either of the two treatment groups (treated with policosanol or policosanol in addition to statin therapy) or placebo compared to the control [127]. Neither policosanols from rice nor wheat germ showed any significant effect on LDL-C, HDL-C, TG, oxLDL, apoB, $L p(a)$, homocysteine, CRP, fibrinogen or blood coagulation factors $[128,129]$. There are several clinical studies demonstrating the efficacy of combinations containing policosanol also in association with other nutraceuticals (such as fermented red rice, berberine), but the role of the lipid-lowering effect of policosanol in these combinations is not clear. Based on all these data, policosanol should not be recommended in clinical practice until new well-designed studies are performed that definitively clarify its lipid-lowering potential effect.

Safety: The tolerability of policosanols is usually very good.

\begin{tabular}{|c|c|c|c|c|c|}
\hline Class & Level & $\begin{array}{c}\text { Active } \\
\text { daily } \\
\text { doses }\end{array}$ & $\begin{array}{c}\text { Expected } \\
\text { effects } \\
\text { on LDL-C }\end{array}$ & $\begin{array}{c}\text { Effects } \\
\text { on other } \\
\text { CV risk } \\
\text { biomark- } \\
\text { ers }\end{array}$ & $\begin{array}{c}\text { Direct } \\
\text { vascular } \\
\text { effects }\end{array}$ \\
\hline III & A & $\begin{array}{c}10-80 \\
\mathrm{mg}\end{array}$ & $\begin{array}{c}\text { Non-sig- } \\
\text { nificant }\end{array}$ & None & $\begin{array}{c}\text { Not } \\
\text { demon- } \\
\text { strated }\end{array}$ \\
\hline
\end{tabular}

\section{Inducer of LDL-cholesterol excretion}

\subsection{Berberine}

Mechanism of action: Berberine (BBR) is a quaternary benzylisoquinoline alkaloid present in the root, rhizome, stem, fruit and bark of various species of plants including Coptis (Coptis chinensis, Coptis japonica), Hydrastis (Hydrastis canadensis) and Berberis (Berberis aristata, Berberis vulgaris, Berberis croatica) [130]. The findings of the lipidlowering effect of berberine are relatively recent. The mechanisms by which BBR regulates plasma cholesterol levels are essentially two: first, it is an inhibitor of proprotein convertase subtilisin/kexin type 9 (PCSK9) through the ubiquitination and degradation of hepatocyte nuclear factor $1 \alpha$ (HNF$1 \alpha$ ), causing increased levels and limited degradation of the hepatic LDL receptor (LDLR). Second, $B B R$ acts directly on the expression of LDLR via two identified mechanisms, causing up-regulation of the receptors through a post-transcriptional mechanism that stabilizes their mRNA (activation of extracellular signal regulated kinases (ERK) and Jun amino-terminal kinase (JNK)-dependent pathways) $[131,132]$. BBR also has some secondary mechanisms of action; recent studies have emphasized that it reduces the intestinal absorption of cholesterol, increasing the fecal excretion and promoting the hepatic cholesterol turnover and the formation of bile acids [133]. Moreover, BBR is an activator of AMPK, which determines an increase of fatty acid oxidation and a reduction of the expression of lipogenic genes. Finally, it is an effective inhibitor of nicotinamide adenine dinucleotide phosphate (NADPH) oxidase-mediated oxidative stress $[134,135]$. It is important to 
A.F.G. Cicero, A. Colletti, G. Bajraktari, O. Descamps, D.M. Djuric, M. Ezhov, Z. Fras, N. Katsiki, M. Langlois, G. Latkovskis, D.B. Panagiotakos, G. Paragh, D.P. Mikhailidis, O. Mitchenko, B. Paulweber, D. Pella, C. Pitsavos, Ž. Reiner, K.K. Ray, M. Rizzo, A. Sahebkar, M.C. Serban, L.S. Sperling, P.P. Toth, D. Vinereanu, M. Vrablík, N.D. Wong, M. Banach

emphasize that BBR is just one of the alkaloids present in the plants; it is therefore possible that some pleiotropic activities (such as antioxidant, anti-inflammatory, insulin sensitizer) might be due to some other substances and not only BBR. In Berberis vulgaris alone, in addition to berberine, the following compounds have been have been identified: alkaloids - acanthine, bargustanine, berbamine, berberrubine, beriambine, bervuleine, columbamine, jatrorrhizine, lambertine, magnoflorine, palmatine, thaliemidine; vitamins - ascorbic acid, vitamin K, $\beta$-carotene; and tannins, flavonoids and flavanols, triterpenes, and coumarins [136]. The bioavailability of BBR is lower than $1 \%$. This is due to the poor intestinal absorption (56\%), caused by a self particulate aggregation which reduces the solubility in the gastrointestinal tract, to the low permeability of the molecule (Biopharmaceutical Classification System (BCS) class III) and to the intestinal and liver first-pass metabolism (43.5\% and $0.14 \%$, respectively) [137]. The effect of the intestinal first pass is still unclear, but it is probably of enzymatic origin including CYP2D6 and CYP3A4 in liver metabolism. Finally, BBR is also the substrate of the efflux pump P-glycoprotein (P-gp). Therefore in recent years alternative approaches have been studied to increase the bioavailability of BBR, using permeability enhancers (sodium caprate, sodium deoxycholate, chitosan), P-gp inhibitors (silymarin), or modified release dosage forms (nanoemulsions, micelles, liposomes, nanoparticles), with quite satisfactory results.

Efficacy: The lipid-lowering efficacy of BBR has been confirmed by a recent meta-analysis that included 27 clinical studies with 2569 participants. The effects of berberine on lipids were: LDL-C: $-0.65 \mathrm{mmol} / \mathrm{l}(95 \% \mathrm{Cl}:-0.75 ;-0.56, p=0.00001)$ (25.14 mg/dl); TG: $-0.39 \mathrm{mmol} / \mathrm{l}(95 \% \mathrm{Cl}:-0.59$; $-0.19, p=0.0001)(34.5 \mathrm{mg} / \mathrm{dl}) ; \mathrm{HDL}-\mathrm{C}: 0.07 \mathrm{mmol} / \mathrm{l}$ (95\% Cl: $0.04 ; 0.10, p=0.00001)(2.71 \mathrm{mg} / \mathrm{dl})$. These effects seem to be additive to those of statins and associated with a positive impact on glucose metabolism and blood pressure as well [138]. A recent study enrolled 130 patients undergoing $\mathrm{PCl}$, randomized to two groups, and treated with BBR $600 \mathrm{mg} /$ day or placebo in addition to standard therapies. The BBR group showed a marked reduction in TG ( $26 \%$ BBR vs. $13 \%$ control; the difference did not reach statistical significance due to large inter-individual variations) and LDL-C ( $24 \%$ vs. $17 \%$ BBR control: $p<0.001)$ compared to the control group. In addition, both groups showed a reduction in the levels of interleukin 6 (IL-6) and monocyte chemoattractant protein-1 (MCP-1) ( $p<0.05$ for each), as well as hs-CRP, intercellular adhesion molecule-1 (ICAM-1), vascular cell adhesion molecule-1 (VCAM-1), and matrix metallopeptidase 9 (MMP-9) ( $p<0.001$ for all) compared to baseline. The levels of MMP-9, ICAM-1 and VCAM-1, after 1 month, were significantly reduced to a greater extent in the BBR group compared to the control and baseline $(p<0.05)$ [137]. In summary, the use of BBR at doses ranging between 500 and $1500 \mathrm{mg}$ has proved to be effective in lipid lowering and relatively safe both in primary and secondary prevention. Compared to nutraceuticals with a statin-similar mechanism of action, BBR has a greater effect in the reduction of triglyceridemia, partly related to its positive effect on insulin-resistance [139]. Its use can therefore be recommended, especially in patients intolerant to statins, with mild hypercholesterolemia and in patients with MetS.

Safety: Based on the abovementioned data, side effects are mild to moderate, mostly gastrointestinal (diarrhea, constipation, abdominal distension) and comparable to the control groups [139]. No significant differences were detected in the levels of aspartate transaminase (AST), alanine transaminase (ALT), and creatinine in comparison to the control group [140].

\begin{tabular}{|c|c|c|c|c|c|}
\hline Class & Level & $\begin{array}{c}\text { Active } \\
\text { daily } \\
\text { doses }\end{array}$ & $\begin{array}{c}\text { Expected } \\
\text { effects } \\
\text { on LDL-C }\end{array}$ & $\begin{array}{l}\text { Effects } \\
\text { on other } \\
\text { CV risk } \\
\text { biomark- } \\
\text { ers }\end{array}$ & $\begin{array}{c}\text { Direct } \\
\text { vascular } \\
\text { effects }\end{array}$ \\
\hline 1 & $A$ & $\begin{array}{c}500- \\
1500 \mathrm{mg}\end{array}$ & $\begin{array}{c}-15 \% \text { to } \\
-20 \%\end{array}$ & $\begin{array}{c}\downarrow \text { ApoB, } \\
\text { TG, } \\
\text { hs-CRP, } \\
\text { IL-6, } \\
\text { MCP-1, } \\
\text { ICAM-1, } \\
\text { VCAM-1, } \\
\text { MMP-9, } \\
\text { glucose, } \\
\text { HOMA } \\
\text { index, } \\
\text { blood } \\
\text { pressure }\end{array}$ & $\begin{array}{c}\text { Not } \\
\text { demon- } \\
\text { strated }\end{array}$ \\
\hline
\end{tabular}

\subsection{Green tea extracts}

Mechanism of action: Some available RCTs on green tea suggest that its consumption could be protective against CHD and CVD [140]. Green tea is particularly rich in antioxidants such as polyphenols (up to $35 \%$ of dried weight) that are well-known cardioprotective compounds. The major fraction of polyphenols in green tea is catechins, structurally flavan-3-ols. The most important one is the epigallocatechin-3-gallate (EGCG), known for its antioxidant and cardioprotective properties. It is possible that beyond the antioxidant effects derived from polyphenols and the reduction of lipid peroxidation, green tea interferes with micellar solubilization and absorption of cholesterol. Green tea is an activator of AMPK (stimulating lipogenesis) and an HMG-CoA reductase inhibitor. Tea catechins have been reported to have an inhibitory effect on the ileal apical sodium-dependent bile acid transporter 
(reducing reabsorption of bile acids) to enhance the hepatic LDL-R expression and the biliary excretion of cholesterol [141, 142].

Efficacy: A meta-analysis of 20 RCTs and 1536 participants showed a reduction of LDL-C (mean difference (MD): $-0.19 \mathrm{mmol} / \mathrm{l}(7.35 \mathrm{mg} / \mathrm{dl}) ; 95 \% \mathrm{Cl}$ : $-0.3 ;-0.09, p=0.0004)$. The lipid-lowering effects of green tea were found to be greater in RCTs with longer duration. Moreover, green tea extract exerts a mild but significant antihypertensive effect. The tested daily doses ranged from 250 to $1200 \mathrm{mg}$ of green tea extract or from 170 to $850 \mathrm{mg}$ of EGCG [143]. Moreover, green tea is associated with an improvement in FMD [144] and pulse wave velocity (PWV) [145], despite no apparent effect on hs-CRP levels [146]. Therefore, overall the consumption of green tea might be associated with a decreased risk of CVD morbidity and mortality [147]. There are also no data on its influence on TG and HDL-C.

Safety: Usually the consumption of green tea is well tolerated; however, in some cases rash, transient elevation of blood pressure and mild gastrointestinal disorders may occur. Moreover, high doses of green tea can cause a deficiency of iron and folate due to its capacity to bind and reduce their intestinal absorption. Therefore, particular attention should be given to green tea consumption during pregnancy [143].

\begin{tabular}{|c|c|c|c|c|c|}
\hline Class & Level & $\begin{array}{c}\text { Active } \\
\text { daily } \\
\text { doses }\end{array}$ & $\begin{array}{c}\text { Expected } \\
\text { effects } \\
\text { on LDL-C }\end{array}$ & $\begin{array}{c}\text { Effects } \\
\text { on other } \\
\text { CV risk } \\
\text { biomark- } \\
\text { ers }\end{array}$ & $\begin{array}{c}\text { Direct } \\
\text { vascular } \\
\text { effects }\end{array}$ \\
\hline Ila & A & $\begin{array}{c}25- \\
100 \mathrm{~g}\end{array}$ & $-5 \%$ & $\begin{array}{c}\downarrow \text { Blood } \\
\text { pressure }\end{array}$ & $\begin{array}{c}\uparrow \mathrm{FMD} \\
\downarrow \mathrm{PWV} \\
\text { (tea) }\end{array}$ \\
\hline
\end{tabular}

\subsection{Soy and lupin proteins}

Mechanism of action: Preclinical and clinical evidence supports the positive effects of soy and lupin proteins on lipid profile. Generally, it is believed that bioactive peptides present in soy and lupin (such as conglutin- $\gamma$ ) may be responsible for the lipid-lowering effect of these legumes [148]. However, the isoflavones could contribute to this effect as well [149]. The cholesterol-lowering mechanisms proposed for soy and lupin seem to be numerous but are still unclear, including the down-regulation of the expression of the hepatic transcription factor of sterol regulatory element binding protein (SREBP-1) (via PI3K/Akt/GSK3 $\beta$ pathways, with decreased hepatic lipoprotein secretion and cholesterol content), the regulation of SREBP-2 (with increased clearance of cholesterol from the blood), the reduction of cholesterol synthesis, the increase of apoB receptor activity or the increase of the fecal excretion of bile salts [150-153].
Efficacy: Several meta-analyses of RCTs have underlined the cholesterol-lowering properties of soy. In particular, a recent one including 35 RCTs and 2670 subjects concluded that soy proteins (in particular B-conglycinin globulin) have a cholesterol-lowering effect with a mean reduction in LDL-C of $3 \%(-0.12 \mathrm{mmol} / \mathrm{l} / 4.6 \mathrm{mg} / \mathrm{dl})$, TC of $2 \%$ $(-0.14 \mathrm{mmol} / \mathrm{l} / 5.4 \mathrm{mg} / \mathrm{dl})$ and TG of $4 \%(-0.06$ $\mathrm{mmol} / \mathrm{l} / 5.3 \mathrm{mg} / \mathrm{dl}$ ) and is able to increase HDL-C by $3 \%(+0.04 \mathrm{mmol} / \mathrm{l} / 1.6 \mathrm{mg} / \mathrm{dl})$, the effect being proportional to the baseline LDL-C level [154]. The mean tested dose was $30 \mathrm{~g} /$ day.

If isoflavones seem not to add significantly to the lipid-lowering effect of soy proteins, they seem to have direct positive effects on endothelial function [155] and arterial stiffness [156].

Yellow lupine (Lupinus luteus) is composed of proteins $(30-35 \%)$, fibers $(30 \%)$, carbohydrates $(3-10 \%)$ and fat $(6 \%$, of which $81 \%$ is unsaturated); in addition, there are both macro-elements (including phosphorus, calcium and magnesium) and microelements (including zinc, copper, chromium and cobalt) [157]. One aspect that differentiates lupin from other legumes is the absence of phytoestrogens, low sodium content and low glycemic index. In a randomized cross-over study, 33 hypercholesterolaemic subjects ( $\mathrm{TC}>6.6 \mathrm{mmol} / \mathrm{l} /$ $255 \mathrm{mg} / \mathrm{dl}$ ) were included and treated for 8 weeks with $25 \mathrm{~g} /$ day of lupin protein isolate (LPI) followed by 4 weeks of washout and 8 weeks of treatment with milk protein isolate (MPI). Compared to baseline, a significant reduction of LDL-C was already observed in both groups after 4 weeks $(-12 \%, p<0.008)$. In the LPI group, the levels of HDL-C increased significantly $(p<0.036)$ and the LDL/HDL ratio decreased ( $p=0.003)$, compared to the MPI group [158]. These results were confirmed by the same author in the next randomized, controlled, double-blind three-phase crossover trial, including 72 patients with hypercholesterolemia treated for 28 days with LPI, MP (milk protein) or MPA (milk protein $1.6 \mathrm{~g} /$ day of arginine). In addition to reducing LDL-C levels (in MPA and LPI groups), the LPI group showed an improvement in the levels of homocysteine (compared to the MPI and MPA groups), uric acid and TG [159]. The cholesterol-lowering properties of lupin were also highlighted in a third RCT proving a reduction of LDL-C (-12\%) comparable to the studies described previously [160]. It is also worth mentioning that exposure to isoflavone-containing soy products modestly, but significantly, improved endothelial function, as demonstrated in a meta-analysis of 17 RCTs [155].

In conclusion, the intake of soy and lupine represents a potential, relatively weak adjuvant therapy in the treatment of hypercholesterolemia, especially in individuals with moderate cholesterol levels. 
A.F.G. Cicero, A. Colletti, G. Bajraktari, O. Descamps, D.M. Djuric, M. Ezhov, Z. Fras, N. Katsiki, M. Langlois, G. Latkovskis, D.B. Panagiotakos, G. Paragh, D.P. Mikhailidis, O. Mitchenko, B. Paulweber, D. Pella, C. Pitsavos, Ž. Reiner, K.K. Ray, M. Rizzo, A. Sahebkar, M.C. Serban, L.S. Sperling, P.P. Toth, D. Vinereanu, M. Vrablík, N.D. Wong, M. Banach

Safety: The chronic use of a high quantity of soy products containing isoflavones could interfere with thyroid function and fertility. Furthermore, soybean and its derivatives contain high amounts of phytic acid that reduces the absorption of minerals such as calcium, magnesium, copper, iron and zinc. Lupine has shown a good safety profile, causing no severe side effects, and those which occurred were mostly gastrointestinal. The large amount of vegetable proteins which have to be taken in order to obtain a significant LDL-C reduction could decrease patient compliance in the long term and should be accompanied by an attentive balance of the other dietary sources of proteins.

\begin{tabular}{|c|c|c|c|c|c|}
\hline Class & Level & $\begin{array}{c}\text { Active } \\
\text { daily } \\
\text { doses }\end{array}$ & $\begin{array}{c}\text { Expected } \\
\text { effects } \\
\text { on LDL-C }\end{array}$ & $\begin{array}{c}\text { Effects } \\
\text { on other } \\
\text { CV risk } \\
\text { biomark- } \\
\text { ers }\end{array}$ & $\begin{array}{c}\text { Direct } \\
\text { vascular } \\
\text { effects }\end{array}$ \\
\hline $\mathrm{Ilb}$ & $\mathrm{A}$ & $\begin{array}{c}25- \\
100 \mathrm{~g}\end{array}$ & $\begin{array}{c}-3 \% \text { to } \\
-10 \%\end{array}$ & $\begin{array}{c}\text { Not } \\
\text { demon- } \\
\text { strated } \\
\text { in hu- } \\
\text { mans }\end{array}$ & $\begin{array}{c}\uparrow \mathrm{FMD} \\
\text { (soy } \\
\text { with } \\
\text { isofla- } \\
\text { vones) }\end{array}$ \\
\hline
\end{tabular}

\section{Other nutraceuticals with mixed mechanisms of action}

\subsection{Polyunsaturated $\omega-3$ fatty acids}

Omega-3 ( $\omega-3)$ fatty acids are polyunsaturated fatty acids (PUFAs) which contain a double bond in position 3 at the end of the carbon chain. Natural sources of $\omega-3$ are present both in animal (fish, krill, egg, squid) and plant (algae, flaxseed, walnut, edible seeds, clary sage, seed) sources [161]. In recent years the EFSA, the AHA and the Food Standards of Australia and New Zealand (FSANZ) organizations have recognized $\omega$-3 fatty acids as preventive nutraceuticals for CVD [27]. EFSA established a claim in 2010 indicating that the intake of at least $2 \mathrm{~g} /$ day of docosahexaenoic acid (DHA) and eicosapentaenoic acid (EPA) has the ability to maintain normal blood TG levels $[162,163]$. The AHA has indicated doses from 2 to $4 \mathrm{~g} /$ day of EPA/DHA to reduce TG levels by 25-30\% [164]. All these guidelines agree about the high safety of PUFAs, despite the relatively frequent fishy aftertaste and occasional abdominal discomfort.

Mechanism of action: The mechanisms through which $\omega-3$ reduce TG are: the reduction of synthesis of hepatic VLDL, the reduction of available substrate for the synthesis of new TG ( $\omega-3$ are false substrates), the reduction of the activity of TG-synthesizing enzymes (diacylglycerol acyltransferase or phosphatidic acid phosphohydrolase), the increase of $\beta$-oxidation of fatty acids, the reduction of the endogenous syn- thesis of fatty acids and the increase of synthesis of phospholipids [165].

Efficacy: EFSA health claims and the statement of the AHA are supported by a large number of RCTs. The meta-analysis of Eslick et al. included 47 RCTs with 16511 participants with hypercholesterolemia to assess the effects of the average daily dose of $3.25 \mathrm{~g}$ of EPA/DHA for 24 weeks. The results showed a significant reduction in TG of $14 \%(-0.34 \mathrm{mmol} / \mathrm{l}(30.12 \mathrm{mg} / \mathrm{dl}), 95 \% \mathrm{Cl}:-0.41$; $-0.27)$. In addition, there was a small insignificant reduction of LDL-C of $0.06 \mathrm{mmol} / \mathrm{l}(2.3 \mathrm{mg} / \mathrm{dl})$, but no differences in HDL-C [166]. These results were confirmed in normolipidemic and borderline subjects in the meta-analysis by Leslie et al. that included 2270 individuals with optimal lipid or suboptimal TG profiles (TG $<2 \mathrm{mmol} / \mathrm{l}(177 \mathrm{mg} / \mathrm{dl})$ ). In studies that used more than $4 \mathrm{~g} /$ day of $\omega-3$ TG were reduced by $9-26 \%$, while a reduction of $4-51 \%$ was found with doses from 1 to $5 \mathrm{~g} /$ day of $\omega-3$ [167]. A dose-dependent effect of $\omega-3$ was also observed by Di Stasi et al. with additional benefits obtainable for lipid profile when supplementation of $\omega-3$ was raised as high as $4.9 \mathrm{~g} /$ day [168]. It was also observed that the administration of EPA or DHA individually gave comparable effects in the reduction of TG, but not other lipid parameters; in fact, DHA showed a very modest reduction of $L D L-C$ by $5 \%$ and slightly increased HDL-C, while EPA produced no significant changes $[169,170]$. PUFAs might also be associated with an improvement of FMD and PWV, and, with larger dosages, with positive effects on inflammatory diseases and mood [171]. Moreover, in the large long-term Gruppo Italiano per lo Studio della Sopravvivenza nell' Infarto miocardico (GISSI) Prevenzione trial that involved 11324 patients surviving recent $\mathrm{MI}$, supplementation with $1 \mathrm{~g}$ of EPA/DHA significantly reduced the risk of CV death [172].

A rich source of $\omega-3$ PUFAs is krill (Euphausia superba), a small crustacean that lives in the Antarctic Ocean, containing many types of long-chain PUFAs. The $\omega-3$ present in krill oil (EPA + DHA) appears to be better absorbed in the gastrointestinal tract than that found in fish oil: this is possible because of phosphatidylcholine (the main phospholipid present in krill (40\%), which binds EPA and DHA), which confers greater stability to fatty acids. In addition, krill oil is rich in antioxidants, including vitamin E and astaxanthin [173]. Therefore, at the same dose, krill oil appears to be more effective than fish oil in the adjustment of lipid profile. Ulven et al. reported that the effects on the reduction of TG of a dose of $543 \mathrm{mg}$ of DHA and EPA contained in krill oil are comparable to doses of $2.66 \mathrm{~g}$ of EPA and DHA present in fish oil [174]. Similar data were obtained by Cicero et al. 
[175]. In the most recent meta-analysis of 7 RCTs with 662 participants Ursoniu et al. found a significant reduction in plasma concentrations of LDL-C (-15.52 mg/dl (0.4 mmol/l); $95 \% \mathrm{Cl}:-28.43$ to $-2.61 ; p=0.018)$, and TG $(-14.03 \mathrm{mg} / \mathrm{dl}(0.16$ $\mathrm{mmol} / \mathrm{l}) ; 95 \% \mathrm{Cl}:-21.38$ to $-6.67 ; p<0.001)$, and significant elevation in plasma concentrations of HDL-C $(6.65 \mathrm{mg} / \mathrm{dl}(0.17 \mathrm{mmol} / \mathrm{l}) ; 95 \% \mathrm{Cl}: 2.30$ to $10.99 ; p=0.003)$ following supplementation with krill oil [176].

Controversial results were obtained with $\alpha$-linolenic acid (ALA), an $\omega-3$ fatty acid found in many vegetable oils (such as olive and flaxseed oil). Nevertheless, a rich source of ALA, the flaxseed ( $\mathrm{Li}$ num usitatissimum, ALA $=50-62 \%$ of flaxseed oil or $22 \%$ of whole flaxseed), an oilseed crop grown on all continents, showed lipid-lowering activity regarding $L D L-C(-0.08 \mathrm{mmol} / \mathrm{l})$. This effect may be explained by the other components of flaxseed including lignans $(0.2-13.3 \mathrm{mg} / \mathrm{g}$ flaxseed) and soluble fibers ( $25 \%$ of total weight) that could enhance the reduction of total cholesterol. The cholesterol-lowering effects were more significant in females (in particular in postmenopausal women) and in individuals with high cholesterol levels at baseline [177]. Flaxseed seems also to exert a mild but significant antihypertensive effect [178]. The available data suggest that the consumption of flaxseed is safe and well tolerated. Another vegetal source of essential fatty acids is sesame. A recent meta-analysis of RCTs showed that sesame fractions intake is associated with a significant TG reduction $(-0.24 \mathrm{mmol} / \mathrm{l}(21.3 \mathrm{mg} / \mathrm{dl})$; $95 \% \mathrm{Cl}:-0.32 ;-0.15, p<0.001)$, while no changes occurred with LDL-C or HDL-C levels [179].

In conclusion, omega-3 EPA and DHA represent a valid nutraceutical to reduce TG in the blood (by $18-25 \%)$ while their effects on LDL-C and HDL-C are clinically insignificant. However, it has to be stressed that CVD outcome studies with $\omega$-3 have produced inconsistent results and their clinical efficacy appears to be related to non-lipid effects. Especially, it needs be noted that smaller doses than 2-4 g/day such as a low dose supplementation of a margarine with $\mathrm{n}-3$ PUFAs $(400 \mathrm{mg} /$ day $E P A+D H A)$ or $\alpha$-linolenic acid (2 g/day) do not significantly reduce TG levels, as was confirmed in an RCT involving 4837 post-MI patients. Such supplementation also did not reduce the rate of major CVD events [180]. A relatively recent meta-analysis including data from 63030 patients from 20 clinical trials showed that treatment with $\omega-3$ did not have an impact on a composite CVD endpoint or total mortality but was associated with a significantly decreased rate of vascular death [181].

Safety: No serious side effects have been reported; most of them have been defined as mild gastrointestinal [169].

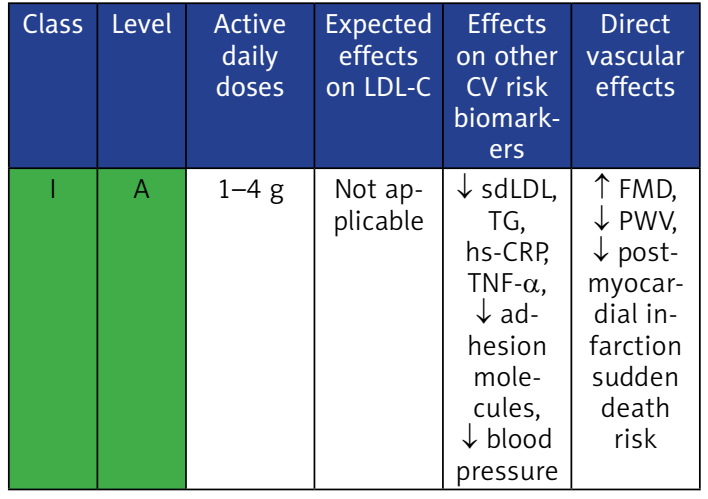

\section{2. $\gamma$-oryzanol}

Mechanism of action: Another nutraceutical with a potential effect on lipid profile is gamma-oryzanol ( $\gamma$-oryzanol) from rice brain oil [182]. $\gamma$-oryzanol is a mix of triterpene alcohol and sterol ferulates with lipid-lowering actions by the inhibition of HMG-COA reductase and the reduction of intestinal cholesterol absorption [183]. To date in Korea at least 16 varieties of rice bran oil, containing different percentages of $\gamma$-oryzanol (26.7 to $61.6 \mathrm{mg} / 100 \mathrm{~g}$ ), have been identified [184].

Efficacy: The lipid-lowering effects of this nutraceutical have been shown in in vitro and in vivo studies (in animals and humans); however, it remains unclear what are the dosages to be used in clinical practice, and what is the impact of $\gamma$-oryzanol on vascular health [182]. A recent meta-analysis of 11 RCTs showed that rice bran oil consumption resulted in a significant decrease in concentrations of LDL-C $(-0.18 \mathrm{mmol} / \mathrm{l}(7 \mathrm{mg} / \mathrm{dl})$, $95 \% \mathrm{Cl}:-0.26 ;-0.09, p<0.001)$. The increase in $\mathrm{HDL}-\mathrm{C}$ levels was considerable only in men (0.17 $\mathrm{mmol} / \mathrm{l}(6.6 \mathrm{mg} / \mathrm{dl}) ; 95 \% \mathrm{Cl}: 0.06 ; 0.28, p=0.002)$ [185].

Safety: Overall, no side effects have been registered with rice bran oil consumption [186].

\begin{tabular}{|c|c|c|c|c|c|}
\hline Class & Level & $\begin{array}{c}\text { Active } \\
\text { daily } \\
\text { doses }\end{array}$ & $\begin{array}{c}\text { Expected } \\
\text { effects } \\
\text { on LDL-C }\end{array}$ & $\begin{array}{c}\text { Effects } \\
\text { on other } \\
\text { CV risk } \\
\text { biomark- } \\
\text { ers }\end{array}$ & $\begin{array}{c}\text { Direct } \\
\text { vascular } \\
\text { effects }\end{array}$ \\
\hline IIb & $\mathrm{B}$ & $\begin{array}{c}300 \mathrm{mg} \\
(\gamma \text {-oryza- } \\
\text { nol })\end{array}$ & $\begin{array}{c}-5 \% \text { to } \\
-10 \%\end{array}$ & $\begin{array}{c}\downarrow \text { ApoB, } \\
\text { HDL-C }\end{array}$ & $\begin{array}{c}\text { Not } \\
\text { demon- } \\
\text { strated }\end{array}$ \\
\hline
\end{tabular}

\subsection{Spirulina}

Mechanism of action: Spirulina (Arthrospira platensis) is a filamentous microalga with known lipid-lowering effects, but with an unclear mechanism of action [186]. Spirulina contains high amounts of antioxidants such as $\beta$-carotene, phycocyanin, microelements ( $\mathrm{K}, \mathrm{Na}$, $\mathrm{Ca}, \mathrm{Mg}, \mathrm{Fe}, \mathrm{Zn}$ ), vitamins (tocopherols), amino acids, and PUFAs. C-phycocyanin, a particular 
A.F.G. Cicero, A. Colletti, G. Bajraktari, O. Descamps, D.M. Djuric, M. Ezhov, Z. Fras, N. Katsiki, M. Langlois, G. Latkovskis, D.B. Panagiotakos, G. Paragh, D.P. Mikhailidis, O. Mitchenko, B. Paulweber, D. Pella, C. Pitsavos, Ž. Reiner, K.K. Ray, M. Rizzo, A. Sahebkar, M.C. Serban, L.S. Sperling, P.P. Toth, D. Vinereanu, M. Vrablík, N.D. Wong, M. Banach

essential pigment of Spirulina, contains a phycocyanobilin, which can activate atheroprotective heme oxygenase-1 (HMOX-1), a key enzyme in the heme catabolic pathway in endothelial cells. Moreover, phycocyanin has proven antioxidant, anti-inflammatory and radical scavenging properties [187].

Efficacy: According to experimental studies in alloxan-injured mice, phycocyanin decreases TC and TG levels in serum, increases the hepatic glycogen level and maintains glucokinase (GK) expression in the liver. $A$ recent meta-analysis that included 7 clinical trials to assess the effect of spirulina supplementation on plasma lipid concentrations showed the lipid-lowering efficacy of spirulina, with a reduction of LDL-C by $-1.07 \mathrm{mmol} / \mathrm{l}$ $(41.32 \mathrm{mg} / \mathrm{dl})(95 \% \mathrm{Cl}:-1.57 ;-0.57, p<0.001)$, TC by $1.21 \mathrm{mmol} / \mathrm{l}(46.76 \mathrm{mg} / \mathrm{dl})(95 \% \mathrm{Cl}:-1.74$; $-0.68, p<0.001)$ and TG by $-0.5 \mathrm{mmol} / \mathrm{l}(44.23$ $\mathrm{mg} / \mathrm{dl})(95 \% \mathrm{Cl}:-0.57 ;-0.43, p<0.001)$ and an increase of HDL-C of $+0.16 \mathrm{mmol} / \mathrm{l}(6.06 \mathrm{mg} / \mathrm{dl})$ (95\% Cl: 0.06; 0.25, $p=0.001$ ) [188].

Safety: Spirulina is considered to be one of the most healing and prophylactic ingredients of nutrition in the $21^{\text {st }}$ century due to its nutrient profile, lack of toxicity and therapeutic effects. According to the available data it seems to be very well tolerated.

\begin{tabular}{|c|c|c|c|c|c|}
\hline Class & Level & $\begin{array}{c}\text { Active } \\
\text { daily } \\
\text { doses }\end{array}$ & $\begin{array}{c}\text { Expected } \\
\text { effects } \\
\text { on LDL-C }\end{array}$ & $\begin{array}{c}\text { Effects } \\
\text { on other } \\
\text { CV risk } \\
\text { biomark- } \\
\text { ers }\end{array}$ & $\begin{array}{c}\text { Direct } \\
\text { vascular } \\
\text { effects }\end{array}$ \\
\hline Ila & B & $\begin{array}{c}400- \\
800 ~ U I\end{array}$ & $-5 \%$ & $\begin{array}{c}\downarrow \text { TG, } \\
\uparrow \text { HDL-C }\end{array}$ & $\begin{array}{c}\text { Not } \\
\text { demon- } \\
\text { strated }\end{array}$ \\
\hline
\end{tabular}

\subsection{Curcumin}

Mechanism of action: Curcumin is the major phenolic compound present in the spice turmeric (in the rhizome of Curcuma longa, curcuminoids constitute approximately $5 \%$ of the weight), associated with different properties including lowering plasma cholesterol, antioxidant and anti-inflammatory effects [188]. Other polyphenolic molecules belonging to the class of curcuminoids are demethoxycurcumin and bisdemethoxycurcumin. As reported in recent meta-analyses of RCTs, curcuminoids showed an increase in serum activities of superoxide dismutase $(p=0.0007)$ and catalase $(p=0.005)$ and glutathione concentrations $(p=0.01)$ and a reduction in serum lipid peroxides $(p=0.008)$ [189] and of TNF- $\alpha$ [190]. The lipid-lowering mechanisms of action of curcuminoids are unclear; nevertheless, it seems that curcumin inhibits the expression of the NPC1L1 transporter via the SREBP2 transcription factor [191], and that it increases the efflux of cholesterol via expression of ABCA1 and activating AMPK-SIRT1-LXR $\alpha$ signaling in THP-macrophage-derived foam cells [192]. Furthermore, curcumin enhances the number of LDL-R and promotes LDL particle uptake through downreg ulation of the expression of PCSK9 [193]. In addition, epigenetic modulators such as microRNAs (miRs) have emerged as novel targets of curcum in [194].

Efficacy: Nevertheless, the results of RCTs regarding the effects of curcumin on lipid profile are still inconsistent; a meta-analysis by Sahebkar et al. showed no significant effects on LDL-C, HDL-C or TG when considering heterogeneous populations [195]. However, recently some available trials have provided more positive data. In a study including MetS patients, treatment with $1 \mathrm{~g} /$ day of curcuminoids as an add-on to the standard therapy resulted in a significant reduction of LDL-C (-0.78 mmol/l (30 mg/dl), $p<0.001)$, TG $(-0.2 \mathrm{mmol} / \mathrm{l}(17.7 \mathrm{mg} / \mathrm{dl}), p=0.006)$, and $\mathrm{Lp}(\mathrm{a})$ $(-0.286 \mu \mathrm{mol} / \mathrm{l}(8 \mathrm{mg} / \mathrm{dl}), p<0.001)$ and an elevation of HDL-C (+0.18 mmol/l $(7 \mathrm{mg} / \mathrm{dl}), p=0.003)$ [196]. These data have since been confirmed in a further trial carried out on 100 MetS patients [197] and in another one with 80 NAFLD patients [198]. In recent RCTs, supplementation with curcumin (1 g/day) was associated with a reduction of serum uric acid $(p<0.001)$ [199], increase of adiponectin $(+76.78 \%, p=0.033)$ levels and reduction of leptin $(-26.49 \%, p=0.238)$ [189]. All these effects seem to be related to the main metabolic effect of curcumin, which is an improvement of insulin resistance [200]. Finally curcumin consumption is also associated with an improvement in FMD [201] and PWV [202].

Safety: Curcumin's safety profile is good and well documented. Nevertheless, a major problem is its oral bioavailability: curcumin has low solubility in water and it is a substrate of rapid metabolism. New strategies of release have been studied and tested such as phytosomal complexation with phosphatidylcholine, coadministration of piperine, using turmeric oleoresin, reducing particle size, and changing the formulation (nanoemulsion, solid lipid nanoparticle, microencapsulation); however, in vivo data of these new formulations are lacking [203].

\begin{tabular}{|c|c|c|c|c|c|}
\hline Class & Level & $\begin{array}{c}\text { Active } \\
\text { daily } \\
\text { doses }\end{array}$ & $\begin{array}{c}\text { Expected } \\
\text { effects } \\
\text { on LDL-C }\end{array}$ & $\begin{array}{c}\text { Effects on } \\
\text { other CV } \\
\text { risk bio- } \\
\text { markers }\end{array}$ & $\begin{array}{c}\text { Direct } \\
\text { vascular } \\
\text { effects }\end{array}$ \\
\hline Ila & B & $1-3 \mathrm{~g}$ & $-5 \%$ & $\begin{array}{c}\downarrow \text { TG, Lp(a), } \\
\text { glucose, } \\
\text { HbA }_{1 c} \\
\text { HOMA in- } \\
\text { dex, hs-CRP, } \\
\text { TNF- } \alpha, \text { IL-6, } \\
\uparrow \text { adiponec- } \\
\text { tin, HDL-C }\end{array}$ & $\begin{array}{l}\uparrow F M D, \\
\downarrow P W V\end{array}$ \\
\hline
\end{tabular}




\subsection{L-carnitine}

Mechanism of action: Carnitine is a hydrophilic quaternary amine that plays a number of essential roles in metabolism with the main function being the transport of long-chain fatty acids from the cytosol to the mitochondrial matrix for $\beta$-oxidation [204].

Efficacy: L-carnitine has no effect on LDL-C levels, but a meta-analysis of 7 RCTs including data from 375 patients showed a significant reduction of $\operatorname{Lp}(\mathrm{a})$ levels following L-carnitine supplementation $(-0.31 \mu \mathrm{mol} / \mathrm{l}(8.82 \mathrm{mg} / \mathrm{dl}), 95 \% \mathrm{Cl}:-0.36$; $-0.27, p<0.001$ ) [205]. Moreover, L-carnitine seems to have a positive impact on body weight management [206]. In the most recent meta-analysis of 10 RCTs with 925 patients Mazidi et al. showed significant reduction of serum CRP and TNF- $\alpha$ concentrations following L-carnitine administration $(-0.60 \mathrm{mg} / \mathrm{l}(5.71 \mathrm{nmol} / \mathrm{l}), 95 \% \mathrm{Cl}:-0.87$ to -0.32 , and $-0.36 \mathrm{pg} / \mathrm{dl}, 95 \% \mathrm{Cl}:-0.56$ to -0.15 , respectively) [207].

Safety: No safety concerns have been raised, but reliable safety data are still lacking.

\begin{tabular}{|c|c|c|c|c|c|}
\hline Class & Level & $\begin{array}{c}\text { Active } \\
\text { daily } \\
\text { doses }\end{array}$ & $\begin{array}{c}\text { Expected } \\
\text { effects } \\
\text { on LDL-C }\end{array}$ & $\begin{array}{c}\text { Effects } \\
\text { on other } \\
\text { CV risk } \\
\text { biomark- } \\
\text { ers }\end{array}$ & $\begin{array}{c}\text { Direct } \\
\text { vascular } \\
\text { effects }\end{array}$ \\
\hline Ilb & B & $1-2 \mathrm{~g}$ & $\begin{array}{c}\text { Not ap- } \\
\text { plicable }\end{array}$ & $\begin{array}{c}\downarrow \text { hs-CRP, } \\
\downarrow \text { Lp(a), } \\
\downarrow \text { body } \\
\text { weight }\end{array}$ & $\begin{array}{c}\text { Not } \\
\text { demon- } \\
\text { strated }\end{array}$ \\
\hline
\end{tabular}

\subsection{Artichoke (Cynara scolymus, Cynara cardunculus)}

Mechanism of action: According to some pre-clinical and clinical investigations, artichoke leaf extract (ALE) has potential hypolipidemic and hepatoprotective effects. The beneficial effects of artichoke can be attributed to its antioxidant action. The main substances are mono- and dicaffeoylquinic acid (cynarin and chlorogenic acid), caffeic acid (1\%), volatile sesquiterpene and flavonoids (1\%), which include the glycosides luteolin-7 $\beta$-rutinoside (scolymoside), luteolin-7 $\beta$-D-glucoside and luteolin-4 $\beta$-D-glucoside [208, 209]. The lipid-lowering mechanisms of artichoke seem to be essentially two: the interaction of luteolin with the HMG-CoA reductase enzyme and the pathways of regulation in the liver of sterol regulatory element-binding proteins (SREBPs) (paradoxically elevated in patients with non-alcoholic steatohepatitis (NASH)) and acetyl-CoA C-acetyltransferase (ACAT) [210].

Efficacy: An RCT (75 patients treated for 12 weeks with $1280 \mathrm{mg} /$ day of artichoke leaf extract or placebo) showed a mean reduction of TC by $4.2 \%$ compared to baseline and an increasing trend of TC levels in the placebo group. The total difference between the two groups was statistically significant $(p=0.0025)$. No significant difference between groups was observed for LDL-C, HDL-C or TG levels [211]. A second RCT (143 patients treated with $1800 \mathrm{mg} /$ day of ALE for 6 weeks) showed a mean reduction of TC of $18.5 \%$ compared to $8.6 \%$ in the placebo group the difference between the two groups was statistically significant $(p<0.00001)$. Moreover, the levels of LDL-C were also significantly decreased in the artichoke leaf extract group (mean: -1.26 $\mathrm{mmol} / \mathrm{l}(48.7 \mathrm{mg} / \mathrm{dl}))$ compared to the placebo group (mean: $-0.33 \mathrm{mmol} / \mathrm{l}(12.8 \mathrm{mg} / \mathrm{dl}$ ), $p<0.00001)$. No differences were observed for other lipid parameters [212]. The third study (44 patients treated with $1920 \mathrm{mg} /$ day of ALE for 12 weeks) showed no significant differences in the lipid profile at the end of the treatment. However, according to a subgroup analysis, patients treated with artichoke leaf extract who had at baseline TC levels greater than $230 \mathrm{mg} / \mathrm{dl}$ showed a significant reduction of TC when compared with those treated with placebo $(p=0.0015)$ [213]. In a recent $\mathrm{RCT}, 60$ patients moderately hyperlipidemic and hypercholesterolemic with NASH were treated with $2700 \mathrm{mg} /$ day of artichoke extract (6 tablets) or placebo for 2 consecutive months. The results showed a significant reduction of LDL-C by $11.5 \%(p=0.039)$ and TG by $20.1 \%$ ( $p=0.011)$ compared to baseline. The most recent meta-analysis of 9 RCTs with 702 subjects suggested a significant decrease in plasma concentrations of TC (weighted mean difference (WMD): $-17.6 \mathrm{mg} / \mathrm{dl}(0.46 \mathrm{mmol} / \mathrm{l}), 95 \% \mathrm{Cl}$ : -22.0, -13.3, $p<0.001)$, LDL-C $(-14.9 \mathrm{mg} / \mathrm{dl}$ (0.39 mmol/l), 95\% Cl: $-20.4,-9.5, p=0.011)$ and triglycerides (WMD: $-9.2 \mathrm{mg} / \mathrm{dl}(0.1 \mathrm{mmol} / \mathrm{l})$, 95\% Cl: $-16.2,-2.1, p=0.011$ ) [214]. In addition, artichoke extract showed pleiotropic activities in the improvement of certain liver enzymes such as AST and ALT ( $p<0.001)$, blood sugar $(p=0.029)$ and systolic blood pressure $(p=0.004)$ [210].

Safety: In all studies reported to date no serious side effects have been detected, confirming the good tolerability and safety of artichoke leaf extract in the short-medium term. What is more, ALE exerts a hepatoprotective effect, and might be useful in statin-intolerant patients with elevated ALT levels. In some cases, there have been minor and transient gastrointestinal effects. Long-term safety studies are not available yet. In conclusion, ALE could represent an adjuvant in the regulation of lipid profile and liver levels of AST and ALT; however, the available clinical data are still preliminary. Studies on vascular outcomes such as arterial stiffness and endothelial function are also needed. 
A.F.G. Cicero, A. Colletti, G. Bajraktari, O. Descamps, D.M. Djuric, M. Ezhov, Z. Fras, N. Katsiki, M. Langlois, G. Latkovskis, D.B. Panagiotakos, G. Paragh, D.P. Mikhailidis, O. Mitchenko, B. Paulweber, D. Pella, C. Pitsavos, Ž. Reiner, K.K. Ray, M. Rizzo, A. Sahebkar, M.C. Serban, L.S. Sperling, P.P. Toth, D. Vinereanu, M. Vrablík, N.D. Wong, M. Banach

\begin{tabular}{|c|c|c|c|c|c|}
\hline Class & Level & $\begin{array}{c}\text { Active } \\
\text { daily } \\
\text { doses }\end{array}$ & $\begin{array}{c}\text { Expected } \\
\text { effects } \\
\text { on LDL-C }\end{array}$ & $\begin{array}{c}\text { Effects } \\
\text { on other } \\
\text { CV risk } \\
\text { biomark- } \\
\text { ers }\end{array}$ & $\begin{array}{c}\text { Direct } \\
\text { vascular } \\
\text { effects }\end{array}$ \\
\hline Ila & B & $1-3 \mathrm{~g}$ & $\begin{array}{c}-5 \% \text { to } \\
-15 \%\end{array}$ & $\begin{array}{c}\downarrow \text { TG } \\
\downarrow \text { AST, } \\
\text { ALT, } \\
\text { glucose }\end{array}$ & $\begin{array}{c}\text { Not } \\
\text { demon- } \\
\text { strated }\end{array}$ \\
\hline
\end{tabular}

\subsection{Vitamin $\mathrm{E}$}

Mechanism of action: Vitamin $\mathrm{E}$ includes eight distinct chemical entities: $\alpha$-, $\beta$-, $\gamma$-, and $\delta$-tocopherol and $\alpha-, \beta-, \gamma-$, and $\delta$-tocotrienol. The most studied is $\alpha$-tocopherol, while other forms are poorly understood. There are several suggested mechanisms of lipid-lowering action of vitamin E: peroxisome proliferator-activated receptor (PPAR- $\alpha$, PPAR- $\beta$, and PPAR- $\gamma$ ) activation, HMG-CoA reductase inhibition and radical scavenger [215].

Efficacy: Data from clinical trials are however disappointing, showing minimal effects of vitamin E on lipid pattern [216]. On the other hand, vitamin $\mathrm{E}$ has shown a preventive action on $\mathrm{CV}$ risk. At doses between 50 and $200 \mathrm{mg}$ it showed an improvement of endothelial function (reducing the serum levels of hs-CRP, advanced glycation end products, metalloproteinases and cell adhesion molecules) and arterial stiffness (improving PWV, pulse volume (PV) and the augmentation index (AI)) $[217,218]$. Clinical studies are needed to finally clarify the conflicting results in the literature, the dosages (100 mg tocotrienols are different to $100 \mathrm{mg}$ of vitamin $\mathrm{E}$ and $100 \mathrm{mg}$ of tocopherols) and vitamin E components, which have greater lipid-lowering efficacy. Even if vitamin E seems not to be an effective lipid-lowering treatment, its supplementation seems to be associated with reduced risk of fatal myocardial infarction [219].

Safety: In humans, doses of tocotrienols up to $1000 \mathrm{mg} /$ day have been reported as safe [220].

\begin{tabular}{|c|c|c|c|c|c|}
\hline Class & Level & $\begin{array}{c}\text { Active } \\
\text { daily } \\
\text { doses }\end{array}$ & $\begin{array}{c}\text { Expected } \\
\text { effects } \\
\text { on LDL-C }\end{array}$ & $\begin{array}{c}\text { Effects } \\
\text { on other } \\
\text { CV risk } \\
\text { biomark- } \\
\text { ers }\end{array}$ & $\begin{array}{c}\text { Direct } \\
\text { vascular } \\
\text { effects }\end{array}$ \\
\hline IIb & B & $\begin{array}{c}400- \\
800 \mathrm{UI}\end{array}$ & $\leq-5 \%$ & $\begin{array}{c}\downarrow \text { ApoB, } \\
\uparrow \text { HDL-C }\end{array}$ & $\begin{array}{c}\uparrow \mathrm{FMD}, \\
\downarrow \text { PWV, } \\
\downarrow \text { risk of } \\
\text { myo- } \\
\text { cardial } \\
\text { infarc- } \\
\text { tion }\end{array}$ \\
\hline
\end{tabular}

\subsection{Anthocyanins}

Mechanism of action: Anthocyanins are flavonoid pigments found in leaves, stems, roots, flowers, fruits and vegetables with dark color as blueberries, black rice, purple cabbage, raspberries, purple grapes and cherries. Among the biological activities exerted by anthocyanins, clinical trials have demonstrated particular antioxidant, anti-inflammatory and lipid-lowering effects [221].

Efficacy: In 58 diabetic patients, $320 \mathrm{mg} /$ day of anthocyanins for 24 weeks significantly decreased LDL-C $(-7.9 \%, p<0.05)$, TG $(-23 \%, p<0.01)$, apoB48 (-16.5\%, $p<0.05)$, and apoCIII $(-11 \%$, $p<0.01)$ and increased HDL-C (+19.4\%, $p<0.05)$ compared to placebo. Moreover, the anthocyanin group showed an improvement of fasting plasma glucose $(-8.5 \%, p<0.05)$, of homeostasis model assessment (HOMA) for insulin resistance index $(p<0.05)$ and of adiponectin concentrations $(+23.4 \%, p<0.01)$ [222]. In addition to lipid-lowering effects, anthocyanins are potent antioxidants, reducing the oxidative stress and inflammation; in humans maqui berry extract significantly decreased lipid peroxidation, urinary F2-isoprostanes and inflammatory mediators [223]. Epidemiological data suggest that higher dietary intakes of anthocyanins are associated with lower carotid-femoral PWV and carotid intima-media thickness [224].

Safety: Anthocyanins are well tolerated without side effects at dosages $\leq 640 \mathrm{mg} /$ day. Further studies are needed to assess the clinical efficacy of anthocyanins in different kinds of populations and to evaluate their vascular effects. Moreover, it will also be important to investigate the bioavailability of these compounds and the efficacy and safety of their metabolites. In fact it is well known that the bioavailability of anthocyanins is low and they are rapidly biotransformed into derivates of phenolic acid [225].

\begin{tabular}{|c|c|c|c|c|c|}
\hline Class & Level & $\begin{array}{c}\text { Active } \\
\text { daily } \\
\text { doses }\end{array}$ & $\begin{array}{c}\text { Expected } \\
\text { effects } \\
\text { on LDL-C }\end{array}$ & $\begin{array}{l}\text { Effects } \\
\text { on other } \\
\text { CV risk } \\
\text { biomark- } \\
\text { ers }\end{array}$ & $\begin{array}{l}\text { Direct } \\
\text { vascular } \\
\text { effects }\end{array}$ \\
\hline IIb & B & $\begin{array}{c}100- \\
450 \mathrm{mg}\end{array}$ & $\begin{array}{c}-5 \% \text { to } \\
10 \%\end{array}$ & $\begin{array}{c}\downarrow \text { oxLDL, } \\
\text { TG, } \\
\text { glucose, } \\
\text { HbA }_{1 c}, \\
\text { HOMA } \\
\text { index, } \\
\uparrow \text { adi- } \\
\text { ponectin, } \\
\text { HDL-C }\end{array}$ & $\begin{array}{c}\text { Not } \\
\text { demon- } \\
\text { strated }\end{array}$ \\
\hline
\end{tabular}

\subsection{Silymarin (Silybum marianum)}

Mechanism of action: Silymarin is a complex of flavonolignans of the fruit Silybum marianum containing silybin, isosilybin, silydianin and silychristin, four polyphenolic molecules with poor water solubility. It is known for its antioxidant and hepatoprotective properties and in recent years as an adjuvant in hyperlipoproteinemias [226]. Silymarin reduces lipid peroxidation of LDL by acting as chain breaking antioxidant by scavenging free radicals and being associated with enzyme complexes such as superoxide dismutase and glutathione. 
Efficacy: There are preliminary studies suggesting a potential role of silymarin as lipid-lowering agent; studies in vitro have shown an inhibitory effect of silybin on HMG-CoA reductase and in vivo an improved uptake of LDL by the liver and a reduction of hepatic cholesterol synthesis [227]. Specific data on hypercholesterolemic patients are not available. In diabetic patients, silymarin improves fasting plasma glucose (FPG) and $\mathrm{HbA}_{1 \mathrm{c}}$, but not lipid parameters [227].

Safety: Silymarin has low bioavailability. Further investigations and combination studies are needed to improve the intestinal absorption of this molecule; e.g. in complex with phosphatidylcholine, silybin increases its bioavailability 10 -fold. Safety data are still lacking.

\begin{tabular}{|c|c|c|c|c|c|}
\hline Class & Level & $\begin{array}{c}\text { Active } \\
\text { daily } \\
\text { doses }\end{array}$ & $\begin{array}{c}\text { Expected } \\
\text { effects } \\
\text { on LDL-C }\end{array}$ & $\begin{array}{c}\text { Effects } \\
\text { on other } \\
\text { CV risk } \\
\text { biomark- } \\
\text { ers }\end{array}$ & $\begin{array}{c}\text { Direct } \\
\text { vascular } \\
\text { effects }\end{array}$ \\
\hline III & C & NA & $-0 \%$ & $\begin{array}{c}\downarrow \text { oxLDL, } \\
\text { AST, ALT, } \\
\gamma \mathrm{GT}, \\
\text { glucose, } \\
\mathrm{HbA}_{1 c}\end{array}$ & $\begin{array}{c}\text { Not } \\
\text { demon- } \\
\text { strated }\end{array}$ \\
\hline
\end{tabular}

\subsection{Conjugated linoleic acid}

Mechanism of action: Conjugated linoleic acids (CLAs) are isomeric forms of linoleic acid, derived prevalently from the fatty tissues and milk of ruminant animals. CLA is both a trans fatty acid and a cis fatty acid [228].

Efficacy: In prospective observational studies, dietary linoleic acid (LA) intake is inversely associated with CHD risk in a dose-response manner [229]. In a recent systematic review and meta-analysis, CLA supplementation was associated with a significant decrease in LDL-C (MD: $-0.22 \mathrm{mmol} / \mathrm{l}(8.5 \mathrm{mg} / \mathrm{dl}) ; 95 \% \mathrm{Cl}:-0.36 ;-0.08$, $p=0.002$ ), while non-significant results were obtained for HDL-C and TG [230]. The results of a small RCT suggest that CLA supplementation could impair endothelial function [231].

Safety: In 2008, FDA categorized CLA as generally recognized as safe.

\begin{tabular}{|c|c|c|c|c|c|}
\hline Class & Level & $\begin{array}{c}\text { Active } \\
\text { daily } \\
\text { doses }\end{array}$ & $\begin{array}{c}\text { Expected } \\
\text { effects } \\
\text { on LDL-C }\end{array}$ & $\begin{array}{c}\text { Effects } \\
\text { on other } \\
\text { CV risk } \\
\text { biomark- } \\
\text { ers }\end{array}$ & $\begin{array}{c}\text { Direct } \\
\text { vascular } \\
\text { effects }\end{array}$ \\
\hline III & C & $1-6 \mathrm{~g}$ & $-5 \%$ & $\begin{array}{r}\text { Not } \\
\text { demon- } \\
\text { strated }\end{array}$ & $\begin{array}{c}\downarrow \text { FMD } \\
\text { (Wors- } \\
\text { ened) }\end{array}$ \\
\hline
\end{tabular}

\subsection{Other nutraceuticals}

Other nutraceuticals commonly cited as improving cholesterol metabolism are resveratrol and Hibiscus sabdarrifa L. (sour tea), but their lipid-lowering effects are not substantiated by available data [232, 233]. However, sour tea could have a significant blood pressure decreasing effect [234]. Astaxanthin, a powerful antioxidant carotenoid, is often cited as having a lipid-lowering effect, but this effect is not supported by clinical evidence, while its supplementation is associated with a mild but significant improvement in fasting plasma glucose [235].

\section{Nutraceutical combinations}

Rational combinations of nutraceuticals with different lipid-lowering activities, particularly when associated with an appropriate lifestyle, should provide an alternative to drug treatment in patients in primary CVD prevention with mildly elevated LDL-C (especially for those who are not on target) and in some statin-intolerant patients [236]. There are many nutraceuticals with significant lipid-lowering properties. Most of them are used in combination with a low dosage of other nutraceuticals, statins and other lipid-lowering drugs, because that allows the risk of side effects to be reduced and the efficacy to be improved (reducing the residual CV risk) [237]. Moreover, natural products with different mechanisms of action can be associated to achieve a potential synergetic effect, acting on the absorption of lipids from the bowel and/or increasing their excretion (soluble fibers, glucomannan, plant sterols, probiotics), enhancing the hepatic uptake of cholesterol (berberine, soybean proteins), inducing LDL-C excretion (berberine, soy proteins, chlorogenic acid), inhibiting HMG-CoA reductase enzyme and limiting the hepatic synthesis of cholesterol (monacolins, policosanols, allicin, soybean proteins, bergamot), reducing the oxidation of LDL and increasing thermogenesis and lipid metabolism (chlorogenic acid) [238].

For the below combination therapies no mechanism of action is described, as it has been presented in detail in the previous sections.

\subsection{Red yeast rice and policosanols}

Efficacy: The association of red yeast rice extract (340 mg containing $5 \mathrm{mg}$ of MonK) and octacosanols $(10 \mathrm{mg})$ was tested in 111 patients with moderate hypercholesterolemia, normal/border-line triglyceridemia and low CVD risk (<20\% according to the Framingham Risk Score (FRS)). The reduction of LDL-C was $20 \%$ and it was similar to that obtained with pravastatin at the dose $20 \mathrm{mg} /$ day, without any serious safety concerns [239]. The efficacy of the combination of red yeast rice extract (200 mg, corresponding to $3 \mathrm{mg}$ of MonK) with linear aliphatic alcohols $(10 \mathrm{mg})$ was also 
A.F.G. Cicero, A. Colletti, G. Bajraktari, O. Descamps, D.M. Djuric, M. Ezhov, Z. Fras, N. Katsiki, M. Langlois, G. Latkovskis, D.B. Panagiotakos, G. Paragh, D.P. Mikhailidis, O. Mitchenko, B. Paulweber, D. Pella, C. Pitsavos, Ž. Reiner, K.K. Ray, M. Rizzo, A. Sahebkar, M.C. Serban, L.S. Sperling, P.P. Toth, D. Vinereanu, M. Vrablík, N.D. Wong, M. Banach

evaluated in the treatment of primary-moderate hypercholesterolemia with a placebo-controlled clinical trial on 240 patients with overall coronary risk < 20\% (FRS); after 4 months a significant reduction in LDL-C (-29\%) and non-HDL-C (-26\%) $(p<0.001)$ was achieved [240]. The combination of red yeast rice extract (200 mg, corresponding to $3 \mathrm{mg}$ of Monacolin K) with policosanol (10 mg) was also tested in a large single-blind, randomized, multicenter study in 411 centers, comparing the effect of the nutraceutical association plus diet versus diet alone with a follow-up of 16 weeks. In 2408 eligible subjects (1665 adults and 743 elderly), LDL-C was reduced by $21 \%$, while HDL-C improved by $13 \%$, without significant changes in TG levels [241]. Beneficial results were also obtained in 40 children with heterozygous familial hypercholesterolemia $(\mathrm{HeFH})$ and familial combined hyperlipidemia $(\mathrm{FCH})$, who received a dietary supplement containing red yeast rice extract $(200 \mathrm{mg}$, corresponding to $3 \mathrm{mg}$ of monacolins) and policosanols $(10 \mathrm{mg}$ ) for 8 weeks; the treatment was effective, safe and well tolerated [242].

Safety: Based on the data from all above-mentioned studies, no serious safety concerns have been raised.

\begin{tabular}{|c|c|c|c|c|c|}
\hline Class & Level & $\begin{array}{c}\text { Active } \\
\text { daily } \\
\text { doses }\end{array}$ & $\begin{array}{c}\text { Expected } \\
\text { effects } \\
\text { on LDL-C }\end{array}$ & $\begin{array}{c}\text { Effects } \\
\text { on other } \\
\text { CV risk } \\
\text { biomark- } \\
\text { ers }\end{array}$ & $\begin{array}{c}\text { Direct } \\
\text { vascular } \\
\text { effects }\end{array}$ \\
\hline I & A & $\begin{array}{c}\text { Mona- } \\
\text { colin K } \\
3-5 \mathrm{mg}, \\
\text { policosa- } \\
\text { nol } \\
10 \mathrm{mg}\end{array}$ & $\begin{array}{c}-15 \% \text { to } \\
-21 \%\end{array}$ & $\begin{array}{c}\text { Not } \\
\text { demon- } \\
\text { strated }\end{array}$ & $\begin{array}{c}\text { Not } \\
\text { demon- } \\
\text { strated }\end{array}$ \\
& & & \\
\hline
\end{tabular}

\subsection{Red yeast rice, policosanols} and berberine

Efficacy: The association of the lipid-lowering properties of red yeast rice ( $3 \mathrm{mg}$ MonK), policosanols (10 mg) and berberine $(500 \mathrm{mg})$ is the most studied in RCTs and the only one for which meta-analyses of RCTs are available. A recent meta-analysis of 14 RCTs including data from 3159 subjects showed than the red yeast rice-policosanol-berberine association improved the plasma level of LDL-C by $-0.61 \mathrm{mmol} / \mathrm{l}(23.6 \mathrm{mg} / \mathrm{dl})$ $(p<0.001), \mathrm{HDL}-\mathrm{C}$ by $0.07 \mathrm{mmol} / \mathrm{l}(2.71 \mathrm{mg} / \mathrm{dl})$ $(p<0.001)$, TG by $-0.16 \mathrm{mmol} / / \mathrm{l}(14.2 \mathrm{mg} / \mathrm{dl})(p<$ $0.001)$ and glucose by $-0.14 \mathrm{mmol} / \mathrm{l}(2.52 \mathrm{mg} / \mathrm{dl})$ $(p=0.010)$. Moreover, the improvement in both lipid and glucose profile appeared to be maintained in the long-term observation [243]. Then, the improvement of lipid profile was not dependent on duration of supplementation or baseline lipid levels, while a greater glucose-lowering effect was found with higher baseline glucose levels and longer durations of supplementation [244] Moreover, the efficacy of this nutraceutical combination was investigated in a recent clinical trial that involved 100 subjects with low-grade systemic inflammation (hs-CRP levels $>2 \mathrm{mg} / \mathrm{l}$ ) and normal-borderline cholesterol levels (LDL-C $=100$ $160 \mathrm{mg} / \mathrm{dl}(2.5-4.1 \mathrm{mmol} / \mathrm{l}))$. After 3 months of treatment a reduction of LDL-C $(-23 \%)(p<0.001)$ was reported; hs-CRP and endothelial microparticle levels were also significantly decreased $(-41 \%$ and $-16 \%$, respectively). It was highlighted that LDL-C change was positively associated with hs-CRP $(p=0.04)$ and endothelial microparticle changes $(p<0.001)$; hs-CRP and endothelial microparticle changes were also related to each other $(p=0.005)$. Therefore, in addition to improving cholesterol profile, there is potential for this combination of nutraceuticals to attenuate the degree of systemic inflammation and endothelial injury in subjects with low-grade systemic inflammation [244]. This combination has also been tested in adult and elderly patients previously intolerant to statins [245, 246], being well tolerated in $80 \%$ of cases. The genetic variants of LDLR and PCSK9 that could be related to variations in response to lipid-lowering effects of this supplement have also been investigated. Three polymorphisms in the 3' UTR region of LDLR and two in the 5' UTR region of PCSK9 were associated with response to the treatment. These results could explain the variability observed in the response among patients with moderate hypercholesterolemia, and they may be useful in identifying subjects who could potentially benefit the most from this supplementation [247]. It was also observed that endothelial function and PWV were improved by the combination of red yeast rice and berberine in dyslipidaemic patients [248, 249].

Safety: Based on the available data, no serious safety concerns have been raised.

\begin{tabular}{|c|c|c|c|c|c|}
\hline Class & Level & $\begin{array}{l}\text { Active } \\
\text { daily } \\
\text { doses }\end{array}$ & $\begin{array}{c}\text { Expected } \\
\text { effects } \\
\text { on LDL-C }\end{array}$ & $\begin{array}{l}\text { Effects } \\
\text { on other } \\
\text { CV risk } \\
\text { biomark- } \\
\text { ers }\end{array}$ & $\begin{array}{l}\text { Direct } \\
\text { vascular } \\
\text { effects }\end{array}$ \\
\hline 1 & $A$ & $\begin{array}{c}\text { Monacol- } \\
\text { in K } \\
3 \mathrm{mg}, \\
\text { polico- } \\
\text { sanol } \\
10 \mathrm{mg} \text {, } \\
\text { berber- } \\
\text { ine } \\
500 \mathrm{mg}\end{array}$ & $\begin{array}{c}-20 \% \text { to } \\
-25 \%\end{array}$ & $\begin{array}{l}\downarrow \text { hs- } \\
\text { CRP, TG, } \\
\text { glucose }\end{array}$ & $\begin{array}{l}\uparrow \mathrm{FMD}, \\
\downarrow \mathrm{PWV}\end{array}$ \\
\hline
\end{tabular}

\subsection{Red yeast rice and plant sterols}

Efficacy: The association of plant sterols/stanols with certain lipid-lowering ingredients was demonstrated to strengthen cholesterol-lowering efficacy and add TG-lowering effects [250]. 
A small cohort of hypercholesterolemic patients (18 subjects) was assigned to the intake of a nutraceutical product containing red yeast rice 1200 $\mathrm{mg}$ (titration in monacolin $\mathrm{K}$ not reported) and phytosterols $1250 \mathrm{mg}$ per daily dose. The results showed a reduction of LDL-C of $33 \%(1.37 \mathrm{mmol} / \mathrm{l}$ $(53 \mathrm{mg} / \mathrm{dl}))$ after 6 weeks of treatment $(p<0.05)$ [251]. These results have been recently confirmed in a double-blind, placebo-controlled, randomized clinical trial evaluating the effect of phytosterols $800 \mathrm{mg}$, red yeast rice (monacolin $\mathrm{K} 5 \mathrm{mg}$ ) and their association in 90 hypercholesterolemic subjects. The group treated with the nutraceutical association experienced a LDL-C reduction by $-27.0 \%$ and apoB decrease by $-19.0 \%$ (both, $p<$ 0.001) [252].

Safety: In the available studies none of the participants reported any muscle pains and no abnormal liver function tests were observed while taking this supplement. However, further studies with longer follow-up are necessary to conclusively confirm this.

\begin{tabular}{|c|c|c|c|c|c|}
\hline Class & Level & $\begin{array}{c}\text { Active } \\
\text { daily } \\
\text { doses }\end{array}$ & $\begin{array}{c}\text { Expected } \\
\text { effects } \\
\text { on LDL-C }\end{array}$ & $\begin{array}{c}\text { Effects } \\
\text { on other } \\
\text { CV risk } \\
\text { biomark- } \\
\text { ers }\end{array}$ & $\begin{array}{c}\text { Direct } \\
\text { vascular } \\
\text { effects }\end{array}$ \\
\hline Ila & B & $\begin{array}{c}\text { Mona- } \\
\text { colin K } \\
\text { 5-10 mg, } \\
\text { phytos- } \\
\text { terols } \\
800- \\
1250 \mathrm{mg}\end{array}$ & $\begin{array}{c}-25 \% \text { to } \\
-30 \%\end{array}$ & $\downarrow$ ApoB & $\begin{array}{c}\text { Not } \\
\text { demon- } \\
\text { strated }\end{array}$ \\
& & & & \\
\hline
\end{tabular}

\subsection{Red yeast rice and artichoke}

Efficacy: Red yeast rice and artichoke have been combined with other nutraceuticals in order to test their activity on lipid parameters and inflammation. Some available trials have been carried out on an association of red yeast rice (166.67 mg, 0.4\% monacolin K), sugar cane-derived policosanols $(3.70 \mathrm{mg}, 90 \%$ policosanolsoctacosanol 60\%), and artichoke leaf extracts (200 mg, 5-6\% chlorogenic acid) to be taken as 3 tablets per day. In a double-blind, randomized, parallel controlled study on 39 subjects with moderate hypercholesterolemia, after 16 weeks of treatment, LDL-C was reduced by $21.4 \%$ (95\% Cl: $-13.3 ;-24.9 \%, p<0.001$ ), while TG decreased by $12.2 \%(95 \% \mathrm{Cl}:-24.4 ;-0.1 \%, p<0.05)$ [253]. In a 16-week, randomized, double-blind, placebo-controlled trial carried out on 100 subjects the authors observed a reduction of LDL-C by $14.3 \%$ $(-0.57 \mathrm{mmol} / \mathrm{l}(22 \mathrm{mg} / \mathrm{dl}), 95 \% \mathrm{Cl}:-0.8 ;-0.31)$, as well as TC, apoB100 and apoB100/apoA-I ratio, without modifying safety parameters [254]. Doubling the daily dose seemed not to add additional benefits, while there were no safety concerns also with the higher dosage [255]. The association of red yeast rice $(200 \mathrm{mg}$, containing monacolin $\mathrm{K}$ $10 \mathrm{mg}$ ), artichoke extract (500 mg), and banaba extract (50 mg) was evaluated in a double-bind, placebo-controlled, cross-over designed trial in 30 adults with suboptimal LDL-C levels, in primary prevention of CVD. Patients followed a period of 6 weeks of treatment with a nutraceutical or placebo, then 2 weeks of washout and finally 6 weeks in crossover. After the active treatment, there was observed a significant improvement in LDL-C (-18.2\%), non-HDL-C (-15\%), glutamic oxaloacetic transaminase $(-10 \%)$, glutamate-pyruvate transaminase $(-30.9 \%)$, and hs-CRP $(-18.2 \%)$ vs. placebo. No changes were observed in the other investigated parameters in both groups [256].

Safety: Based on the available data, no serious safety concerns have been raised, but further studies with longer follow-up are necessary to conclusively confirm this.

\begin{tabular}{|c|c|c|c|c|c|}
\hline Class & Level & $\begin{array}{c}\text { Active } \\
\text { daily } \\
\text { doses }\end{array}$ & $\begin{array}{c}\text { Expected } \\
\text { effects } \\
\text { on LDL-C }\end{array}$ & $\begin{array}{c}\text { Effects } \\
\text { on other } \\
\text { CV risk } \\
\text { biomark- } \\
\text { ers }\end{array}$ & $\begin{array}{c}\text { Direct } \\
\text { vascular } \\
\text { effects }\end{array}$ \\
\hline Ila & B & $\begin{array}{c}\text { Mona- } \\
\text { colin K } \\
2-10 \mathrm{mg}, \\
\text { arti- } \\
\text { choke } \\
\text { extract } \\
500-\end{array}$ & $\begin{array}{c}-14 \% \text { to } \\
-21 \%\end{array}$ & $\begin{array}{c}\downarrow \text { hs-CRP, } \\
\text { TG }\end{array}$ & $\begin{array}{c}\text { Not } \\
\text { demon- } \\
\text { strated }\end{array}$ \\
& & & & \\
& & & & \\
& & & & \\
\hline
\end{tabular}

\subsection{Red yeast rice, policosanol, and silymarin}

Efficacy: A double-blind, placebo-controlled trial evaluated the effects of a combination of red yeast rice (334 mg containing monacolin $10 \mathrm{mg}$ ), policosanol (30 mg), and silymarin (150 mg) compared to placebo on lipid profile, endothelial and inflammatory parameters in 134 low-risk dyslipidemic patients. After 3 months of treatment, the nutraceutical supplement decreased LDL-C compared to baseline $(p=0.041)$ and to placebo ( $p=0.037$, respectively). Triglycerides were reduced by the active product $(p=0.039)$, but not by the placebo, even though, in the groupto-group comparison, no significant difference was recorded $(p=0.061)$. All tested inflammatory parameters (soluble intercellular adhesion molecule-1, soluble vascular cell adhesion molecule-1, soluble E-selectin, MMP-2 and -9, hs-CRP, IL- 6 and TNF- $\alpha$ ) were reduced by the nutraceutical combination [257]. Another research group tested the same combination in a group of 80 hypercholesterolemic subjects in an 8-week randomized clinical trial. When compared to placebo, nutraceutical combination treated patients experienced a more favorable percentage change 
A.F.G. Cicero, A. Colletti, G. Bajraktari, O. Descamps, D.M. Djuric, M. Ezhov, Z. Fras, N. Katsiki, M. Langlois, G. Latkovskis, D.B. Panagiotakos, G. Paragh, D.P. Mikhailidis, O. Mitchenko, B. Paulweber, D. Pella, C. Pitsavos, Ž. Reiner, K.K. Ray, M. Rizzo, A. Sahebkar, M.C. Serban, L.S. Sperling, P.P. Toth, D. Vinereanu, M. Vrablík, N.D. Wong, M. Banach

in LDL-C (-23.3\%), hs-CRP $(-2.4 \%)$, and endothelial function (pulse volume displacement vs. baseline: $+17 \%)$. No significant difference was observed with respect to effects on TG, HDL-C and safety parameters [258].

Safety: Further studies with a long follow-up are necessary to evaluate the safety issues for this combination.

\begin{tabular}{|c|c|c|c|c|c|}
\hline Class & Level & $\begin{array}{c}\text { Active } \\
\text { daily } \\
\text { doses }\end{array}$ & $\begin{array}{c}\text { Expected } \\
\text { effects } \\
\text { on LDL-C }\end{array}$ & $\begin{array}{c}\text { Effects } \\
\text { on other } \\
\text { CV risk } \\
\text { biomark- } \\
\text { ers }\end{array}$ & $\begin{array}{c}\text { Direct } \\
\text { vascular } \\
\text { effects }\end{array}$ \\
\hline Ilb & B & $\begin{array}{c}\text { Mona- } \\
\text { colin K } \\
10 \mathrm{mg}, \\
\text { policosa- } \\
\text { nol } \\
30 \mathrm{mg}, \\
\text { silymarin } \\
150 \mathrm{mg}\end{array}$ & $\begin{array}{c}-14 \% \text { to } \\
-23 \%\end{array}$ & $\begin{array}{c}\downarrow \\
\text { inflam- } \\
\text { matory } \\
\text { biomark- } \\
\text { ers }\end{array}$ & FMD \\
& & & \\
\end{tabular}

\subsection{Red yeast rice and antioxidants}

Efficacy: A nutraceutical supplement composed of red yeast rice (10 mg MonK) and coenzyme Q10 (CoQ10) (30 mg) was tested in a double-blind, placebo-controlled, crossover, randomized clinical trial carried out on 25 healthy, mildly hypercholesterolemic subjects. The treatment duration was 4 weeks. When compared to the placebo group, monacolins/CoQ10-treated patients experienced a more favorable percent change in LDL-C $(-21.99 \%, 95 \% \mathrm{Cl}:-26.63 ;-17.36)$, nonHDL-C (-14.67\%, 95\% Cl: -19.22; -10.11), MMP-2 $(-28.05 \%, \quad 95 \% \quad \mathrm{Cl}:-35.18 ;-20.93), \quad$ MMP-9 $(-27.19 \%, 95 \% \mathrm{Cl}:-36.21 ;-18.15)$, and hs-CRP $(-23.77 \%, 95 \% \mathrm{Cl}:-30.54 ;-17.01)$. No significant differences were observed with respect to TGs, HDL-C, and safety parameters [259]. The same combination was then evaluated in 40 moderately hypercholesterolemic subjects with a double-blind, placebo-controlled, randomized clinical trial. After 6 months of active treatment, the results showed a more favourable percentage change in LDL-C $(-26.3 \%$; $p<0.05)$, endothelial reactivity (PV displacement: $+6.0 \%$; $p<0.05$ ) and arterial stiffness (PWV: $-4.7 \% ; p<$ 0.05 ) [260]. Red yeast rice (10 mg monacolins) has also been associated with a pool of antioxidants (green tea dry extract, $100 \mathrm{mg}$; CoQ10, $20 \mathrm{mg}$; astaxanthin, $2 \mathrm{mg}$; resveratrol, $20 \mathrm{mg}$; and quercetin, $50 \mathrm{mg}$ ) and has been tested in a crossover, double-blind, placebo-controlled randomized clinical trial on 25 moderately hypercholesterolemic, pharmacologically untreated subjects, as primary prevention for CVD. After 4 weeks of the active treatment patients experienced an improvement of cholesterol levels (LDL-C -22.36\%; non-HDL-C -22.83\%), hs-CRP
$-2.33 \%$ and endothelial function (PV displacement after monacolin treatment, 18.59\%) [261].

Safety: Based on the available data, no serious safety concerns have been raised.

\begin{tabular}{|c|c|c|c|c|c|}
\hline Class & Level & $\begin{array}{c}\text { Active } \\
\text { daily } \\
\text { doses }\end{array}$ & $\begin{array}{c}\text { Expected } \\
\text { effects } \\
\text { on LDL-C }\end{array}$ & $\begin{array}{c}\text { Effects } \\
\text { on other } \\
\text { CV risk } \\
\text { biomark- } \\
\text { ers }\end{array}$ & $\begin{array}{c}\text { Direct } \\
\text { vascular } \\
\text { effects }\end{array}$ \\
\hline Ila & B & $\begin{array}{c}\text { Mona- } \\
\text { colin K } \\
10 \text { mg, } \\
\text { CoQ10 } \\
\text { or other } \\
\text { antioxi- } \\
\text { dants }\end{array}$ & $\begin{array}{c}-20 \% \text { to } \\
-26 \%\end{array}$ & $\downarrow$ hs-CRP & $\begin{array}{c}\uparrow \text { FMD, } \\
\downarrow \text { PWV }\end{array}$ \\
\hline
\end{tabular}

\subsection{Berberine combined with bioactive lipid-lowering agents other than red yeast rice}

Efficacy: Berberis aristata extract $(588 \mathrm{mg}$, containing $500 \mathrm{mg}$ berberine) was combined with chlorogenic acid $(67 \mathrm{mg})$ and tocotrienols (143 mg) in a double-blind, cross-over designed trial versus placebo, in 40 overweight subjects with mixed hyperlipidemia. After 8 weeks of treatment, there was observed a significant improvement in LDL-C (-24\%), TG (-19\%), non-HDL-C (-22\%), fasting insulin (-5\%) and HOMA index (-10\%) [262]. Another double-blind, placebo-controlled, crossover RCT tested the efficacy of the administration of Berberis aristata (588 mg extract containing $500 \mathrm{mg}$ berberine) with Silybum marianum (105 mg extract) twice a day in 102 dyslipidemic patients. The results showed a reduction of $L D L-C$ and TG, and an increase of HDL-C after the first 3 months of treatment; the lipid profile worsened after a 2-month washout period and improved again when the nutraceutical combination was reintroduced for a further 3 months [263]. Given the low lipid-lowering activity of components different from berberine, it is not clear whether the observed effects are related to berberine per se or not.

Safety: Based on the available data, no serious safety concerns have been raised, but further studies with a long follow-up are still necessary to confirm this.

\begin{tabular}{|c|c|c|c|c|c|}
\hline Class & Level & $\begin{array}{c}\text { Active } \\
\text { daily } \\
\text { doses }\end{array}$ & $\begin{array}{c}\text { Expected } \\
\text { effects } \\
\text { on LDL-C }\end{array}$ & $\begin{array}{l}\text { Effects } \\
\text { on other } \\
\text { CV risk } \\
\text { biomark- } \\
\text { ers }\end{array}$ & $\begin{array}{l}\text { Direct } \\
\text { vascular } \\
\text { effects }\end{array}$ \\
\hline $\mathrm{IIb}$ & B & $\begin{array}{c}\text { Ber- } \\
\text { berine } \\
500- \\
1000 \mathrm{mg}, \\
\text { CoQ10 } \\
\text { or other } \\
\text { antioxi- } \\
\text { dants }\end{array}$ & $\begin{array}{c}-16 \% \text { to } \\
-24 \%\end{array}$ & $\begin{array}{c}\downarrow T G, \\
\text { HOMA } \\
\text { index }\end{array}$ & $\begin{array}{c}\text { Not } \\
\text { demon- } \\
\text { strated }\end{array}$ \\
\hline
\end{tabular}




\subsection{Soy proteins and plant sterols}

Efficacy: Low dosed soy proteins and plant sterols have been demonstrated to have mild but additive cholesterol-lowering effects in humans [264]. The intake of soy proteins with plant sterols in patients with MetS and LDL-C $\geq$ $160 \mathrm{mg} / \mathrm{dl}(4.1 \mathrm{mmol} / \mathrm{l})$ showed a significant $(p<0.05)$ improvement in LDL-C, non-HDL-C, cholesterol/HDL-C and TG/HDL-C ratios, apoB, apoB/ apoA-1 ratio, homocysteine, total LDL particle number and large HDL particle number, in particular after 12 weeks of treatment [265]. Soy proteins (16.2 g/1000 kcal) and plant sterols (1.2 g/ $1000 \mathrm{kcal})$ were also combined with viscous fibers (8.3 g/1000 kcal) and almonds (16.6 g/1000 kcal) in the treatment of a small cohort of hypercholesterolemic subjects: after their intake for 4 weeks, there was reported a reduction of LDL-C of 35.0 $\pm 3.1 \%(p<0.001)$, and the ratio of LDL-C to HDL-C (30.0 $\pm 3.5 \%, p<0.001)$ [266].

Safety: Based on the available data, no safety concerns have been raised, but further studies with a long follow-up are still necessary to confirm this.

\begin{tabular}{|c|c|c|c|c|c|}
\hline Class & Level & $\begin{array}{c}\text { Active } \\
\text { daily } \\
\text { doses }\end{array}$ & $\begin{array}{c}\text { Expected } \\
\text { effects } \\
\text { on LDL-C }\end{array}$ & $\begin{array}{c}\text { Effects } \\
\text { on other } \\
\text { CV risk } \\
\text { biomark- } \\
\text { ers }\end{array}$ & $\begin{array}{c}\text { Direct } \\
\text { vascular } \\
\text { effects }\end{array}$ \\
\hline IIa & B & $\begin{array}{c}\text { Soy } \\
\text { protein } \\
\text { 8-25 g, } \\
\text { phytos- } \\
\text { terols } \\
800- \\
\end{array}$ & $\begin{array}{c}-16 \% \text { to } \\
-30 \%\end{array}$ & $\downarrow$ ApoB & $\begin{array}{c}\text { Not } \\
\text { demon- } \\
\text { strated }\end{array}$ \\
& & & & \\
& & & & \\
& & & & \\
\end{tabular}

\subsection{Different nutraceutical combinations supported by single RCTs}

For these combined products, due to lack of enough data, is not possible, at this moment, to suggest a final classification. The level of evidence might have been limited to "B" or "C" - expert opinion with the class of suggestion "Ilb" waiting for confirmative trials.

\subsubsection{Red yeast rice and omega-3 polyunsaturated fatty acids}

Efficacy: The efficacy of a combined nutraceutical with red yeast rice (5 $\mathrm{mg}$ monacolin $\mathrm{K}$ ) and PUFAs (610 mg: $183 \mathrm{mg}$ EPA, $122 \mathrm{mg}$ DHA) was evaluated in a clinical trial on 107 pharmacologically untreated subjects, affected by primary polygenic hypercholesterolemia and MetS, in primary prevention for CVD. After 8 weeks of treatment, the results showed a significant decrease in LDL-C $(-0.97 \pm 0.35 \mathrm{mmol} / \mathrm{l}(37.5 \mathrm{mg} / \mathrm{dl}) ;-22 \pm 3 \%)$, TG $(-0.22 \pm 0.28 \mathrm{mmol} / \mathrm{l}(19.5 \mathrm{mg} / \mathrm{dl}) ;-9 \pm 5 \%)$ and
non-HDL-C $(-21 \pm 3 \%)$ and a significant increase in HDL-C $(+1.5 \pm 0.5 \%)$ ( $p<0.001$ for all), without the modification of safety parameters. In particular, $75 \%$ of subjects reached an LDL-C target of less than $160 \mathrm{mg} / \mathrm{dl}$ and $25 \%$ of less than $130 \mathrm{mg} / \mathrm{dl}$. Moreover, the study highlighted a greater decrease in TG levels only in patients with baseline TG > $500 \mathrm{mg} / \mathrm{dl}$, who showed a $11 \%$ reduction $(p<0.001$ vs. subjects with baseline TG $<150 \mathrm{mg} / \mathrm{dl}$ ) [267].

Safety: No safety concerns. Very limited data; further studies are necessary.

\subsubsection{Red yeast rice, bitter gourd chlorella, soy protein, and licorice}

Efficacy: Extracts from red yeast rice, bitter gourd, chlorella, soy protein and licorice were combined to evaluate their effects in subjects with MetS in a 12-week, randomized, placebocontrolled clinical trial (106 participants). Each tablet was composed $0.37 \mathrm{~g}$ of red yeast rice, $40 \mathrm{~g}$ of fresh bitter gourd, $1.5 \mathrm{~g}$ of chlorella, $1.1 \mathrm{~g}$ of soybean and $2.2 \mathrm{~g}$ of licorice. The active group was treated with three tablets/day. LDL-C decreased significantly after the treatment $(3.4 \pm 0.7(131 \mathrm{mg} /$ dl) to $2.7 \pm 0.5 \mathrm{mmol} / \mathrm{l}(104 \mathrm{mg} / \mathrm{dl}), p<0.001)$. In addition, TGs were reduced $(-0.2 \pm 0.3 \mathrm{mmol} / \mathrm{l}$ $(18 \mathrm{mg} / \mathrm{dl}), p=0.039)$. Moreover, this nutraceutical compound has also shown potential in normalizing blood pressure [268].

Safety: No safety concerns. Very limited data; further studies are necessary.

\subsubsection{Psyllium and plant sterols}

Efficacy: A nutraceutical supplement with psyllium (7.68 g) and plant sterols (2.6 g) was administered to a small cohort of subjects (33 patients), with LDL-C levels between $2.58(100 \mathrm{mg} / \mathrm{dl})$ and $4.13 \mathrm{mmol} / \mathrm{l}(160 \mathrm{mg} / \mathrm{dl})$, in a placebo-controlled clinical trial. Subjects were treated for 4 weeks with the nutraceutical combination vs. placebo, followed by a 3-week washout period, and finally received the alternative treatment (placebo/nutraceutical) for another 4 weeks. The improvement in lipid profile included a reduction of LDL-C from $3.5 \pm 0.7 \mathrm{mmol} / \mathrm{l}(135 \mathrm{mg} / \mathrm{dl})$ to $3.1 \pm 0.8 \mathrm{mmol} / \mathrm{l}$ $(120 \mathrm{mg} / \mathrm{dl})$ after the intake of the nutraceutical product $(p<0.01)$. Moreover, this combination led to a reduction of plasma apoB concentrations $(p<0.01)$ [269].

Safety: No safety concerns. Very limited data; further studies are necessary.

\subsubsection{Psyllium and n-3 polyunsaturated fatty acids}

Efficacy: Plant sterols with omega-3 fatty acids have synergistic lipid-lowering effects, as demon- 
A.F.G. Cicero, A. Colletti, G. Bajraktari, O. Descamps, D.M. Djuric, M. Ezhov, Z. Fras, N. Katsiki, M. Langlois, G. Latkovskis, D.B. Panagiotakos, G. Paragh, D.P. Mikhailidis, O. Mitchenko, B. Paulweber, D. Pella, C. Pitsavos, Ž. Reiner, K.K. Ray, M. Rizzo, A. Sahebkar, M.C. Serban, L.S. Sperling, P.P. Toth, D. Vinereanu, M. Vrablík, N.D. Wong, M. Banach

strated in a 3-week randomized, placebo controlled clinical trial on 60 hyperlipidemic individuals. The participants were divided into 4 groups and received either Sunola oil or $\omega-3$ long chain PUFAs capsules (1.4 g/day) with or without phytosterols ( $2 \mathrm{~g}$ ) or placebo. The combination of phytosterols and $\omega-3$ PUFAs reduced LDL-C by $12.5 \%$ $(p=0.002)$ and TG by $25.9 \%(p=0.005)$; moreover, it increased HDL-C (8.6\%, $p=0.04)$ [270].

Safety: No safety concerns. Very limited data; further studies are necessary.

\subsubsection{Garlic and omega-3 polyunsaturated fatty acids}

Efficacy: Garlic oil (500 mg) and fish oil (600 mg) were administered to a small sample of hypercholesterolemic subjects (16 patients) for 2 months and compared with a control group (16 patients). The results showed an improvement of lipid parameters: LDL-C $-21 \%$, TG $-37 \%$, VLDL $-36.7 \%$, TC/HDL-C ratio $-23.4 \%$, HDL-C $+5.1 \%$ [271].

Safety: No safety concerns. Very limited data; further studies are necessary.

\subsection{6. $\gamma$-oryzanol and $\omega-3$ polyunsaturated fatty acids}

Efficacy: The combination of $\gamma$-oryzanol (40 mg) with $\omega-3$ polyunsaturated fatty acids $(1100 \mathrm{mg})$ was demonstrated to improve lipid profile (LDL-C $-0.93 \pm 0.97 \mathrm{mmol} / \mathrm{l}(36 \mathrm{mg} / \mathrm{dl}), p<0.0001, \mathrm{TG}$ $-0.60 \pm 0.63 \mathrm{mmol} / \mathrm{l}(23.2 \mathrm{mg} / \mathrm{dl})$, all $p<0.001)$, as well as inflammatory and oxidative status in dyslipidemic volunteers [272].

Safety: No safety concerns. Very limited data; further studies are necessary.

\subsubsection{Plant proteins and soluble fibers}

Efficacy: Plant proteins (lupin protein or pea protein) associated with soluble fibers (oat fiber or apple pectin) demonstrated lipid-lowering activity in hypercholesterolemic patients in primary prevention of CVD: significant reductions of TC levels were observed in all groups (each one with 25 subjects), in particular lupin protein + cellulose $(-0.3 \mathrm{mmol} / \mathrm{l}(11.6 \mathrm{mg} / \mathrm{dl}),-4.2 \%)$, casein + apple pectin $(-0.39 \mathrm{mmol} / \mathrm{l}(15 \mathrm{mg} / \mathrm{dl}),-5.3 \%)$, pea protein + oat fiber $(-0.35 \mathrm{mmol} / \mathrm{l}(13.5 \mathrm{mg} / \mathrm{dl})$, $-4.7 \%)$ and pea protein + apple pectin $(-0.43$ $\mathrm{mmol} / \mathrm{l}(16.6 \mathrm{mg} / \mathrm{dl}),-6.4 \%)(p<0.05)$. Moreover, LDL-C was significantly reduced in pea protein + apple pectin combinations $(-0.27 \mathrm{mmol} / \mathrm{l}(10.4 \mathrm{mg} /$ dl), $9.2 \%)$ ( $p<0.004$ vs. control). The association of pea protein + oat fiber also showed $4 \%$ glucose reduction, $57 \%$ insulin reduction and $25 \%$ decrease of the HOMA index [273].

Safety: No safety concerns. Very limited data; further studies are necessary.

\subsubsection{Glucomannan and plant sterols}

Efficacy: Glucomannan (10 g/day) and plant sterols (1.8 g/day) were tested in a randomized, crossover trial on 34 mild hypercholesterolemic subjects. The study consisted of four phases of 21 days, with each phase separated by a 28-day washout. An improvement of lipid parameters was assessed after the treatment (LDL-C $2.9 \pm 0.2$ $\mathrm{mmol} / \mathrm{l}(112 \mathrm{mg} / \mathrm{dl})$ vs. control group $3.6 \pm 0.2$ $\mathrm{mmol} / \mathrm{l}(140 \mathrm{mg} / \mathrm{dl}), p<0.05)$. Plasma lathosterol concentrations, an index of cholesterol biosynthesis, were lowered after the combination treatment $(p<0.05)$, as well [274].

Safety: No safety concerns. Very limited data; further studies are necessary.

\subsubsection{Pantethine, soybean plant sterols, green tea extract, delta-tocotrienol and phytolens}

Efficacy: A clinical trial on 30 hyperlipidemic untreated patients showed a significant improvement in serum lipids using a nutraceutical product with a combination of pantethine $(900 \mathrm{mg})$, soybean plant sterols ( $800 \mathrm{mg}$ ), green tea extract (600 mg containing 50\% epigallocatechin gallate), $\gamma / \delta$ tocotrienols from annatto seed $(75 \mathrm{mg})$ and Phytolens from lentil husks ( $5 \mathrm{mg}$ ). After 2 months of treatment, there was a significant reduction of LDL-C by $14 \%$ ( $p<0.003$ ), VLDL dropped by $20 \%$ $(p<0.01)$ and sdLDL particles fell by $25 \%$ (type III and IV) [275].

Safety: No safety concerns. Very limited data; further studies are necessary.

\section{Nutraceuticals combined with pharmacological therapy}

Many available data, including the most recent studies with PCSK9 inhibitors, support the LDL-C concept that "lower is better" [276]. Even knowing that statins are the drugs of choice in patients with high LDL-C levels and moderate-to-high CV risk, the use of high-intensity statins increases the side effects and therefore reduces the therapy adherence and compliance [277, 278]. On the other side, even with the good statin therapy tolerability, the LDL-C targeted levels might not be achieved for $30-70 \%$ of patients (depending on the risk), even in the combination with ezetimibe for high and very high risk patients [279]. Many nutraceutical options are available either alone or in combination with statins to help to reach recommended goals in a safe and tolerable way for most patients [280]. Clinical trials have reported that many nutraceuticals have an additive effect to lipid-lowering drugs, allowing the statin doses to be reduced without diminishing the results in terms of TC and LDL-C reduction and significant- 
ly limiting adverse effects [281]. However, most of the combinations presented below have been tested only in a single study, and the obtained results have not been confirmed yet, so no recommendations can be made.

\subsection{Statins and polyunsaturated fatty acids}

Efficacy: The effect of PUFAs in statin-treated subjects is simply addictive in terms of dose-related TG reduction [282, 283]. Data from a long-term randomized clinical trial support the concept that combining statins with $\omega-3$ fatty acids seems to further decrease CHD risk by $19 \%$ in primary prevention [284] and CHD mortality by $17 \%$ in secondary prevention [285]. Given the availability of data on CVD event risk reduction the supplementation of PUFAs in statin-treated patients can be recommended, especially in hypertriglyceridemic and post-CHD patients.

Safety: No safety concerns; limited data - further studies are necessary.

\subsection{Statins and soluble fibers}

Efficacy: The lipid-lowering effects of psyllium (10 g/day) and lovastatin (20 mg/day), alone and in combination, were evaluated on 36 volunteers. After 4 weeks of treatment, the mean LDL-C and TG levels in the group receiving $20 \mathrm{mg}$ of lovastatin plus $10 \mathrm{~g}$ of psyllium fell by $30.9 \%$ and $26.2 \%$ from baseline compared with $24.8 \%$ and $32.9 \%$ in the group receiving $20 \mathrm{mg}$ of lovastatin and $3.6 \%$ and $10.9 \%$ in the group receiving $10 \mathrm{~g}$ of psyllium, respectively [286]. Another 12-week blinded placebo-controlled study tested the effects of $20 \mathrm{mg}$ of simvastatin plus placebo, $10 \mathrm{mg}$ of simvastatin plus placebo or $10 \mathrm{mg}$ of simvastatin plus $15 \mathrm{~g}$ of psyllium daily, enrolling 68 patients. After 8 weeks, the mean lowering of LDL-C $(-63 \mathrm{mg} / \mathrm{dl} /-1.63 \mathrm{mmol} /$; $p=0.03$ ) in the group receiving $20 \mathrm{mg}$ of simvastatin plus placebo was the same as that in the group receiving $10 \mathrm{mg}$ of simvastatin plus psyllium and was greater than that obtained with $10 \mathrm{mg}$ of simvastatin plus placebo $(55 \mathrm{mg} / \mathrm{dl} /$ $1.42 \mathrm{mmol} / \mathrm{l} ; p=0.03)$. Similar results were reported for $a p o B$ and TC, while there were not observed significant changes of TG or HDL-C levels [287]. In a further randomized, parallel-design clinical trial, patients with primary hypercholesterolemia $(n=116)$ were assigned to receive a daily dose of $25 \mathrm{~g}$ of fiber (corresponding to $6 \mathrm{~g}$ of soluble fibers) plus rosuvastatin $40 \mathrm{mg}$ $(n=28)$, rosuvastatin $40 \mathrm{mg}$ alone $(n=30)$, simvastatin $40 \mathrm{mg}$ plus ezetimibe $10 \mathrm{mg}$ plus $25 \mathrm{~g}$ of fiber $(n=28)$, or simvastatin $40 \mathrm{mg}$ plus ezetimibe $10 \mathrm{mg}(n=30)$ alone during 12 weeks. These therapies led to similar reductions in LDL-C and TC ( $p<0.001$ vs. baseline), while no change was observed in HDL-C. Among patients treated with highly effective lipid-lowering therapy, the intake of $25 \mathrm{~g}$ of fibers added favorable effects: a reduction of phytosterolemia, improvement in blood glucose $(p=0.047)$, weight loss $(p=0.04)$ and reduced body mass index $(p=0.002)$ [288]. Given the availability of data from different RCTs, the supplementation of fibers in statin-treated patients might be recommended especially in patients with stipsis or irritable bowel disease. It remains to be clarified however whether the supplemented fibers interfere with other drugs administered by patients at high CVD risk.

Safety: No safety concerns; limited data - further studies are necessary.

\subsection{Ezetimibe, red yeast rice, policosanol and berberine}

Efficacy: Ezetimibe and nutraceuticals have been both introduced, alone or in association, as alternative therapies for statin-intolerant patients and proved to be effective and well tolerated. A clinical trial evaluated the effects of a combination of nutraceuticals (red yeast rice extract $200 \mathrm{mg}$ (equivalent to $3 \mathrm{mg}$ monacolins), policosanol $10 \mathrm{mg}$, and berberine $500 \mathrm{mg}$ ) and ezetimibe on statin-intolerant dyslipidemic subjects with IHD treated with $\mathrm{PCl}$. At 1-year follow-up, $58(72.5 \%)$ patients of the combined therapy group $(n=86)$ reached the therapeutic goal $(\mathrm{LDL}-\mathrm{C}<2.58 \mathrm{mmol} / \mathrm{l}(100 \mathrm{mg} / \mathrm{dl}))$. No patient experienced important undesirable effects [289]. Berberine $(500 \mathrm{mg})$, red yeast rice $(200 \mathrm{mg})$ and policosanol $(10 \mathrm{mg}$ ) were also associated with ezetimibe $(10 \mathrm{mg})$ in a study on 26 patients with primary hypercholesterolemia, with a history of statin intolerance or refusing statin treatment. After 3 months of treatment, it was observed that this treatment was as effective as statins in moderate doses (LDL-C -37\%, TG -23\%) [290].

Safety: No safety concerns; limited data - further studies are necessary.

\subsection{Ezetimibe or statins and berberine with silymarin}

Efficacy: Berberis aristata (588 mg, containing berberine $500 \mathrm{mg}$ ) and Silybum marianum (105 mg) extracts, twice a day, were administered to $45 \mathrm{pa}$ tients diagnosed with type 2 diabetes with hypercholesterolemia and statin intolerance. The intake of berberine/silymarin with statins led to an improvement of lipid parameters (LDL-C $-15 \%$ and $-28 \%$, respectively after 6 and 12 months) and also when added to ezetimibe (LDL-C $-20 \%$ and $-33 \%$ respectively after 6 and 12 months). In the control group, in which only berberine/silymarin 
A.F.G. Cicero, A. Colletti, G. Bajraktari, O. Descamps, D.M. Djuric, M. Ezhov, Z. Fras, N. Katsiki, M. Langlois, G. Latkovskis, D.B. Panagiotakos, G. Paragh, D.P. Mikhailidis, O. Mitchenko, B. Paulweber, D. Pella, C. Pitsavos, Ž. Reiner, K.K. Ray, M. Rizzo, A. Sahebkar, M.C. Serban, L.S. Sperling, P.P. Toth, D. Vinereanu, M. Vrablík, N.D. Wong, M. Banach

was administered, there was also a reduction of LDL-C (LDL-C $-17 \%$ and $-26 \%$ respectively after 6 and 12 months). Glycemic control improved in all groups. All reported side effects lasted a few days and did not lead to interruption of treatment [291].

Safety: No safety concerns; limited data - further studies are necessary.

\subsection{Statins/ezetimibe and plant sterols}

Efficacy: A randomized clinical trial with parallel arms was designed to evaluate the lipid-lowering effects of the addition of plant sterols to lipid-lowering drugs. Eighty-six subjects were submitted to a 4-week run-in period with atorvastatin $10 \mathrm{mg}$ (baseline), followed by another 4-week period in which subjects received atorvastatin $40 \mathrm{mg}$, ezetimibe $10 \mathrm{mg}$ or a combination of both drugs (phase I); finally, capsules containing $2.0 \mathrm{~g}$ of plant sterols were added to previous assigned treatments for 4 weeks (phase II). Compared with baseline, atorvastatin $40 \mathrm{mg}$ showed a reduction of LDL-C $(22 \%, p<0.05)$, and increased $\beta$-sitosterol, campesterol/cholesterol, and $\beta$-sitosterol/cholesterol ratios (39\%, $47 \%$, and $32 \%$, respectively, $p<0.05$ ); ezetimibe $10 \mathrm{mg}$ reduced campesterol and campesterol/cholesterol ratio (67\% and $70 \%$, respectively, $p<0.05)$, while the combined therapy decreased LDL-C (38\%, $p<0.05)$, campesterol, $\beta$-sitosterol, and campesterol/cholesterol ratio $(54 \%, 40 \%$, and $27 \%, p<0.05)$. This study demonstrated that the addition of plant sterols further reduced LDL-C by $\sim 6.5 \%$ in the atorvastatin therapy group and $5.0 \%$ and $4.0 \%$ in the combined therapy group ( $p<0.05$ for all) [292].

Eleven hypercholesterolemic coronary patients on a low-fat, low-cholesterol baseline diet added simvastatin (20 mg/day) for 3 months and then dietary plant stanol ester margarine (2.25 g of stanols/day) for 8 weeks; afterwards, cholestyramine $8 \mathrm{~g} /$ day was added for another 8 weeks. The results highlighted that simvastatin reduced LDL-C by $39 \%(p<0.001)$ and additional stanol ester margarine reduced it by a further $13 \%(p<0.05)$. The triple treatment led to $67 \%$ reduction from baseline $(p<0.001)$, with all LDL-C values being $<2.6 \mathrm{mmol} / \mathrm{l}$, and increased $\mathrm{HDL}-\mathrm{C}$ by $15 \%(p<0.01)$. It also increased the serum lathosterol/cholesterol ratio $(p<0.01)$, thus showing upregulation of cholesterol synthesis, and increased the serum sitosterol ratio $(p<0.01)$. These results support the use of stanol ester with only moderate doses of statin and resin to control LDL-C levels in hypercholesterolemic patients [293].

Safety: No safety concerns; limited data - further studies are necessary.

\subsection{Statins and tocotrienols}

Efficacy: A clinical trial with 28 hypercholesterolemic subjects was carried out to assess the efficacy of the tocotrienol-rich fraction of rice bran alone and in the combination with lovastatin. The combination of the tocotrienol-rich fraction (50 mg) and lovastatin (10 mg) plus the AHA step1 diet was demonstrated to significantly reduce LDL-C by $25 \%$ ( $p<0.001)$, an additional $10 \%$ in comparison to statin therapy alone [294].

Safety: No safety concerns; limited data - further studies are necessary.

\subsection{Statins and bergamot}

Efficacy: The association of bergamot-derived polyphenolic fraction (1000 mg/daily for 30 days) with rosuvastatin (10 mg/day for 30 days) was evaluated in a study that enrolled 77 patients with mixed hyperlipidemia. It was observed that the combined therapy significantly reduced LDL-C $(-53 \%)$ compared to rosuvastatin alone, an effect which was nearly the same as the one produced by $20 \mathrm{mg}$ of rosuvastatin. In addition, TGs were reduced by $36 \%$ and $\mathrm{HDL}-\mathrm{C}$ increased by $37 \%$, an effect that was significantly higher when compared to the use of rosuvastatin alone. Moreover, a significant reduction of biomarkers used for detecting oxidative vascular damage was reported, suggesting antioxidant activity of bergamot in patients on statin therapy [120].

Safety: No safety concerns; limited data - further studies are necessary.

\subsection{Statins and garlic}

Efficacy: The therapeutic effect of the combination of black seed with garlic as a treatment for dyslipidemia was evaluated in a randomized, double-blind, placebo-controlled, two arms parallel study on 258 subjects who met the Adult Treatment Panel (ATP)-III criteria for drug treatment of hyperlipidemia and dietary intervention. Patients who followed 8-week treatment with simvastatin $(10 \mathrm{mg})$ plus placebo obtained a significant reduction in nonHDL-C (-10.8\%), TG (-6.9\%), and LDL-C (-11.6\%) $(p \leq 0.01)$, and an increase in HDL-C (+10.4\%) $(p=$ $0.02)$. Patients who received simvastatin $(10 \mathrm{mg})$, plus black seed $(500 \mathrm{mg}$ ) and garlic (250 mg) for 8 weeks showed a greater improvement of lipid parameters, LDL-C (-29.4\%), TG (-20.1\%), non-HDL-C $(-27.4 \%)$, and HDL-C $(+21.4 \%)(p=0.01)$. The higher (2.1 to 2.9 times) results obtained with simvastatin plus black seed and garlic as compared to the other group demonstrated the synergetic effect of this association of a nutraceutical combination with pharmacological treatment [295].

Safety: No safety concerns; limited data - further studies are necessary. 


\subsection{Statins and vitamin D}

Efficacy: Low vitamin D status has been associated with hyperlipidemia. A double-blind, placebo-controlled trial was assessed on 56 hypercholesterolemic patients, who were randomly assigned to receive vitamin D 200 IU/day ( $n=$ $28)$ or a placebo $(n=28)$ as an add-on to statin for 6 months. At the end of the treatment, subjects who received vitamin $D$ supplementation had an increased level of serum 25-hydroxyvitamin $D$ concentrations compared with placebo (+16.3 \pm 11.4 compared with $+2.4 \pm 7.1 \mathrm{ng} / \mathrm{ml}$; $p<0.001)$. Moreover, the differences in TC and TG levels between the statin + vitamin D group and statin + placebo group were significant: $-0.57 \mathrm{mmol} / \mathrm{l}(22 \mathrm{mg} / \mathrm{dl})(95 \% \mathrm{Cl}:-0.83 ;-0.32$, $p<0.001)$ and $-0.32 \mathrm{mmol} / \mathrm{l}(28.3 \mathrm{mg} / \mathrm{dl})(95 \% \mathrm{Cl}$ : $-0.55 ;-0.09, p<0.001)$, respectively. Moreover, in patients with 25 -hydroxyvitamin D level $<30 \mathrm{ng}$ / $\mathrm{ml}$ at baseline $(n=43)$, serum TC and TG levels were further reduced by $-0.74 \pm 0.31 \mathrm{mmol} / \mathrm{l}$ $(28 \mathrm{mg} / \mathrm{dl})(p<0.001)$ and $-0.42 \pm 0.22 \mathrm{mmol} / \mathrm{l}$ (37 mg/dl) $(p<0.001)$, respectively. Therefore, the intake of vitamin D together with statin can be a useful tool in the management of hypercholesterolemic subjects [296]. Taking into consideration that low serum vitamin $D$ level seems to be associated with CVD risk and development of statin-related myopathy, the supplementation of vitamin D should always be considered in subjects with low vitamin D levels [297].

Safety: No safety concerns; limited data - further studies are necessary.

\section{Conclusions}

A large number of nutraceuticals have been tested in available trials, demonstrating their lipid-lowering effects. It is, however, important to once again emphasize that nutraceuticals cannot replace lipid-lowering therapy but might essentially help to optimize it (reducing CV residual risk). Taking into account the influence of some of the presented nutraceuticals on different lipid parameters, it seems that this therapy might be especially important to consider for patients with mixed dyslipidemia, especially atherogenic dyslipidemia in patients with diabetes and MetS, in patients with low-to-moderate hypercholesterolemia not on target, as well as in all patients with statin-associated side effects, who cannot be treated with statins/suitable doses of statins and are at higher risk of CV events [298].

However, the main concern is still which lipid-lowering effects of nutraceuticals are clinically relevant, which are maintained in the long term and which might also be associated with an improvement in CVD risk. Combinations of lipid-low- ering nutraceuticals could improve their safety (reducing the dosages of the single components), but their efficacy has been rarely tested in more than one study/RCT, while some of the tested nutraceutical combinations contained underdosed components. On the other hand, both single components and some combinations (in particular red yeast rice, berberine, policosanol combination) have proved to maintain their efficacy in the long term (years), to have a positive impact on CVD risk factors other than LDL-C, and to improve some markers of vascular aging (endothelial function, pulse wave velocity). Finally, some nutraceuticals have been shown to significantly improve the efficacy of standard pharmacological treatments. In this context, an evidence-based approach to the use of lipid-lowering nutraceuticals could improve the quality of the treatment, including therapy adherence, and achievement of the LDL-C goal in clinical practice. However, it has to be clearly stressed that there are still no outcome studies proving that nutraceuticals can prevent CVD morbidity or mortality.

\section{Acknowledgments}

Funding: This position paper was written independently; no company or institution supported it financially. No professional writer was involved in the preparation of this meta-analysis.

\section{Declaration of interest}

Maciej Banach: speakers bureau: Abbott/Mylan, Abbott Vascular, Actavis, Akcea, Amgen, Biofarm, KRKA, MSD, Sanofi-Aventis and Valeant; consultant to Abbott Vascular, Akcea, Amgen, Daichii Sankyo, Esperion, Lilly, MSD, Resverlogix, Sanofi-Aventis; Grants from Sanofi and Valeant; Arrigo F.G. Cicero: consultant for the R\&D of Meda SpA and received research grants from IBSA SpA; Olivier Descamps: speakers bureau: Amgen, MSD, Sanofi-Aventi; consultant to Amgen, Astrazeneca, MSD, Sanofi-Aventis and Phacobel; Grants from Sanofi, MSD and Amgen; Niki Katsiki has given talks, attended conferences and participated in trials sponsored by Amgen, Angelini, Astra Zeneca, Boehringer Ingelheim, MSD, Novartis, Novo Nordisk, Sanofi and WinMedica; Gustavs Latkovskis: speakers bureau: Amgen, Astra-Zeneca, Bayer, Berlin-Chemie/Menarini, Boehringer Ingelheim, GlaxoSmithCline, Mylan, Novo Nordisk, Pfizer, Sanofi-Aventis, Servier, Siemens Laboratories; research grant on the topic of polyprenols and coenzyme Q10 from Pharma and Chemistry Competence Center of Latvia; Dimitri P. Mikhailidis: has given talks and attended conferences sponsored by MSD, AstraZeneca and Libytec; Peter P. Toth: speakers bureau: Amarin, Amgen, Kowa, Merck, Novartis, Regeneron, Sanofi-Aventis; consultant to Amgen, AstraZeneca, Kowa, Merck, and 
A.F.G. Cicero, A. Colletti, G. Bajraktari, O. Descamps, D.M. Djuric, M. Ezhov, Z. Fras, N. Katsiki, M. Langlois, G. Latkovskis, D.B. Panagiotakos, G. Paragh, D.P. Mikhailidis, O. Mitchenko, B. Paulweber, D. Pella, C. Pitsavos, Ž. Reiner, K.K. Ray, M. Rizzo, A. Sahebkar, M.C. Serban, L.S. Sperling, P.P. Toth, D. Vinereanu, M. Vrablík, N.D. Wong, M. Banach

Regeneron; Dragos Vinereanu has given talks and attended conferences sponsored by BMS/Pfizer, Novartis, Servier, Amgen, Bayer, AstraZeneca. Speaker fees from Pfizer, Novartis, Servier, Bayer, AstraZeneca, Terapia; Michal Vrablik reports personal fees from Abbott, Actavis, AstraZeneca, Amgen, BMS, Genzyme, KRKA, MSD, Novartis, Pfizer and Sanofi-Regeneron; Gani Bajraktari, Alessandro Colletti, Dragan M. Djuric, Marat Ezhov, Zlatko Fras, Kausik K. Ray, Michel Langlois, Olena Mitchenko, Demosthenes B. Panagiotakos, Gyorgy Paragh, Bernhard Paulweber, Daniel Pella, Christos Pitsavos, Željko Reiner, Manfredi Rizzo, Amirhossein Sahebkar, Maria-Corina Serban, Laurence S. Sperling, and Nathan D. Wong have no conflict of interest.

\section{References}

1. Organisation WH. Cardiovascular diseases (CVDs) 2015. Available from: http://www.who.int/mediacentre /factsheets/fs317/en/. Last access Aug 28, 2016.

2. Perk J, De Backer G, Gohlke H, et al.; European Association for Cardiovascular Prevention \& Rehabilitation (EACPR); ESC Committee for Practice Guidelines (CPG). European Guidelines on cardiovascular disease prevention in clinical practice (version 2012). The Fifth Joint Task Force of the European Society of Cardiology and Other Societies on Cardiovascular Disease Prevention in Clinical Practice (constituted by representatives of nine societies and by invited experts). Eur Heart $J$ 2012; 33: 1635-701.

3. Bloom DE, Cafiero ET, Jané-Llopis E, et al. The Global Economic Burden of Noncommunicable Diseases. Geneva: World Economic Forum; 2011 September. Report No.: 080911.

4. SIGN (Scottish Intercollegiate Guidelines Network). Risk estimation and the prevention of cardiovascular disease. A national clinical guideline. February 2007. Report No. 97.

5. National Cholesterol Education Program (NCEP) Expert Panel on Detection, Evaluation, and Treatment of High Blood Cholesterol in Adults (Adult Treatment Panel III). Third Report of the National Cholesterol Education Program (NCEP) Expert Panel on Detection, Evaluation, and Treatment of High Blood Cholesterol in Adults (Adult Treatment Panel III) final report. Circulation 2002; 106: 3143-421.

6. Australian Institute of Health and Welfare. High Blood Cholesterol. Cat. No. AUS 156. Ed. Canberra: Australian Institute of Health and Welfare; 2012-2013.

7. Colantonio LD, Bittner V, Reynolds K, et al. Association of serum lipids and coronary heart disease in contemporary observational studies. Circulation 2016; 133 256-64.

8. Ford ES, Li C, Pearson WS, Zhao G, Mokdad AH. Trends in hypercholesterolemia, treatment and control among United States adults. Int J Cardiol 2010; 140: 226-35.

9. Writing Group Members, Mozaffarian D, Benjamin EJ, Go AS, et al.; American Heart Association Statistics Committee; Stroke Statistics Subcommittee. Heart Disease and Stroke Statistics-2016 Update: A Report From the American Heart Association. Circulation 2016; 133: e38-360.

10. Baigent C, Keech A, Kearney PM, et al.; Cholesterol Treatment Trialists' (CTT) Collaborators. Efficacy and safety of cholesterol-lowering treatment: prospective metaanalysis of data from 90,056 participants in 14 randomised trials of statins. Lancet 2005; 366: 1267-78.

11. NCD Risk Factor Collaboration (NCD-RisC). Trends in total cholesterol and lipid fractions in 22 Western and Asian countries. Lancet 2017 (in press).

12. Hobbs FD, Banach M, Mikhailidis DP, Malhotra A, Capewell S. Is statin-modified reduction in lipids the most important preventive therapy for cardiovascular disease? A pro/con debate. BMC Med 2016; 14: 4.

13. Baigent C, Blackwell L, Emberson J, et al.; Cholesterol Treatment Trialists' (CTT) Collaboration. Efficacy and safety of more intensive lowering of LDL cholesterol: a meta-analysis of data from 170,000 participants in 26 randomised trials. Lancet 2010; 376: 1670-81.

14. Heart Protection Study Collaborative Group. MRC/BHF Heart Protection Study of cholesterol lowering with simvastatin in 20,536 high-risk individuals: a randomised placebo-controlled trial. Lancet 2002; 360: 7-22.

15. Shepherd J, Blauw GJ, Murphy MB, et al.; PROSPER Study Group. Pravastatin in elderly individuals at risk of vascular disease (PROSPER): a randomised controlled trial. Lancet 2002; 360: 1623-30.

16. Jacobson TA, Ito MK, Maki KC, et al. National lipid association recommendations for patient-centered management of dyslipidemia: part 1--full report. J Clin Lipidol 2015; 9: 129-69.

17. Law MR, Wald NJ, Thompson SG. By how much and how quickly does reduction in serum cholesterol concentration lower risk of ischaemic heart disease? BMJ 1994; 308: 367-72.

18. Catapano AL, Graham I, De Backer G, et al.; Authors/ Task Force Members. 2016 ESC/EAS Guidelines for the Management of Dyslipidaemias: The Task Force for the Management of Dyslipidaemias of the European Society of Cardiology (ESC) and European Atherosclerosis Society (EAS) Developed with the special contribution of the European Assocciation for Cardiovascular Prevention \& Rehabilitation (EACPR). Atherosclerosis 2016; 253: 281-344.

19. Reiner Ž. Hypertriglyceridemia and risk of coronary artery disease. Nat Rev Cardiol 2017; Mar 16 [Epub ahead of print] doi: 10.1038/nrcardio.2017.3.

20. Booth JN $3^{\text {rd }}$, Colantonio LD, Howard G, et al. Healthy lifestyle factors and incident heart disease and mortality in candidates for primary prevention with statin therapy. Int J Cardiol 2016; 207: 196-202.

21. Banach M, Jankowski P, Jóźwiak J, et al. PoLA/CFPiP/ PCS Guidelines for the management of dyslipidaemias for family physicians 2016. Arch Med Sci 2017; 13: 1-45.

22. Piepoli MF, Hoes AW, Agewall S, et al. 2016 European Guidelines on cardiovascular disease prevention in clinical practice: The Sixth Joint Task Force of the European Society of Cardiology and Other Societies on Cardiovascular Disease Prevention in Clinical Practice (constituted by representatives of 10 societies and by invited experts): Developed with the special contribution of the European Association for Cardiovascular Prevention \& Rehabilitation (EACPR). Eur J Prev Cardiol 2016; 23: NP1-96.

23. Vanhees L, Geladas N, Hansen D, et al.; on behalf of the writing group. Importance of characteristics and modalities of physical activity and exercise in the management of cardiovascular health in individuals with cardiovascular risk factors: recommendations 
from the EACPR (Part II). Eur J Prev Cardiol 2012; 19: 1005-33.

24. American Heart Association Nutrition Committee, Lichtenstein AH, Appel LJ, Brands M, et al. Diet and lifestyle recommendations revision 2006: a scientific statement from the American Heart Association Nutrition Committee. Circulation 2006; 114: 82-96.

25. American Heart Association. Lifestyle Changes and Cholesterol. Available at: http://www.heart.org/ HEARTORG/Conditions/Cholesterol/PreventionTreatmentofHighCholesterol/Lifestyle-Changes-andCholesterol_UCM_305627_Article.jsp Last accessed: March 31, 2017.

26. Appel LJ, Sacks FM, Carey VJ, et al.; OmniHeart Collaborative Research Group. Effects of protein, monounsaturated fat, and carbohydrate intake on blood pressure and serum lipids: results of the OmniHeart randomized trial. JAMA 2005; 294: 2455-64.

27. Brown MS, Goldstein JL. Biomedicine. Lowering LDL not only how low, but how long? Science 2006; 311: 1721-31.

28. Brinton EA. Management of hypertriglyceridemia for prevention of atherosclerotic cardiovascular disease. Endocrinol Metab Clin North Am 2016; 45: 185-204.

29. Patti AM, Toth PP, Giglio RV, et al. Nutraceuticals as an important part of combination therapy in dyslipidaemia. Curr Pharm Des 2017 Mar 17. doi: 10.2174/1381 612823666170317145851.

30. Chen ZY, Jiao R, Ma KY. Cholesterol-lowering nutraceuticals and functional foods. J Agric Food Chem 2008; 56: 8761-73.

31. Cicero AF, Colletti A. Role of phytochemicals in the management of metabolic syndrome. Phytomedicine 2016; 23: 1134-44.

32. Sahebkar A, Serban MC, Gluba-Brzózka A, et al. Lipid-modifying effects of nutraceuticals: an evidence-based approach. Nutrition 2016; 32: 1179-92.

33. Houston $M$. The role of nutraceutical supplements in the treatment of dyslipidemia. J Clin Hypertens 2012; 14: 121-32.

34. Cicero AF, Fogacci F, Colletti A. Food and plant bioactives for reducing cardiometabolic disease risk: an evidence based approach. Food Funct 2017; 8: 2076-88.

35. Stroes ES, Thompson PD, Corsini A, et al.; European Atherosclerosis Society Consensus Panel. Statin-associated muscle symptoms: impact on statin therapy - European Atherosclerosis Society Consensus Panel Statement on Assessment, Aetiology and Management. Eur Heart J 2015; 36: 1012-22.

36. Bangalore S, Fayyad R, Hovingh GK, et al.; Treating to New Targets Steering Committee and Investigators. Statin and the risk of renal-related serious adverse events: analysis from the IDEAL, TNT, CARDS, ASPEN, SPARCL, and other placebo-controlled trials. Am J Cardiol 2014; 113: 2018-20.

37. Reiner Ž. Resistance and intolerance to statins. Nutr Metab Cardiovasc Dis 2014; 24: 1057-66.

38. Banach M, Rizzo M, Toth PP, et al. Statin intolerance an attempt at a unified definition. Position paper from an International Lipid Expert Panel. Arch Med Sci 2015; 11: 1-23.

39. Patel J, Martin SS, Banach M. Expert opinion: the therapeutic challenges faced by statin intolerance. Expert Opin Pharmacother 2016; 17: 1497-507.

40. Banach M, Serban MC. Discussion around statin discontinuation in older adults and patients with wasting diseases. J Cachexia Sarcopenia Muscle 2016; 7: 396-99.
41. Banach M, Aronow WS, Serban MC, Rysz J, Voroneanu L, Covic A. Lipids, blood pressure and kidney update 2015. Lipids Health Dis 2015; 14: 167.

42. Devaraj S, Jialal I. The role of dietary supplementation with plant sterols and stanols in the prevention of cardiovascular disease. Nutr Rev 2006; 64: 348-54.

43. Law M. Plant sterol and stanol margarines and health. BMJ 2000; 320: 861-4.

44. Ras RT, Hiemstra H, Lin Y, Vermeer MA, Duchateau GS, Trautwein EA. Consumption of plant sterol-enriched foods and effects on plasma plant sterol concentrations: a meta-analysis of randomized controlled studies. Atherosclerosis 2013; 230: 336-46.

45. Ferguson JJ, Stojanovski E, MacDonald-Wicks L, Garg ML. Fat type in phytosterol products influence their cholesterol-lowering potential: a systematic review and meta-analysis of RCTs. Prog Lipid Res 2016; 64: 16-29.

46. Demonty I, Ras RT, van der Knaap HC, et al. The effect of plant sterols on serum triglyceride concentrations is dependent on baseline concentrations: a pooled analysis of 12 randomised controlled trials. Eur J Nutr 2013; 52: $153-60$.

47. Athyros VG, Kakafika Al, Papageorgiou AA, et al. Effect of a plant stanol ester-containing spread, placebo spread, or Mediterranean diet on estimated cardiovascular risk and lipid, inflammatory and haemostatic factors. Nutr Metab Cardiovasc Dis 2011; 21: 213-21.

48. Talati R, Sobieraj DM, Makanji SS, Phung OJ, Coleman Cl. The comparative efficacy of plant sterols and stanols on serum lipids: a systematic review and meta-analysis. J Am Diet Assoc 2010; 110: 719-26.

49. Ras RT, Fuchs D, Koppenol WP, et al. The effect of a low-fat spread with added plant sterols on vascular function markers: results of the Investigating Vascular Function Effects of Plant Sterols (INVEST) study. Am J Clin Nutr 2015; 101: 733-41.

50. Gylling $\mathrm{H}$, Halonen J, Lindholm $\mathrm{H}$, et al. The effects of plant stanol ester consumption on arterial stiffness and endothelial function in adults: a randomised controlled clinical trial. BMC Cardiovasc Disord 2013; 13: 50.

51. Brown L, Rosner B, Willett WW, Sacks FM. Cholesterol-lowering effects of dietary fiber: a meta-analysis. Am J Clin Nutr 1999; 69: 30-42.

52. Doi K. Effect of konjac fibre (glucomannan) on glucose and lipids. Eur J Clin Nutr 1995; 49 (Suppl 3): S190-7.

53. Zhu X, Sun X, Wang M, et al. Quantitative assessment of the effects of beta-glucan consumption on serum lipid profile and glucose level in hypercholesterolemic subjects. Nutr Metab Cardiovasc Dis 2015; 25: 714-23.

54. EFSA Panel on Dietetic Products, Nutrition and Allergies (NDA). Scientific opinion on the substantiation of a health claim related to oat beta-glucan and lowering blood cholesterol and reduced risk of (coronary) heart disease pursuant to Article 14 of Regulation (EC) No 1924/2006. EFSA J 2010; 8: 188.

55. Reiner Z, Catapano A, De Backer G, et al. The task force for the management of dyslipidaemias of the European Society of Cardiology (ESC) and the European Atherosclerosis Society (EAS). ESC/EAS guidelines for the management of dyslipidaemias. Eur Heart J 2011; 32: 1769-818.

56. Cleeman J, Grundy S, Becker D, Clark L. Expert panel on Detection, Evaluation and Treatment of High blood Cholesterol in Adults. Executive Summary of the Third Report of the National Cholesterol Education Program (NCEP) Adult Treatment Panel (ATP III). JAMA 2001; 285: 2486-97. 
A.F.G. Cicero, A. Colletti, G. Bajraktari, O. Descamps, D.M. Djuric, M. Ezhov, Z. Fras, N. Katsiki, M. Langlois, G. Latkovskis, D.B. Panagiotakos, G. Paragh, D.P. Mikhailidis, O. Mitchenko, B. Paulweber, D. Pella, C. Pitsavos, Ž. Reiner, K.K. Ray, M. Rizzo, A. Sahebkar, M.C. Serban, L.S. Sperling, P.P. Toth, D. Vinereanu, M. Vrablík, N.D. Wong, M. Banach

57. Tabesh F, Sanei H, Jahangiri $M$, et al. The effects of beta-glucan rich oat bread on serum nitric oxide and vascular endothelial function in patients with hypercholesterolemia. Biomed Res Int 2014; 2014: 481904.

58. Anderson JW. Dietary fibre, complex carbohydrate and coronary artery disease. Can J Cardiol 1995; 11 (SupplG): 55G-62G.

59. Wei ZH, Wang H, Chen XY, et al. Time- and dose-dependent effect of psyllium on serum lipids in mild-to-moderate hypercholesterolemia: a meta-analysis of controlled clinical trials. Eur J Clin Nutr 2009; 63: 821-7.

60. Ribas SA, Cunha DB, Sichieri R, Santana da Silva LC. Effects of psyllium on LDL-cholesterol concentrations in Brazilian children and adolescents: a randomised, placebo-controlled, parallel clinical trial. Br J Nutr 2015; 113: 134-41.

61. Anderson JW, Zettwoch N, Feldman T, Tietyen-Clark J, Oeltgen P, Bishop CW. Cholesterol-lowering effects of psyllium hydrophilic mucilloid for hypercholesterolemic men. Arch Intern Med 1988; 148: 292-6.

62. Gibb RD, McRorie JW Jr, Russell DA, Hasselblad V, D’Alessio DA. Psyllium fiber improves glycemic control proportional to loss of glycemic control: a meta-analysis of data in euglycemic subjects, patients at risk of type 2 diabetes mellitus, and patients being treated for type 2 diabetes mellitus. Am J Clin Nutr 2015; 102: 1604-14.

63. Pal S, Khossousi A, Binns C, Dhaliwal S, Radavelli-Bagatini $\mathrm{S}$. The effects of 12-week psyllium fibre supplementation or healthy diet on blood pressure and arterial stiffness in overweight and obese individuals. $\mathrm{Br}$ J Nutr 2012; 107: 725-34.

64. Anderson JW, Allgood LD, Lawrence A, et al. Cholesterol-lowering effects of psyllium intake adjunctive to diet therapy in men and women with hypercholesterolemia: meta-analysis of 8 controlled trials. Am J Clin Nutr 2000; 71: 472-9.

65. Behera SS, Ray RC. Konjac glucomannan, a promising polysaccharide of Amorphophallus konjac K. Koch in health care. Int J Biol Macromol 2016; 92: 942-56.

66. Sood N, Baker WL, Coleman Cl. Effect of glucomannan on plasma lipid and glucose concentrations, body weight, and blood pressure: systematic review and meta-analysis. Am J Clin Nutr 2008; 88: 1167-75.

67. Onakpoya I, Posadzki P, Ernst E. The efficacy of glucomannan supplementation in overweight and obesity: a systematic review and meta-analysis of randomized clinical trials. J Am Coll Nutr 2014; 33: 70-8.

68. Guardamagna O, Abello F, Cagliero P, Visioli F. Could dyslipidemic children benefit from glucomannan intake? Nutrition 2013; 29: 1060-5.

69. Martino F, Martino E, Morrone F, Carnevali E, Forcone R, Niglio T. Effect of dietary supplementation with gluco mannan on plasma total cholesterol and low density lipoprotein cholesterol in hypercholesterolemic children. Nutr Metab Cardiovasc Dis 2005; 15: 174-80.

70. Martino F, Puddu PE, Pannarale G, et al. Low dose chromium-polynicotinate or policosanol is effective in hypercholesterolemic children only in combination with glucomannan. Atherosclerosis 2013; 228: 198-202.

71. Baker WL, Tercius A, Anglade M, White CM, Coleman $\mathrm{Cl}$. A meta-analysis evaluating the impact of chitosan on serum lipids in hypercholesterolemic patients. Ann Nutr Metab 2008; 55: 368-74.

72. Rizzo M, Giglio RV, Nikolic D, et al. Effects of chitosan on plasma lipids and lipoproteins: a 4-month prospective pilot study. Angiology 2014; 65: 538-42.
73. Jull AB, Ni Mhurchu C, Bennett DA, Dunshea-Mooij CA, Rodgers A. Chitosan for overweight or obesity. Cochrane Database Syst Rev 2008; 3: CD003892.

74. Kim HJ, Ahn HY, Kwak JH, et al. The effects of chitosan oligosaccharide (GO2KA1) supplementation on glucose control in subjects with prediabetes. Food Funct 2014; 10: 2662-9.

75. Mhurchu CN, Poppitt S, McGill A, et al. The effect of the dietary supplement, chitosan, on body weight: a randomised controlled trial in 250 overweight and obese adults. Int J Obes 2004; 28: 1149-56.

76. Guarner F, Schaafsma GJ. Probiotics. Int J Food Microbiol 1998; 39: 237-8.

77. Gilliland SE, Nelson CR, Maxwell C. Assimilation of cholesterol by Lactobacillus acidophilus. Appl Environ Microbiol 1985; 49: 377-81.

78. Mistry P. Natural cholesterol-lowering products: focus on probiotics. Br J Community Nurs 2014; 19 (Suppl 11): S14-8.

79. Kim GB, Yi SH, Lee BH. Purification and characterization of three different types of bile salt hydrolases from Bifidobacterium strains. J Dairy Sci 2004; 87: 258-66.

80. Liong MT, Dunshea FR, Shah NP. Effects of a synbiotic containing Lactobacillus acidophilus ATCC 4962 on plasma lipid profiles and morphology of erythrocytes in hypercholesterolaemic pigs on high- and low-fat diets. Br J Nutr 2007; 98: 736-44.

81. Cho YA, Kim J. Effect of probiotics on blood lipid concentrations: a meta-analysis of randomized controlled trials. Medicine 2015; 94: e1714.

82. Agerholm-Larsen L, Bell ML, Grunwald GK, Astrup A. The effect of a probiotic milk product on plasma cholesterol: a meta-analysis of short-term intervention studies. Eur J Clin Nutr 2000; 54: 856-60.

83. Shimizu M, Hashiguchi M, Shiga T, Tamura HO, Mochizuki M. Meta-analysis: effects of probiotic supplementation on lipid profiles in normal to mildly hypercholesterolemic individuals. PLoS One 2015; 10: e0139795.

84. Doron S, Snydman DR. Risk and safety of probiotics. Clin Infect Dis (Review) 2015; 60 Suppl 2: S129-34.

85. Ma J, Li Y, Ye Q, et al. Constituents of red yeast rice, a traditional Chinese food and medicine. J Agric Food Chem 2000; 48: 5220-5.

86. Gordon RY, Cooperman T, Obermeyer W, Becker DJ. Marked variability of monacolin levels in commercial red yeast rice products: buyer beware! Arch Intern Med 2010; 170: 1722-7.

87. Wang RW, Kari PH, Lu AY, Thomas PE, Guengerich FP, Vyas KP. Biotransformation of lovastatin. IV. Identification of cytochrome P450 3A proteins as the major enzymes responsible for the oxidative metabolism of lovastatin in rat and human liver microsomes. Arch Biochem Biophys 1991; 290: 355-61.

88. Li YG, Zhang F, Wang ZT, Hu ZB. Identification and chemical profiling of monacolins in red yeast rice using high-performance liquid chromatography with photodiode array detector and mass spectrometry. J Pharm Biomed Anal 2004; 35: 1101-12.

89. Gerards MC, Terlou RJ, Yu H, Koks CH, Gerdes VE. Traditional Chinese lipid-lowering agent red yeast rice results in significant $L D L$ reduction but safety is uncertain - a systematic review and meta-analysis. Atherosclerosis 2015; 240: 415-23.

90. Mazzanti G, Moro PA, Raschi E, Da Cas R, Menniti-Ippolito F. Adverse reactions to dietary supplements containing red yeast rice: assessment of cases from the Italian surveillance system. Br J Clin Pharmacol 2017 Jan 17, doi: 10.1111/bcp.13171 [Epub ahead of print]. 
91. Liu J, Zhang J, Shi Y, Grimsgaard S, Alraek T, Fønnebø V. Chinese red yeast rice (Monascus purpureus) for primary hyperlipidemia: a meta-analysis of randomized controlled trials. Chin Med 2006; 1: 4.

92. Zhao SP, Liu L, Cheng YC, et al. Xuezhikang, an extract of cholestin, protects endothelial function through antiinflammatory and lipid-lowering mechanisms in patients with coronary heart disease. Circulation 2004; 110: 915-20.

93. DFG Permanent Senate Commission on Food Safety. Toxicological evaluation of red mould rice: an update 2012.

94. Kantola T, Kivistö KT, Neuvonen PJ. Grapefruit juice greatly increases serum concentrations of lovastatin and lovastatin acid. Clin Pharmacol Ther 1998; 63: 397-402.

95. Prasad GV, Wong T, Meliton G, Bhaloo S. Transplantation. Rhabdomyolysis due to red yeast rice (Monascus purpureus) in a renal transplant recipient. Transplantation 2002; 74: 1200-1.

96. Rasheva TV, Nedeva TS, Hallet JN, Kujumdzieva AV. Characterization of a non-pigment producing Monascus purpureus mutant strain. Antonie Van Leeuwenhoek 2003; 83: 333-40.

97. Arai $M$, Hibino T. Tumorigenicity of citrinin in male F344 rats. Cancer Lett 1983; 17: 281-7.

98. Chan WH, Shiao NH. Effect of citrinin on mouse embryonic development in vitro and in vivo. Reprod Toxicol 2007; 24: 120-5

99. Singh ND, Sharma AK, Dwivedi P, Patil RD, Kumar M. Experimentally induced citrinin and endosulfan toxicity in pregnant Wistar rats: histopathological alterations in liver and kidneys of fetuses. J Appl Toxicol 2008; 28: 901-7.

100. EFSA, Scientific Opinion on the risks for public and animal health related to the presence of citrinin in food and feed. EFSA Panel on Contaminants in the Food Chain (CONTAM). European Food Safety Authority (EFSA), Parma, Italy. EFSA J 2012; 10: 2605.

101. EFSA, Scientific Opinion on the substantiation of health claims related to monacolin $\mathrm{K}$ from red yeast rice and maintenance of normal blood LDL-cholesterol concentrations (ID 1648, 1700) pursuant to Article 13(1) of Regulation (EC) No 1924/20061; EFSA Panel on Dietetic Products, Nutrition and Allergies (NDA), European Food Safety Authority (EFSA), Parma, Italy. EFSA J 2011; 9: 2304.

102. Borlinghaus J, Albrecht F, Grunhlke MCH, Nwachukwu ID, Slusarenko A. Allicin: chemistry and biological properties. Molecules 2014; 19: 12591-618.

103. Ried K, Toben C, Fakler P. Effect on garlic on serum lipids: an updated meta-analysis. Nutr Rev 2013; 71: 282-99.

104. Ackermann RT, Mulrow CD, Ramirez G, Gardner CD, Morbidoni L, Lawrence VA. Garlic shows promise for improving some cardiovascular risk factors. Arch Intern Med 2001; 161: 813-24.

105. Ried K. Garlic lowers blood pressure in hypertensive individuals, regulates serum cholesterol, and stimulates immunity: an updated meta-analysis and review. J Nutr 2016; 146: 389S-396S.

106. Jung ES, Park SH, Choi EK, et al. Reduction of blood lipid parameters by a 12-wk supplementation of aged black garlic: a randomized controlled trila. Nutrition 2014; 30: 1034-9.

107. Sahebkar A, Serban C, Ursoniu S, Banach M. Effect of garlic on plasma lipoprotein(a) concentrations: a systematic review and meta-analysis of randomized controlled clinical trials. Nutrition 2016; 32: 33-40.
108. Morihara N, Hino A. Aged garlic extract suppresses platelet aggregation by changing the functional property of platelets. J Nat Med 2017; 71: 249-256.

109. Cighetti G, Del Puppo M, Paroni R, Galli Kienle M. Modulation of HMG-CoA reductase activity by pantetheine/ pantethine. Biochim Biophys Acta 1988; 963: 389-93.

110. Cighetti G, Del Puppo M, Paroni R, Fiorica E, Galli Kienle M. Pantethine inhibits cholesterol and fatty acid syntheses and stimulates carbon dioxide formation in isolated rat hepatocytes. J Lipid Res 1987; 28: 152-61.

111. Eto M, Watanabe K, Chonan N, Ishii K. Lowering effect of pantethine on plasma beta-thromboglobulin and lipids in diabetes mellitus. Artery 1987; 15: 1-12.

112. Binaghi P, Cellina G, Lo Cicero G, Bruschi F, Porcaro E, Penotti M. Evaluation of the cholesterol-lowering effectiveness of pantethine in women in perimenopausal age. Minerva Med 1990; 81: 475-9.

113. Rumberger JA, Napolitano J, Azumano I, Kamiya T, Evans $M$. Pantethine, a derivative of vitamin B(5) used as a nutritional supplement, favorably alters low-density lipoprotein cholesterol metabolism in low- to moderate-cardiovascular risk North American subjects: a triple-blinded placebo and diet-controlled investigation. Nutr Res 2011; 31: 608-15.

114. Bertolini S, Donati C, Elicio N, et al. Lipoprotein changes induced by pantethine in hyperlipoproteinemic patients: adults and children. Int J Clin Pharmacol Ther Toxicol 1986; 24: 630-7.

115. Evans M, Rumberger JA, Azumano I, Napolitano JJ, Citrolo D, Kamiya T. Pantethine, a derivative of vitamin B5, favorably alters total, LDL and non-HDL cholesterol in low to moderate cardiovascular risk subjects eligible for statin therapy: a triple-blinded placebo and diet-controlled investigation. Vasc Health Risk Manag 2014; 10: 89-100.

116. Donati C, Barbi G, Cairo G, Prati GF, Degli Esposti E. Pantethine improves the lipid abnormalities of chronic hemodialysis patients: results of a multicenter clinical trial. Clin Nephrol 1986; 25: 70-4.

117. Giglio RV, Patti AM, Nikolic D, et al. The effect of bergamot on dyslipidemia. Phytomedicine 2016; 23: 1175-81.

118. Di Donna L, De Luca G, Mazzotti F, Napoli A, Salerno R, Taverna D, Sindona G. Statin-like principles of bergamot fruit (Citrus bergamia): isolation of 3-hydroxymethylglutaryl flavonoid glycosides. J Nat Prod 2009; 72: 1352-4.

119. Miceli N, Mondello MR, Monforte MT, et al. Hypolipidemic effects of Citrus bergamia Risso et Poiteau juice in rats fed a hypercholesterolemic diet. J Agric Food Chem 2007; 55: 10671-7.

120. Gliozzi M, Walker R, Muscoli S, et al. Bergamot polyphenolic fraction enhances rosuvastatin-induced effect on LDL-cholesterol, LOX-1 expression and protein kinase $B$ phosphorylation in patients with hyperlipidemia. Int J Cardiol 2013; 170: 140-5.

121. Gliozzi M, Carresi C, Musolino V, et al. The effect of Bergamot-derived polyphenolic fraction on LDL small dense particles and non alcoholic fatty liver disease in patients with metabolic syndrome. Adv Biol Chem 2014; 4: 129-37.

122. Athyros VG, Tziomalos K, Katsiki N, Doumas M, Karagiannis A, Mikhailidis DP. Cardiovascular risk across the histological spectrum and the clinical manifestations of non-alcoholic fatty liver disease: an update. World J Gastroenterol 2015; 21: 6820-34. 
A.F.G. Cicero, A. Colletti, G. Bajraktari, O. Descamps, D.M. Djuric, M. Ezhov, Z. Fras, N. Katsiki, M. Langlois, G. Latkovskis, D.B. Panagiotakos, G. Paragh, D.P. Mikhailidis, O. Mitchenko, B. Paulweber, D. Pella, C. Pitsavos, Ž. Reiner, K.K. Ray, M. Rizzo, A. Sahebkar, M.C. Serban, L.S. Sperling, P.P. Toth, D. Vinereanu, M. Vrablík, N.D. Wong, M. Banach

123. Mollace V, Sacco I, Janda E, et al. Hypolipemic and hypo glycaemic activity of bergamot polyphenols: from animal models to human studies. Fitoterapia 2011; 82: 309-16.

124. Chen JT, Wesley R, Shamburek RD, Pucino F, Csako G. Meta-analysis of natural therapies for hyperlipidemia: plant sterols and stanols versus policosanol. Pharmacotherapy 2005; 25: 171-83.

125. Singh DK, Li L, Porter TD. Policosanol inhibits cholesterol synthesis in hepatoma cells by activation of AMP-kinase. J Pharmacol Exp Ther 2006; 318: 1020-6.

126. Berthold HK, Unverdorben S, Degenhardt R, Bulitta M, Gouni-Berthold I. Effect of policosanol on lipid levels among patients with hypercholesterolemia or combined hyperlipidemia: a randomized controlled trial. JAMA 2006; 295: 2262-9.

127. Backes JM, Gibson CA, Ruisinger JF, Moriarty PM. Modified-policosanol does not reduce plasma lipoproteins in hyperlipidemic patients when used alone or in com bination with statin therapy. Lipids 2011; 46: 923-9.

128. Reiner Ž, Tedeschi-Reiner E, Romić Ž. Effects of rice policosanol on serum lipoproteins, homocysteine, fibrinogen and C-reactive protein in hypercholesterolaemic patients. Clin Drug Invest 2005; 25: 701-7.

129. Reiner Ž, Tedeschi-Reiner E. Rice policosanol does not have any effects on blood coagulation factors in hypercholesterolemic patients. Coll Antropol 2007; 31: 315-9.

130. Liu CS, Zheng YR, Zhang YF, Long XY. Research progress on berberine with a special focus on its oral bioavailability. Fitoterapia 2016; 109: 274-82.

131. Abidi P, Zhou Y, Jiang JD, Liu J. Extracellular signal-regulated kinase-dependent stabilization of hepatic low-density lipoprotein receptor mRNA by herbal medicine berberine. Arterioscler Thromb Vasc Biol 2005; 25: 2170-6.

132. Li H, Dong B, Park SW, Lee HS, Chen W, Liu J. Hepatocyte nuclear factor 1 alpha plays a critical role in PCSK9 gene transcription and regulation by the natural hypocholesterolemic compound berberine. J Biol Chem 2009; 284: 28885-95.

133. Li XY, Zhao ZX, Huang $M$, et al. Effect of Berberine on promoting the excretion of cholesterol in high-fat diet-induced hyperlipidemic hamsters. J Transl Med 2015; 13: 278.

134. Qiang X, Xu L, Zhang M, et al. Demethyleneberberine attenuates non-alcoholic fatty liver disease with activation of AMPK and inhibition of oxidative stress. Biochem Biophys Res Commun 2016; 472: 603-9.

135. Kim WS, Lee YS, Cha SH, et al. Berberine improves lipid dysregulation in obesity by controlling central and peripheral AMPK activity. Am J Physiol Endocrinol Metab 2009; 296: E812-9.

136. Zarei A, Changizi-Ashtiyani S, Taheri S, Ramezani M. A quick overview on some aspects of endocrinological and therapeutic effects of Berberis vulgaris L. Avicenna J Phytomed 2015; 5: 485-97.

137. Meng S, Wang LS, Huang ZQ, et al. Berberine ameliorates inflammation in patients with acute coronary syndrome following percutaneous coronary intervention. Clin Exp Pharmacol Physiol 2012; 39: 406-11.

138. Lan J, Zhao Y, Dong F, et al. Meta-analysis of the effect and safety of berberine in the treatment of type 2 diabetes mellitus, hyperlipemia and hypertension. J Ethnopharmacol 2015; 161: 69-81.

139. Derosa G, Maffioli P, Cicero AF. Berberine on metabolic and cardiovascular risk factors: an analysis from preclinical evidences to clinical trials. Expert Opin Biol Ther 2012; 12: 1113-24.
140. Sosnowska B, Penson P, Banach M. The role of nutraceuticals in the prevention of cardiovascular disease. Cardiovasc Diagn Ther 2017; 7 (Suppl 1): S21-31.

141. Way TD, Lin HY, Kuo DH, et al. Pu-erh tea attenuates hyperlipogenesis and induces hepatoma cells growth arrest through activating AMP-activated protein kinase (AMPK) in human HepG2 cells. J Agric Food Chem 2009; 57: 5257-64

142. Shishikura Y, Khokhar S, Murray BS. Effects of tea polyphenols on emulsification of olive oil in a small intestine model system. J Agric Food Chem 2006; 54: 1906-13.

143. Onakpoya I, Spencer E, Heneghan C, Thompson M. The effect of green tea on blood pressure and lipid profile: a systematic review and meta-analysis of randomized clinical trials. Nutr Metab Cardiovasc Dis 2014; 24 823-36.

144. Park CS, Kim W, Woo JS, et al. Green tea consumption improves endothelial function but not circulating endothelial progenitor cells in patients with chronic renal failure. Int J Cardiol 2010; 145: 261-2.

145. Lin QF, Qiu CS, Wang SL, et al. A cross-sectional study of the relationship between habitual tea consumption and arterial stiffness. J Am Coll Nutr 2016; 35: 354-61.

146. Serban C, Sahebkar A, Antal D, Ursoniu S, Banach M. Effects of supplementation with green tea catechins on plasma C-reactive protein concentrations: a systematic review and meta-analysis of randomized controlled trials. Nutrition 2015; 31: 1061-71.

147. Zhang C, Qin YY, Wei X, Yu FF, Zhou YH, He J. Tea consumption and risk of cardiovascular outcomes and total mortality: a systematic review and meta-analysis of prospective observational studies. Eur J Epidemiol 2015; 30: 103-13.

148. Cicero AF, Fogacci F, Colletti A. Potential role of bioactive peptides in prevention and treatment of chronic diseases: a narrative review. Br J Pharmacol 2017; 174: 1378-94.

149. Weggemans RM, Trautwein EA. Relation between soy-associated isoflavones and LDL and HDL cholesterol concentrations in humans: a meta-analysis. Eur J Clin Nutr 2003; 57: 940-6.

150. Cho SJ, Juillerat MA, Lee $\mathrm{CH}$. Cholesterol lowering mechanism of soybean protein hydrolysate. J Agric Food Chem 2007; 55: 10599-604.

151. Grieco A, Miele L, Pompili M, et al. Acute hepatitis caused by a natural lipid-lowering product: when "alternative" medicine is no "alternative" at all. J Hepatol 2009; 50: 1273-7.

152. Potter SM. Overview of proposed mechanisms for the hypocholesterolemic effect of soy. J Nutr 1995; 125 (3 Suppl): 606S-11S.

153. Lammi C, Zanoni C, Scigliuolo GM, D’Amato A, Arnoldi $A$. Lupin peptides lower low-density lipoprotein (LDL) cholesterol through an up-regulation of the LDL receptor/sterol regulatory element binding protein 2 (SREBP2) pathway at HepG2 cell line. J Agric Food Chem 2014; 62: 7151-9.

154. Tokede OA, Onabanjo TA, Yansane A, Gaziano JM, Djo ussé L. Soya products and serum lipids: a meta-analysis of randomised controlled trials. Br J Nutr 2015; 114: 831-43.

155. Beavers DP, Beavers KM, Miller M, Stamey J, Messina MJ. Exposure to isoflavone-containing soy products and endothelial function: a Bayesian meta-analysis of randomized controlled trials. Nutr Metab Cardiovasc Dis 2012; 22: 182-91.

156. Hazim S, Curtis PJ, Schär MY, et al. Acute benefits of the microbial-derived isoflavone metabolite equol on arte- 
rial stiffness in men prospectively recruited according to equol producer phenotype: a double-blind randomized controlled trial. Am J Clin Nutr 2016; 103: 694-702.

157. Arnoldi A, Greco S. Nutraceutical characteristics of lupin protein. Nutrafoods 2011; 10: 23-9.

158. Bähr M, Fechner A, Krämer J, Kiehntopf $M$, Jahreis G. Lupin protein positively affects plasma LDL cholesterol and LDL:HDL cholesterol ratio in hypercholesterolemic adults after four weeks of supplementation: a randomized, controlled crossover study. Nutr J 2013; 12: 107.

159. Bähr M, Fechner A, Kiehntopf M, Jahreis G. Consuming a mixed diet enriched with lupin protein beneficially affects plasma lipids in hypercholesterolemic subjects: a randomized controlled trial. Clin Nutr 2015; 34: 7-14.

160. Fechner A, Kiehntopf $M$, Jahreis $G$. The formation of short-chain fatty acids is positively associated with the blood lipid-lowering effect of lupin kernel fiber in moderately hypercholesterolemic adults. J Nutr 2014; 144: 599-607.

161. EFSA Panel on Dietetic Products NaAN Scientific Opinion on the substantiation of health claims related to EPA, DHA, DPA and maintenance of normal blood pressure (ID 502), maintenance of normal HDL-cholesterol concentrations (ID 515), maintenance of normal (fasting) blood concentrations of triglycerides (ID 517), maintenance of normal LDL-cholesterol concentrations (ID 528, 698) and maintenance of joints (ID 503, $505,507,511,518,524,526,535,537)$ pursuant to Article 13(1) of Regulation (EC) No 1924/2006. EFSA J 2009; 7: 1263-89.

162. EFSA Panel on Dietetic Products NaAN Scientific Opinion on the substantiation of health claims related to eicosapentaenoic acid (EPA), docosahexaenoic acid (DHA), docosapentaenoic acid (DPA) and maintenance of normal cardiac function (ID 504, 506, 516, 527, 538, $703,1128,1317,1324,1325)$, maintenance of normal blood glucose concentrations (ID 566), maintenance of normal blood pressure (ID 506, 516, 703, 1317, 1324), maintenance of normal blood HDL-cholesterol concentrations (ID 506), maintenance of normal (fasting) blood concentrations of triglycerides (ID 506, 527, $538,1317,1324,1325)$, maintenance of normal blood LDL-cholesterol concentrations (ID 527, 538, 1317, $1325,4689)$, protection of the skin from photo-oxidative (UV-induced) damage (ID 530), improved absorption of EPA and DHA (ID 522, 523), contribution to the normal function of the immune system by decreasing the levels of eicosanoids, arachidonic acid-derived mediators and pro-inflammatory cytokines (ID 520, 2914), and "immunomodulating agent" (4690) pursuant to Article 13(1) of Regulation (EC) No 1924/20061. EFSA J 2010; 8: 1796-828.

163. Howe P, Mori T, Buckley J. Long chain omega-3 fatty acids and cardiovascular disease - FSANZ consideration of a commissioned review. FSANZ. 2013. PDF: http://www. foodstandards.gov.au/consumer/labelling/nutrition/ documents/FSANZ\%20consideration\%20of\%20omega-3\%20review1.pdf. Last accessed: 31 March, 2017.

164. Miller M, Stone NJ, Ballantyne C, et al. Triglycerides and cardiovascular disease: a scientific statement from the American Heart Association. Circulation 2011; 123: 2292-333.

165. Harris WS, Bulchandani D. Why do omega-3 fatty acids lower serum triglycerides? Curr Opin Lipidol 2006; 17: 387-93.

166. Eslick GD, Howe PR, Smith C, Priest R, Bensoussan A. Benefits of fish oil supplementation in hyperlipidemia: a systematic review and meta-analysis. Int J Cardiol 2009; 136: 4-16.

167. Leslie MA, Cohen DJ, Liddle DM, Robinson LE, Ma DW. A review of the effect of omega-3 polyunsaturated fatty acids on blood triacylglycerol levels in normolipidemic and borderline hyperlipidemic individuals. Lipids Health Dis 2015; 14: 53.

168. Di Stasi D, Bernasconi R, Marchioli R, et al. Early modifications of fatty acid composition in plasma phospholipids, platelets and mononucleates of healthy volunteers after low doses of n-3 polyunsaturated fatty acids. Eur J Clin Pharmacol 2004; 60: 183-90.

169. Trumbo P, Schlicker S, Yates AA, Poos M; Food and Nutrition Board of the Institute of Medicine, The National Academies. Dietary reference intakes for energy, carbohydrate, fiber, fat, fatty acids, cholesterol, protein and amino acids. J Am Diet Assoc 2002; 102: 1621-30.

170. Wei MY, Jacobson TA. Effects of eicosapentaenoic acid versus docosahexaenoic acid on serum lipids: a systematic review and meta-analysis. Curr Atheroscler Rep 2011; 13: 474-83.

171. Cicero AF, Reggi A, Parini A, Borghi C. Application of polyunsaturated fatty acids in internal medicine: beyond the established cardiovascular effects. Arch Med Sci 2012; 8: 784-93.

172. Gruppo Italiano per lo Studio della Sopravvivenza nell'Infarto miocardico (GISSI). Dietary supplementation with $n-3$ polyunsaturated fatty acids and vitamin $E$ after myocardial infarction: results of the GISSI-Prevenzione trial. Lancet 199; 354: 447-55.

173. Cicero AF, Colletti A. Krill oil: evidence of a new source of polyunsaturated fatty acids with high bioavailability. Clin Lipidol 2015; 10: 1-4.

174. Ulven SM, Kirkhus B, Lamglait A, et al. Metabolic effects of krill oil are essentially similar to those of fish oil but at lower dose of EPA and DHA, in healthy volunteers. Lipids 2011; 46: 37-46.

175. Cicero AF, Rosticci M, Morbini $M$, et al. Lipid-lowering and anti-inflammatory effects of omega 3 ethyl esters and krill oil: a randomized, cross-over, clinical trial. Arch Med Sci 2016; 12: 507-12.

176. Ursoniu S, Sahebkar A, Serban MC, et al.; Lipid and Blood Pressure Meta-analysis Collaboration Group. Lipid-modifying effects of krill oil in humans: systematic review and meta-analysis of randomized controlled trials. Nutr Rev 2017; 75: 361-73.

177. Pan A, Yu D, Demark-Wahnefried W, Franco OH, Lin X. Meta-analysis of the effects of flexseed interventions on blood lipids. Am J Clin Nutr 2009; 90: 288-97.

178. Ursoniu S, Sahebkar A, Andrica F, Serban C, Banach M; Lipid and Blood Pressure Meta-analysis Collaboration (LBPMC) Group. Effects of flaxseed supplements on blood pressure: a systematic review and meta-analysis of controlled clinical trial. Clin Nutr 2016; 35: 615-25.

179. Khalesi S, Paukste E, Nikbakht E, Khosravi-Boroujeni H. Sesame fractions and lipid profiles: a systematic review and meta-analysis of controlled trials. $\mathrm{Br} J$ Nutr 2016; 115: 764-73.

180. Kromhout D, Giltay EJ, Geleijnse JM; Alpha Omega Trial Group. n-3 fatty acids and cardiovascular events after myocardial infarction. N Engl J Med 2010; 363: 2015-26.

181. Kotwal S, Jun M, Sullivan D, Perkovic V, Neal B. Omega 3 fatty acids and cardiovascular outcomes: systematic review and meta-analysis. Circ Cardiovasc Qual Outcomes 2012; 5: 808-18. 
A.F.G. Cicero, A. Colletti, G. Bajraktari, O. Descamps, D.M. Djuric, M. Ezhov, Z. Fras, N. Katsiki, M. Langlois, G. Latkovskis, D.B. Panagiotakos, G. Paragh, D.P. Mikhailidis, O. Mitchenko, B. Paulweber, D. Pella, C. Pitsavos, Ž. Reiner, K.K. Ray, M. Rizzo, A. Sahebkar, M.C. Serban, L.S. Sperling, P.P. Toth, D. Vinereanu, M. Vrablík, N.D. Wong, M. Banach

182. Cicero AF, Gaddi A. Rice bran oil and gamma-oryzano in the treatment of hyperlipoproteinaemias and other conditions. Phytother Res 2001; 15: 277-89.

183. Mäkynen K, Chitchumroonchokchai C, Adisakwattana S, Failla M, Ariyapitipun T. Effect of gamma-oryzanol on the bioaccessibility and synthesis of cholesterol. Eur Rev Med Pharmacol Sci 2012; 16: 49-56.

184. Kim HW, Kim JB, Cho SM, et al. Characterization and quantification of gamma-oryzanol in grains of $16 \mathrm{Ko}$ rean rice varieties. Int J Food Sci Nutr 2015; 66: 166-74.

185. Jolfaie NR, Rouhani MH, Surkan PJ, Siassi F, Azadbakht L. Rice bran oil decreases total and LDL cholesterol in humans: a systematic review and meta-analysis of randomized controlled clinical trials. Horm Metab Res 2016; 48: 417-26.

186. Nagaoka S, Shimizu K, Kaneko H, et al. A novel protein C-phycocyanin plays a crucial role in the hypocholes terolemic action of Spirulina platensis concentrate in rats. J Nutr 2005; 135: 2425-30.

187. Serban MC, Sahebkar A, Dragan S, et al. A systematic review and meta-analysis of the impact of Spirulina supplementation on plasma lipid concentrations. Clin Nutr 2016; 35: 842-51.

188. Pulido-Moran M, Moreno-Fernandez J, Ramirez-Tortosa C, Ramirez-Tortosa M. Curcumin and health. Molecules 2016; 21: 264.

189. Panahi Y, Hosseini MS, Khalili N, et al. Effects of supplementation with curcumin on serum adipokine concen trations: A randomized controlled trial. Nutrition 2016; 32: 1116-22.

190. Sahebkar A, Cicero AF, Simental-Mendía LE, Aggarwal BB, Gupta SC. Curcumin downregulates human tumor necrosis factor-alpha levels: a systematic review and meta-analysis of randomized controlled trials. Pharmacol Res 2016; 107: 234-42.

191. Kumar P, Malhotra P, Ma K, et al. SREBP2 mediates the modulation of intestinal NPC1L1 expression by curcumin. Am J Physiol Gastrointest Liver Physiol 2011; 301: G148-55.

192. Liu XL, Liu MH, Hu HJ, et al. Curcumin enhanced choelsterol efflux by upregulating ABCA1 expression through AMPK-SIRT1-LXRalpha signaling in THP-1 macrophage-derived foam cells. DNA Cell Biol 2015; 34: 561-72.

193. Tai MH, Chen PK, Chen PY, Wu MJ, Ho CT, Yen JH. Curcumin enhances cell-surface LDLR level and promotes LDL uptake through downregulation of PCSK9 gene expression in HepG2 cells. Mol Nutr Food Res 2014; 58: 2133-45.

194. Momtazi AA, Derosa G, Maffioli P, Banach M, Sahebkar A. Role of microRNAs in the therapeutic effects of curcumin in non-cancer diseases. Mol Diagn Ther 2016; 20: 335-45.

195. Sahebkar A. A systematic review and meta-analysis of randomized controlled trials investigating the effects of curcumin on blood lipid levels. Clin Nutr 2014; 33: 406-14.

196. Yang YS, Su YF, Yang HW, Lee YH, Chou J, Ueng KC. Lipid-lowering effects of curcumin in patients with metabolic syndrome: a randomized, double-blind, placebo-controlled trial. Phytother Res 2014; 28: 1770-7.

197. Panahi Y, Khalili N, Hosseini MS, Abbasinazari M, Sahebkar A. Lipid-modifying effects of adjunctive therapy with curcuminoids-piperine combination in patients with metabolic syndrome: results of a randomized controlled trial. Complement Ther Med 2014; 22: 851-7.

198. Rahmani S, Asgary S, Askari G, et al. Treatment of non-alcoholic fatty liver disease with curcumin: a ran domized placebo-controlled trial. Phytother Res 2016 Jun 8. doi: 10.1002/ptr.5659 [Epub ahead of print].

199. Panahi Y, Kianpour P, Mohtashami R, Jafari R, Simental-Mendía LE, Sahebkar A. Curcumin lowers serum lipids and uric acid in subjects with non-alcoholic fatty liver disease: a randomized controlled trial. J Cardiovasc Pharmacol 2016; 68: 223-9.

200. Derosa G, Limas CP, Macías PC, Estrella A, Maffioli P. Dietary and nutraceutical approach to type 2 diabetes. Arch Med Sci 2014; 10: 336-44.

201. Nakayama H, Tsuge N, Sawada H, et al. A single consumption of curry improved postprandial endothelial function in healthy male subjects: a randomized, controlled crossover trial. Nutr J 2014; 13: 67.

202. Chuengsamarn S, Rattanamongkolgul S, Phonrat B, Tungtrongchitr R, Jirawatnotai S. Reduction of atherogenic risk in patients with type 2 diabetes by curcuminoid extract: a randomized controlled trial. J Nutr Biochem 2014; 25: 144-50.

203. Rahimi HR, Nedaeinia R, Sepehri Shamloo A, Nikdoust S, Kazemi Oskuee R. Novel delivery system for natural products: nano-curcumin formulations. Avicenna J Phytomed 2016; 6: 383-98.

204. El-Hattab AW, Scaglia F. Disorders of carnitine biosynthesis and transport. Mol Genet Metab 2015; 116: 107-12.

205. Serban MC, Sahebkar A, Mikhailidis DP, et al. Impact of L-carnitine on plasma lipoprotein(a) concentrations: a systematic review and meta-analysis of randomized controlled trials. Sci Rep 2016; 6: 19188.

206. Pooyandjoo M, Nouhi M, Shab-Bidar S, Djafarian K, Olyaeemanesh $A$. The effect of (L-) carnitine on weight loss in adults: a systematic review and meta-analysis of randomized controlled trials. Obes Rev 2016; 17: 970-6.

207. Mazidi M, Rezaie P, Banach M. Impact of L-carnitine on C-reactive protein: a systematic review and meta-analysis of 10 randomized control trials with 925 patients. Presentation at $2^{\text {nd }}$ CPPEI Congress in Vienna, July 2017 (data unpublished).

208. Capasso F, Gaginella TS, Grandolini G, Izzo AA. Phytotherapy: a Quick Reference to Herbal Medicine. Springer, Berlin 2003.

209. Safaa M, Hanaa A, Abdel F, Nahila A, Abdelaaty S. Cynara scolymus for relieving on nonalcoholic steatohepatitis induced in rat. Int J Pharm Pharmac Sci 2013; 5: 57-66.

210. Rangboo V, Noroozi M, Zavoshy R, Rezadoost SA, Mohammadpoorasl A. The effect of artichoke leaf extract on alanine aminotransferase and aspartate aminotransferase in the patients with nonalcoholic steatohepatitis. Int J Hepatol 2016;2016: 4030476.

211. Bundy R, Walker AF, Middleton RW, Wallis C, Simpson HC. Artichoke leaf extract (Cynara scolymus) reduces plasma cholesterol in otherwise healthy hypercholesterolemic adults: a randomized, double blind placebo controlled trial. Phytomedicine 2008; 15: 668-75.

212. Englisch W, Beckers C, Unkauf M, Ruepp M, Zinserling V. Efficacy of Artichoke dry extract in patients with hyperlipoproteinemia. Arzneimittelforschung 2000; 50: 260-5.

213. Petrowicz O, Gebhardt R, Donner $M$, Schwandt $M$ Kraft K. Effects of artichoke leaf extract (ALE) on lipoprotein metabolism in vitro and in vivo. Atherosclerosis 1997; 129: 147.

214. Sahebkar A, Pirro M, Banach M, Mikhailidis DP, Atkin SL, Cicero AFG. Lipid-lowering activity of artichoke extracts: a systematic review and meta-analysis. Crit Rev Food Sci Nutr 2017 Jun 13. doi: 10.1080/10408398.2017.1332572. 
215. Li F, Tan W, Kang Z, Wong CW. Tocotrienol enriched palm oil prevents atherosclerosis through modulating the activities of peroxisome proliferators-activated receptors. Atherosclerosis 2010; 211: 278-82.

216. Ajuluchukwu JN, Okubadejo NU, Mabayoje M, et al. Comparative study of the effect of tocotrienols and -tocopherol on fasting serum lipid profiles in patients with mild hypercholesterolaemia: a preliminary report. Niger Postgrad Med I 2007; 14: 30-3.

217. Rasool AH, Rahman AR, Yuen KH, Wong AR. Arterial compliance and vitamin $E$ blood levels with a self emulsifying preparation of tocotrienol rich vitamin $\mathrm{E}$. Arch Pharm Res 2008; 31: 1212-7.

218. Prasad K. Tocotrienols and cardiovascular health. Curr Pharm Des 2011; 17: 2147-54.

219. Loffredo L, Perri L, Di Castelnuovo A, lacoviello L, De Gaetano G, Violi F. Supplementation with vitamin E alone is associated with reduced myocardial infarction: a meta-analysis. Nutr Metab Cardiovasc Dis 2015; 25: 354-63.

220. Sen CK, Khanna S, Rink C, Roy S. Tocotrienols: the emerging face of natural vitamin E. Vitam Horm 2007; 76: 203-61.

221. Wallace TC, Slavin M, Frankenfeld CL. Systematic review of anthocyanins and markers of cardiovascular disease. Nutrients 2016; 8: pii: E32. doi: 10.3390/ nu8010032.

222. Li D, Zhang Y, Liu Y, Sun R, Xia M. Purified anthocyanin supplementation reduces dyslipidemia, enhances antioxidant capacity, and prevents insulin resistance in diabetic patients. J Nutr 2015; 145: 742-8.

223. Davinelli S, Bertoglio JC, Zarrelli A, Pina R, Scapagnini G. A randomized clinical trial evaluating the efficacy of an anthocyanin-Maqui Berry Extract (Delphinol ${ }^{\circledR}$ ) on oxidative stress biomarkers. J Am Coll Nutr 2015; 34 (Suppl 1): 28-33.

224. Jennings A, Welch AA, Fairweather-Tait SJ, et al. Higher anthocyanin intake is associated with lower arterial stiffness and central blood pressure in women. Am J Clin Nutr 2012; 96: 781-8.

225. Marques C, Fernandes I, Norberto S, et al. Pharmacokinetics of blackberry anthocyanins consumed with or without ethanol: a randomized and crossover trial. Nutr Food Res 2016; 60: 2319-30.

226. Skottová N, Krecman V. Silymarin as a potential hypocholesterolaemic drug. Physiol Res 1998; 47: 1-7.

227. Voroneanu L, Nistor I, Dumea R, Apetrii M, Covic A. Silymarin in type 2 diabetes mellitus: a systematic review and meta-analysis of randomized controlled trials. J Diabetes Res 2016; 2016: 5147468.

228. Mitchell PL, McLeod RS. Conjugated linoleic acid and atherosclerosis: studies in animal models. Biochem Cell Biol 2008; 86: 293-301.

229. Farvid MS, Ding M, Pan A, et al. Dietary linoleic acid and risk of coronary heart disease: a systematic review and meta-analysis of prospective cohort studies. Circulation 2014; 130: 1568-78.

230. Derakhshande-Rishehri SM, Mansourian M, Kelishadi R, Heidari-Beni M. Association of foods enriched in conjugated linoleic acid (CLA) and CLA supplements with lipid profile in human studies: a systematic review and meta-analysis. Public Health Nutr 2015; 18: 2041-54.

231. Taylor JS, Williams SR, Rhys R, James P, Frenneaux MP. Conjugated linoleic acid impairs endothelial function. Arterioscler Thromb Vasc Biol 2006; 26: 307-12.

232. Sahebkar A, Serban C, Ursoniu S, et al.; Lipid and Blood Pressure Meta-analysis Collaboration Group. Lack of efficacy of resveratrol on C-reactive protein and selected cardiovascular risk factors: results from a systematic review and meta-analysis of randomized controlled trials. Int J Cardiol 2015; 189: 47-55.

233. Aziz Z, Wong SY, Chong NJ. Effects of Hibuscus sabdariffa L. on serum lipids: a systematic review and meta-analysis and meta-analysis. J Ethnopharmacol 2013; 150: 442-50.

234. Serban C, Sahebkar A, Ursoniu S, Andrica F, Banach M. Effect of sour tea (Hibiscus sabdariffa L) on arterial hypertension: a systematic review and meta-analysis of randomized controlled trials. J Hypertens 2015; 33: 1119-27.

235. Ursoniu S, Sahebkar A, Serban MC, Banach M. Lipid profile and glucose changes after supplementation with astaxanthin: a systematic review and meta-analysis of randomized controlled trials. Arch Med Sci 2015; 11: 253-66.

236. Cicero AF, Colletti A. Combinations of phytomedicines with different lipid lowering activity for dyslipidemia management: the available clinical data. Phytomedicine 2016; 23: 1113-8.

237. Cicero AF, Ferroni A, Ertek S. Tolerability and safety of commonly used dietary supplements and nutraceuticals with lipid-lowering effects. Expert Opin Drug Saf 2012; 11: 753-66.

238. Cicero AF, Parini A, Rosticci M. Nutraceuticals and cholesterol-lowering action. Int I Cardiol Med Endocr 2015; 6: $1-4$.

239. Cicero AF, Brancaleoni M, Laghi L, Donati F, Mino M. Antihyperlipidaemic effect of a Monascus purpureus brand dietary supplement on a large sample of subjects at low risk for cardiovascular disease: a pilot study. Complement Ther Med 2005; 13: 273-8.

240. Stefanutti C, Mazza F, Vivenzio A, et al. Combined treatment with Dif1stat and diet reduce plasma lipid indicators of moderate hypercholesterolemia more effectively than diet alone: a randomized trial in parallel groups. Lipids 2009; 44: 1141-8.

241. Cicero AF, Benvenuti C, ARMoweb study Group. Efficacy of a red yeast rice based nutraceutical in large subgroups of hypercholesterolemic subjects in every day clinical practice. Med I Nutr Metab 2010; 3: 239-46.

242. Guardamagna O, Abello F, Baracco V, Stasiowska B, Martino F. The treatment of hypercholesterolemic children: efficacy and safety of a combination of red yeast rice extract and policosanols. Nutr Metab Cardiovasc Dis 2011; 21: 424-9.

243. Pirro M, Mannarino MR, Bianconi V, et al. The effects of a nutraceutical combination on plasma lipids and glucose: a systematic review and meta-analysis of randomized controlled trials. Pharmacol Res 2016; 110: 76-88.

244. Pirro M, Mannarino MR, Ministrini S, et al. Effects of a nutraceutical combination on lipids, inflammation and endothelial integrity in patients with subclinical inflammation: a randomized clinical trial. Sci Rep 2016; 6: 23587.

245. Marazzi G, Cacciotti L, Pelliccia F, et al. Long-term effects of nutraceuticals (berberine, red yeast rice, policosanol) in elderly hypercholesterolemic patients. Adv Ther 2011; 28: 1105-13.

246. Cicero AF, Derosa G, Borghi C. Red yeast rice and statin-intolerant patients. Am J Cardiol 2010; 105: 1504.

247. De Castro-Orós I, Solà R, Valls RM, et al. Genetic variants of LDLR and PCSK9 associated with variations in response to antihypercholesterolemic effects of armolipid plus with berberine. PLoS One 2016; 11: e0150785. 
A.F.G. Cicero, A. Colletti, G. Bajraktari, O. Descamps, D.M. Djuric, M. Ezhov, Z. Fras, N. Katsiki, M. Langlois, G. Latkovskis, D.B. Panagiotakos, G. Paragh, D.P. Mikhailidis, O. Mitchenko, B. Paulweber, D. Pella, C. Pitsavos, Ž. Reiner, K.K. Ray, M. Rizzo, A. Sahebkar, M.C. Serban, L.S. Sperling, P.P. Toth, D. Vinereanu, M. Vrablík, N.D. Wong, M. Banach

248. Affuso F, Ruvolo A, Micillo F, Saccà L, Fazio S. Effects of a nutraceutical combination (berberine, red yeast rice and policosanols) on lipid levels and endothelial function randomized, double-blind, placebo-controlled study. Nutr Metab Cardiovasc Dis 2010; 20: 656-61.

249. Cicero AF, Parini A, Rosticci $M$, et al. Effect of a lipid-lowering nutraceutical on pulse-wave-velocity in hypercholesterolemic patients with or without chronic kidney disease. Open Hypertens J (TOJH) 2013; 5: 18-22.

250. Kamal-Eldin A, Moazzami A. Plant sterols and stanols as cholesterol-lowering ingredients in functional foods. Recent Pat Food Nutr Agric 2009; 1: 1-14.

251. Feuerstein JS, Bjerke WS. Powdered red yeast rice and plant stanols and sterols to lower cholesterol. J Diet Suppl 2012; 9: 110-5.

252. Cicero AF, Fogacci F, Rosticci $M$, et al. Effect of a shortterm dietary supplementation with phytosterols, red yeast rice or both on lipid pattern in moderately hypercholesterolemic subjects: a three-arm, double-blind, randomized clinical trial. Nutr Metab 2017; In press.

253. Ogier N, Amiot MJ, Georgé S, et al. LDL-cholesterol-lowering effect of a dietary supplement with plant extracts in subjects with moderate hypercholesterolemia. Eur J Nutr 2013; 52: 547-57.

254. Barrat E, Zaïr Y, Ogier N, et al. A combined natural supplement lowers LDL cholesterol in subjects with moderate untreated hypercholesterolemia: a randomized placebo-controlled trial. Int J Food Sci Nutr 2013; 64: 882-9.

255. Barrat E, Zaïr Y, Sirvent P, et al. Effect on LDL-cholesterol of a large dose of a dietary supplement with plant extracts in subjects with untreated moderate hypercholesterolaemia: a randomised, double-blind, placebo-controlled study. Eur J Nutr 2013; 52: 1843-52.

256. Cicero AF, Colletti A, Fogacci F, Bove M, Rosticci M, Borghi C. Effects of a combined nutraceutical on lipid pattern, glucose metabolism and inflammatory parameters in moderately hypercholesterolemic subjects: a double-blind, cross-over, randomized clinical trial. High Blood Press Cardiovasc Prev 2016; 24: 13-8.

257. Derosa G, Bonaventura A, Bianchi L, et al. A randomized, placebo-controlled study on the effects of a nutraceutical combination of red yeast rice, silybum marianum and octasonol on lipid profile, endothelial and inflammatory parameters. J Biol Regul Homeost Agents 2014; 28: 317-24.

258. Cicero AF, Colletti A, Rosticci M, Grandi E, Borghi C. Efficacy and tolerability of a combined lipid-lowering nutraceutical on cholesterolemia, hs-CRP level and endothelial function in moderately hypercholesterolemic subjects. J Biol Regul Homeost Agents 2016; 30: 593-8.

259. Cicero AF, Derosa G, Parini A, et al. Red yeast rice improves lipid pattern, high-sensitivity C-reactive protein, and vascular remodeling parameters in moderately hypercholesterolemic Italian subjects. Nutr Res 2013; 33: 622-8

260. Cicero AF, Morbini M, Rosticci M, D’Addato S, Grandi E, Borghi C. Middle-term dietary supplementation with red yeast rice plus coenzyme Q10 improves lipid pattern, endothelial reactivity and arterial stiffness in moderately hypercholesterolemic subjects. Ann Nutr Metab 2016; 68: 213-9.

261. Cicero AF, Morbini M, Parini A, et al. Effect of red yeast rice combined with antioxidants on lipid pattern, hs-CRP level, and endothelial function in moderately hypercholesterolemic subjects. Ther Clin Risk Manag 2016; 12: 281-6.
262. Cicero AF, Rosticci M, Parini A, et al. Short-term effects of a combined nutraceutical of insulin-sensitivity, lipid level and indexes of liver steatosis: a double-blind, randomized, cross-over clinical trial. Nutr J 2015; 14: 30.

263. Derosa G, Bonaventura A, Bianchi L, et al. Berberis aristata/Silybum marianum fixed combination on lipid profile and insulin secretion in dyslipidemic patients. Expert Opin Biol Ther 2013; 13: 1495-506.

264. Cicero AF, Fiorito A, Panourgia MP, Sangiorgi Z, Gaddi A. Effects of a new soy/beta-sitosterol supplement on plasma lipids in moderately hypercholesterolemic subjects. J Am Diet Assoc 2002; 102: 1807-11.

265. Lerman RH, Minich DM, Darland G, et al. Subjects with elevated LDL cholesterol and metabolic syndrome benefit from supplementation with soy protein, phytosterols, hops rho iso-alpha acids, and Acacia nilotica proanthocyanidins. J Clin Lipidol 2010; 4: 59-68.

266. Jenkins DJ, Kendall CW, Marchie A, et al. The effect of combining plant sterols, soy protein, viscous fibers, and almonds in treating hypercholesterolemia. Metabolism 2003; 52: 1478-83.

267. Cicero AF, Derosa G, Pisciotta L, Barbagallo C; SISA-PUFACOL Study Group. Testing the short-term efficacy of a lipid-lowering nutraceutical in the setting of clinical practice: a multicenter study. J Med Food 2015; 18: 1270-3.

268. Lee IT, Lee WJ, Tsai CM, Su IJ, Yen HT, Sheu WH. Combined extractives of red yeast rice, bitter gourd, chlorella, soy protein, and licorice improve total cholesterol, low-density lipoprotein cholesterol, and triglyceride in subjects with metabolic syndrome. Nutr Res 2012; 32: 85-92.

269. Shrestha S, Volek JS, Udani J, et al. A combination therapy including psyllium and plant sterols lowers LDL cholesterol by modifying lipoprotein metabolism in hypercholesterolemic individuals. J Nutr 2006; 136: 2492-7.

270. Micallef MA, Garg ML. The lipid-lowering effects of phytosterols and (n-3) polyunsaturated fatty acids are synergistic and complementary in hyperlipidemic men and women. J Nutr 2008; 138: 1085-90.

271. Jeyaraj S, Shivaji G, Jeyaraj SD, Vengatesan A. Effect of combined supplementation of fish oil with garlic pearls on the serum lipid profile in hypercholesterolemic subjects. Indian Heart J 2005; 57: 327-31.

272. Accinni R, Rosina M, Bamonti F, et al.Effects of combined dietary supplementation on oxidative and inflammatory status in dyslipidemic subjects. Nutr Metab Cardiovasc Dis 2006; 16: 121-7.

273. Sirtori CR, Triolo M, Bosisio R, et al. Hypocholesterolaemic effects of lupin protein and pea protein/fibre combinations in moderately hypercholesterolaemic individuals. Br J Nutr 2012; 107: 1176-83.

274. Yoshida M, Vanstone CA, Parsons WD, Zawistowski J, Jones PJ. Effect of plant sterols and glucomannan on lipids in individuals with and without type II diabetes. Eur J Clin Nutr 2006; 60: 529-37.

275. Houston M, Sparks W. Effect of combination pantethine, plant sterols, green tea extract, delta-tocotrienol and phytolens on lipid profiles in patients with hyperlipidemia. JANA 2010; 13: 15-20.

276. Sabatine MS. Advances in the treatment of dyslipidemia. Cleve Clin J Med 2016; 83: 181-6.

277. Šimić I, Reiner Ž. Adverse effects of statins - myths and reality. Curr Pharm Des 2015; 21: 1220-6.

278. Banach M, Stulc T, Dent R, Toth PP. Statin non-adherence and residual cardiovascular risk: there is need 
for substantial improvement. Int J Cardiol 2016; 225: 184-96.

279. Reiner Ž. Combined therapy in the treatment of dyslipidemia. Fundam Clin Pharmacol 2010; 24: 19-28.

280. Cicero AF, Morbini M, Bove M, et al. Additional therapy for cholesterol lowering in ezetimibe-treated, statin-intolerant patients in clinical practice: results from an internal audit of a university lipid clinic. Curr Med Res Opin 2016 Jun 8: 1-6 [Epub ahead of print].

281. Cicero AF, Colletti A. Statins and nutraceuticals/functional food: could they be combined? In: Combination Therapy In Dyslipidemia. Banach $M$ (ed.). Springer International Publishing 2016; 127-42.

282. Maki KC, Orloff DG, Nicholls SJ, et al. A highly bioavailable omega-3 free fatty acid formulation improves the cardiovascular risk profile in high-risk, statin-treated patients with residual hypertriglyceridemia (the ESPRIT trial). Clin Ther 2013; 35: 1400-11.e1-3.

283. Kim SH, Kim MK, Lee HY, Kang HJ, Kim YJ, Kim HS. Prospective randomized comparison between omega-3 fatty acid supplements plus simvastatin versus simvastatin alone in Korean patients with mixed dyslipidemia: lipoprotein profiles and heart rate variability. Eur J Clin Nutr 2011; 65: 110-6.

284. Yokoyama M, Origasa H, Matsuzaki M, et al. Japan EPA lipid intervention study (JELIS) investigators. Lancet 2007; 369: 1090-8.

285. Dietary supplementation with $\mathrm{n}-3$ polyunsaturated fatty acids and vitamin $\mathrm{E}$ after myocardial infarction: results of the GISSI-Prevenzione trial. Gruppo Italiano per lo Studio della Sopravvivenza nell'Infarto miocardico. Lancet 1999; 354: 447-55.

286. Agrawal AR, Tandon M, Sharma PL. Effect of combining viscous fibre with lovastatin on serum lipids in normal human subjects. Int J Clin Pract 2007; 61: 1812-8.

287. Moreyra AE, Wilson AC, Koraym A. Effect of combining psyllium fiber with simvastatin in lowering cholesterol. Arch Intern Med 2005; 165: 1161-6.

288. Ramos SC, Fonseca FA, Kasmas SH, et al. The role of soluble fiber intake in patients under highly effective lipid-lowering therapy. Nutr J 2011; 10: 80.

289. Marazzi G, Pelliccia F, Campolongo G, et al. Usefulness of nutraceuticals (Armolipid Plus) versus ezetimibe and combination in statin-intolerant patients with dyslipidemia with coronary heart disease. Am J Cardiol 2015; 116: 1798-801.

290. Pisciotta L, Bellocchio A, Bertolini S. Nutraceutical pill containing berberine versus ezetimibe on plasma lipid pattern in hypercholesterolemic subjects and its additive effect in patients with familial hypercholesterolemia on stable cholesterol-lowering treatment. Lipids Health Dis 2012; 11: 123.

291. Di Pierro F, Bellone I, Rapacioli G, Putignano P. Clinical role of a fixed combination of standardized Berberis aristata and Silybum marianum extracts in diabetic and hypercholesterolemic patients intolerant to statins. Diabetes Metab Syndr Obes 2015; 8: 89-96.

292. Malina DM, Fonseca FA, Barbosa SA, et al. Additive effects of plant sterols supplementation in addition to different lipid-lowering regimens. J Clin Lipidol 2015; 9: 542-52.

293. Gylling H, Miettinen TA. LDL cholesterol lowering by bile acid malabsorption during inhibited synthesis and absorption of cholesterol in hypercholesterolemic coronary subjects. Nutr Metab Cardiovasc Dis 2002; 12: 19-23.

294. Qureshi AA, Sami SA, Salser WA, Khan FA. Synergistic effect of tocotrienol-rich fraction (TRF 25) of rice bran and lovastatin on lipid parameters in hypercholesterolemic humans. J Nutr Biochem 2001; 12: 318-29.

295. Ahmad Alobaidi AH. Effect of Nigella sativa and Allium sativum coadminstered with simvastatin in dyslipidemia patients: a prospective, randomized, double-blind trial. Antiinflamm Antiallergy Agents Med Chem 2014; 13: 68-74.

296. Qin XF, Zhao LS, Chen WR, Yin da W, Wang H. Effects of vitamin $D$ on plasma lipid profiles in statin-treated patients with hypercholesterolemia: a randomized placebo-controlled trial. Clin Nutr 2015; 34: 201-6.

297. Michalska-Kasiczak M, Sahebkar A, Mikhailidis DP, et al.; Lipid and Blood Pressure Meta-analysis Collaboration (LBPMC) Group. Analysis of vitamin D levels in patients with and without statin-associated myalgia - a systematic review and meta-analysis of 7 studies with 2420 patients. Int J Cardiol 2015; 178: 111-6.

298. Serban MC, Colantonio LD, Manthripragada AD, et al. Statin intolerance and risk of coronary heart events and all-cause mortality following myocardial infarction. J Am Coll Cardiol 2017; 69: 1386-95. 